\title{
Alloying effects on high-temperature deformation behavior of nickel aluminide intermetallics
}

\author{
Robert Adrian Coulter II \\ West Virginia University
}

Follow this and additional works at: https://researchrepository.wvu.edu/etd

\section{Recommended Citation}

Coulter, Robert Adrian II, "Alloying effects on high-temperature deformation behavior of nickel aluminide intermetallics" (2000). Graduate Theses, Dissertations, and Problem Reports. 1055.

https://researchrepository.wvu.edu/etd/1055

This Thesis is protected by copyright and/or related rights. It has been brought to you by the The Research Repository @ WVU with permission from the rights-holder(s). You are free to use this Thesis in any way that is permitted by the copyright and related rights legislation that applies to your use. For other uses you must obtain permission from the rights-holder(s) directly, unless additional rights are indicated by a Creative Commons license in the record and/ or on the work itself. This Thesis has been accepted for inclusion in WVU Graduate Theses, Dissertations, and Problem Reports collection by an authorized administrator of The Research Repository @ WVU. For more information, please contact researchrepository@mail.wvu.edu. 


\title{
Alloying Effects on High Temperature Deformation Behavior of Nickel Aluminide Intermetallics
}

\author{
By \\ Robert A. Coulter \\ Thesis Submitted to the \\ College of Engineering and Mineral Resources \\ At West Virginia University \\ In Partial Fulfillment of the Requirements
}

For the degree of

Master of Science

In

Mechanical Engineering

Keh-Minn Chang, Ph.D., Chair

Bruce Kang, Ph.D.

Kenneth Means, Ph.D.

Department of Mechanical and Aerospace Engineering

Morgantown, West Virginia

2000

Keywords: Nickel Aluminide, Creep, Compression, Stress Relaxation, Solid Solution Strengthening 


\section{Abstract \\ Alloying Effects on High Temperature Deformation Behavior of Nickel Aluminide Intermetallics}

\section{Robert A. Coulter}

The increasing demand placed on materials used in high temperature applications has become a great challenge. The objective of this research is to examine the possibility of using nickel aluminide for high temperature structural applications. It seems to be a desirable candidate based on its low density, high thermal conductivity, high melting temperature, and its proven resistance to oxidation. Nickel aluminide is currently used as the protective coating on all high temperature turbine blades. Currently, limited ductility at lower temperatures and low creep resistance at high temperatures limit the capabilities of NiAl. However, there has been much progress made improving the properties of NiAl. Through different processing techniques, such as directional solidification and single crystal formation, $\mathrm{NiAl}$ has shown improvements over the conventionally cast polycrystal form. Through controlling microstructure and alloy strengthening it is believed that the disadvantages of the binary form can be improved.

For this research four different alloys were investigated to determine the effects of alloy strengthening. In addition to binary $\mathrm{NiAl}$, three other alloys have been selected with two atomic percent of chromium, molybdenum, or niobium. The three elements are next to one another on the periodic table, which will provide the electron number effect (Mo vs. $\mathrm{Nb}$ ) and the atomic size effect (Cr vs. Mo).

All alloys used in this study were directionally solidified to help reduce intergranular fractures. Due to the low ductility of NiAl at low temperatures, all of the specimens were tested in compression. The specimens were tested at constant strain rates ranging from $10^{-6}$ to $10^{-3} \mathrm{~s}^{-1}$. At high temperatures, the flow stress becomes dependent on both strain rate and temperature. The materials were evaluated by comparing the flow stress of each alloy at various applied strain rates. Stress relaxation tests were also performed for comparison. The testing temperatures ranged from $850^{\circ} \mathrm{C}$ to $1200^{\circ} \mathrm{C}$.

It was found from comparing the testing data that flow stress becomes very dependent on temperature and strain rate. As testing temperatures increased above 1100 ${ }^{\circ} \mathrm{C}$, the atomic size factor became less effective as a strengthening mechanism in nickel aluminide. However the electron number effect produced more effective strengthening than the atomic size factor with increasing temperatures. 


\section{Acknowledgements}

First and foremost, I would like to thank my family for their support and encouragement over the past few years. Without their support and encouragement none of this would have been possible.

I would next like to thank professor Keh-Minn Chang, for all the advice and guidance through this research project. The material testing equipment and the resources for completing this project would not have been available without the help of Dr. Chang. I would like to thank Dr. Chang for providing the specimens for testing and help with the test set-up. I would also like to thank the rest of Dr. Chang's research group for taking the time to give me advice and answer my questions.

Finally, I would like to thank some of my close friends. I would like to thank Matt for the help he provided me setting up the testing system and completing the testing. I would also like to thank April and Shadow for being supportive and understanding about the long hours I have spent away from home. 


\section{Table of Contents}

Title Page $\quad$ i

$\begin{array}{ll}\text { Abstract } & \text { ii }\end{array}$

Acknowledgements

Table of Contents $\quad$ iv

List of Tables vii

List of Figures viii

Chapter 1 - Introduction $\quad 1$

1.1 Nickel Aluminide 1

$\begin{array}{ll}\text { 1.2 High Temperature Creep } & 3\end{array}$

1.3 Intermetallics

$\begin{array}{ll}\text { 1.4 Directional Solidification } & 6\end{array}$

$\begin{array}{ll}\text { 1.5 Solid Solution Strengthening } & 7\end{array}$

$\begin{array}{lr}\text { 1.6 Research Objectives } & 10\end{array}$

$\begin{array}{ll}\text { Chapter } 2 \text { - Literature Review } & 11\end{array}$

$\begin{array}{ll}\text { 2.1 Nickel Aluminide Properties } & 11\end{array}$

2.2 Microstructural Behavior of Alloyed Nickel Aluminide 12

2.3 Alloy and Microstructure Effect on Creep Behavior 15

2.3.1 Atomic Size and Electron Number Effect on Strength $\quad 15$

Behavior of Ni-Base Superalloys

2.3.2 Microstructural Effect on High Temperature Deformation 17

Behavior

2.3.3 Alloying Effect on High Temperature Deformation Behavior 19 
$\begin{array}{ll}\text { Chapter } 3 \text { - Experimental Program } & 21\end{array}$

$\begin{array}{ll}\text { 3.1 Material } & 21\end{array}$

3.2 Microstructural Evaluation $\quad 22$

3.2.1 Optical Microstructural Evaluation Procedure 22

3.2.2 SEM Microstructural Evaluation Procedure $\quad 24$

3.3 Microstructural Analysis Procedure 24

3.4 High Temperature Mechanical Testing Setup 26

3.4.1 Compression Testing $\quad 27$

3.4.2 Stress Relaxation Testing $\quad 28$

3.4.3 Mechanical Testing Error $\quad 28$

3.5 Mechanical Testing Data Analysis 31

3.5.1 Compression Data Analysis 31

3.5.2 Stress Relaxation Data Analysis 33

$\begin{array}{ll}\text { Chapter } 4 \text { - Results } & 37\end{array}$

$\begin{array}{ll}\text { 4.1 Microstructural Evaluation } & 37\end{array}$

4.1.1 Optical Microstructures $\quad 38$

4.1.2 SEM Microstructures $\quad 40$

4.2 Compression Test 45

4.2.1 Temperature Effect $\quad 46$

4.2.2 Alloying Effect $\quad 51$

4.3 Stress Relaxation Test 56

4.3.1 Stress Relaxation Curves $\sigma$ vs. Time $\quad 57$

$\begin{array}{ll}\text { 4.3.2 Temperature Effect } & 60\end{array}$ 
$\begin{array}{ll}\text { 4.3.3 Alloying Effect } & 62\end{array}$

Chapter 5 - Discussion $\quad 66$

5.1 Alloy Effect $\quad 66$

5.1.1 Mechanical Test Comparison 66

5.1.2 Atomic Size Factor $\quad 69$

5.1.3 Electron Number Effect $\quad 72$

5.2 Stress Relaxation/Compression Comparison $\quad 74$

$\begin{array}{ll}\text { 5.3 Single Crystal Comparison } & 75\end{array}$

$\begin{array}{ll}\text { 5.4 High Temperature Deformation Properties } & 79\end{array}$

$\begin{array}{ll}\text { 5.5 Metallurgical Consideration } & 85\end{array}$

Chapter 6 - Conclusion and Recommendations 86

$\begin{array}{ll}\text { 6.1 Conclusions } & 86\end{array}$

$\begin{array}{ll}\text { 6.2 Recommendations } & 87\end{array}$

$\begin{array}{ll}\text { References } & 88\end{array}$

Appendix A - Compression Data $\quad 90$

$\begin{array}{ll}\text { Vita } & 94\end{array}$ 


\section{List of Tables}

Title

$\begin{array}{lr}\text { Table 2.1: NiAl Properties } & 11\end{array}$

Table 2.2: NiAl <001> Single Crystal Testing Properties 17

Table 2.3: NiAl <223> Single Crystal Testing Properties 17

Table 2.4: NiAl <111> Single Crystal Testing Properties 18

Table 2.5: NiAl Single Crystal Testing Properties $\quad 18$

Table 2.6: NiAl Single Crystal Testing Properties 19

Table 2.7: NiAl-1Hf <001> Testing Properties 19

$\begin{array}{lr}\text { Table 3.1: Specimen Composition } & 21\end{array}$

Table 3.2: Mechanical Testing Error $\quad 29$

Table 4.1: Stress Exponent Compression Test 56

Table 4.2: Stress Exponent Stress Relaxation Test 65

Table 5.1: Percent Volume Change $\quad 70$

$\begin{array}{ll}\text { Table 5.2: Electron Configuration } & 73\end{array}$

Table A.1: Compression Data NiAl 91

Table A.2: Compression Data NiAlCr $\quad 92$

Table A.3: Compression Data NiAIMo 93

$\begin{array}{ll}\text { Table A.4: Compression Data NiAINb } & 93\end{array}$ 


\section{List of Figures}

Title

Figure 1.1: B2 Body-Centered Cubic 1

Figure 1.2: NiAl Phase Diagram 1

Figure 1.3: Creep Curve 5

$\begin{array}{ll}\text { Figure 1.4: B2 BCC Sustitutional Strengthening } & 7\end{array}$

Figure 2.1: NiAl Alloy Phase Behavior Diagram 12

Figure 2.2: NiAlCr Pseudo-Binary Phase Diagram 14

Figure 2.3: Nickel-Base Superalloy Table of Alloying Elements 15

Figure 2.4: Effect of Solute Position on Periodic Table 16

$\begin{array}{ll}\text { Figure 2.5: Single Crystal Graph } & 20\end{array}$

Figure 3.1: Compression Specimen $\quad 22$

Figure 3.2: Specimen Cutting $\quad 22$

$\begin{array}{ll}\text { Figure 3.3: Mechanical Test Setup } & 26\end{array}$

Figure 3.4: Compression Analysis Example $\quad 32$

Figure 3.5: Compression Analysis Example 33

Figure 3.6: Stress Relaxation Analysis Example $\quad 34$

Figure 3.7: Stress Relaxation Analysis Example 36

Figure 4.1: Optical Microstructure: NiAl 38

Figure 4.2: Optical Microstructure: NiAl-2Cr 39

Figure 4.3: Optical Microstructure: NiAl-2Mo 39

Figure 4.4: Optical Microstructure: NiAl-2Nb $\quad 40$

Figure 4.5: SEM Microstructure: NiAl-2Cr 41 
Figure 4.6: EDS: NiAl-2Cr Matrix 41

Figure 4.7: EDS: NiAl-2Cr Secondary Phase 41

Figure 4.8: SEM Microstructure: NiAl-2Mo 42

Figure 4.9: X-Ray Mapping: NiAl-2Mo 43

Figure 4.10: SEM Microstructure: NiAl-2Nb 44

Figure 4.11: EDS: NiAl-2Nb Matrix 44

Figure 4.12: EDS: NiAl-2Nb Secondary Phase 44

Figure 4.13: Plastic Flow Curves NiAl 46

$\begin{array}{ll}\text { Figure 4.14: Plastic Flow Curves NiAl-2Cr } & 47\end{array}$

Figure 4.15: Plastic Flow Curves NiAl-2Mo $\quad 47$

Figure 4.16: Plastic Flow Curves NiAl-2Nb 48

Figure 4.17: Compression Graph: NiAl 49

Figure 4.18: Compression Graph: NiAl-2Cr 50

Figure 4.19: Compression Graph: NiAl-2Mo 50

Figure 4.20: Compression Graph: NiAl-2Nb 51

Figure 4.21: Plastic Flow Curves 1000 C 52

Figure 4.22: Plastic Flow Curves 1100 C 53

Figure 4.23: Plastic Flow Curves 1200 C 53

Figure 4.24: Compression Graph: 850 C

Figure 4.25: Compression Graph: $1000 \mathrm{C}$

Figure 4.26: Compression Graph: $1100 \mathrm{C}$

Figure 4.27: Stress Relaxation $\sigma$ vs. Time: NiAl 58

Figure 4.28: Stress Relaxation $\sigma$ vs. Time: NiAl-2Cr 58 
Figure 4.29: Stress Relaxation $\sigma$ vs. Time: NiAl-2Mo

Figure 4.30: Stress Relaxation $\sigma$ vs. Time: NiAl-2Nb 59

Figure 4.31: Stress Relaxation Graph: NiAl 60

Figure 4.32: Stress Relaxation Graph: NiAl-2Cr 61

Figure 4.33: Stress Relaxation Graph: NiAl-2Mo

Figure 4.34: Stress Relaxation Graph: NiAl-2Nb 62

Figure 4.35: Stress Relaxation Graph: 1000 C 63

Figure 4.36: Stress Relaxation Graph: 1050 C 63

Figure 4.37: Stress Relaxation Graph: 1100 C 64

Figure 4.38: Stress Relaxation Graph: 1150 C 64

Figure 4.39: Stress Relaxation Graph: 1200 C 65

Figure 5.1: Compression Graph: $10^{-3} \quad 67$

$\begin{array}{ll}\text { Figure 5.2: Compression Graph: } 10^{-4} & 67\end{array}$

$\begin{array}{ll}\text { Figure 5.3: Compression Graph: } 10^{-5} & 67\end{array}$

Figure 5.4: Compression Graph: $10^{-6} \quad 68$

Figure 5.5: Stress Exponent Comparison $\quad 69$

Figure 5.6: Percent Volume Change: Atomic Size Factor 70

Figure 5.7: Periodic Table $\quad 72$

Figure 5.8: Stress Relaxation/Compression Comparison 75

Figure 5.9: Single Crystal Comparison 850 C 76

Figure 5.10: Single Crystal Comparison 1000 C 77

Figure 5.11: Single Crystal Comparison 1200 C 77

Figure 5.12: Stress Dependency Graph Single/DS NiAl 78 
Figure 5.13: Stress Dependency Graph Alloyed Single/DS NiAl

Figure 5.14: Creep Mechanisms

81

Figure 5.15: Creep Mechanisms: NiAl

83

Figure 5.16: Creep Mechanisms: NiAlCr

Figure 5.17: Creep Mechanisms: NiAlMo

84

Figure 5.18: Creep Mechanisms: NiAINb 


\section{Chapter 1 - Introduction}

\subsection{Nickel Aluminide}

Nickel-Based superalloys have been used as the principal structural material for high temperature applications, such as gas turbine engines, for many years.[1] Due to ever-changing technology, material capabilities are being pushed to their limits. The increase in technological improvement creates the need for materials to operate at higher temperatures with increased oxidation resistance. Superalloys are important due to their endurance at high temperatures and resistance to hot corrosion.

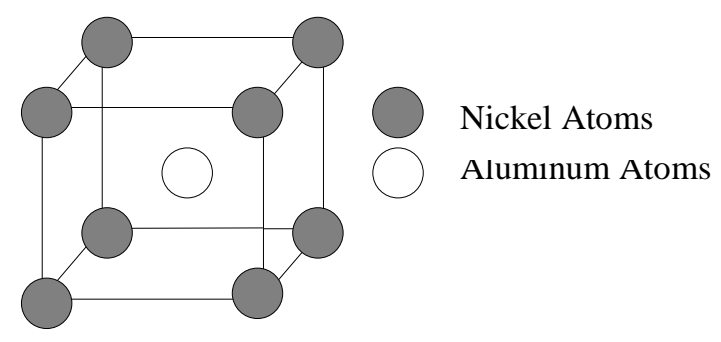

Figure 1.1: B2 BCC Structure Containing Nickel and Aluminum [2]

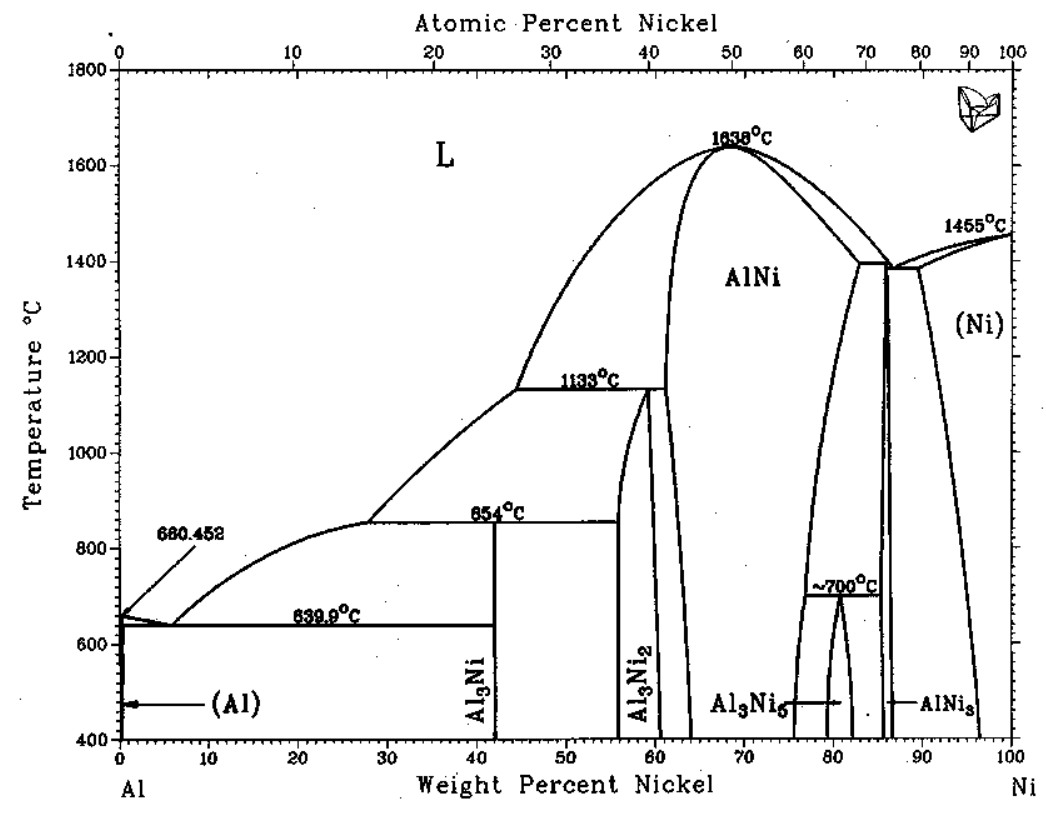

Figure 1.2: Binary Phase Diagram for NiAl [6] 
Nickel aluminide is an intermetallic compound containing 50 at.\% nickel and 50 at.\% aluminum. It is made up of a B2 body-centered cubic structure. From figure 1.2, the $\mathrm{NiAl}$ phase diagram, it can be seen that $\mathrm{NiAl}$ has a melting temperature of $1638^{\circ} \mathrm{C}$ and a very wide phase range from 45 to 60 at $\%$ nickel, which makes it a very desirable material for improvements to use as a high temperature structural alloy. Nickel aluminide offers several other advantages over current nickel-base superalloys.[2] Nickel aluminide has a very low density of $5.95 \mathrm{~g} / \mathrm{cm}^{3}$, which is approximately two-thirds the density of state of the art superalloys.[2] A reduce density would result in less weight, reducing the centrifugal forces that arise from spinning turbine blades.[2] Nickel aluminide also has a much higher thermal conductivity than superalloys.[2] This would make a more uniform heat distribution over parts made from nickel aluminide.[2] Having a more uniform heat distribution would lower thermal stresses acquired from "hot spots" from temperature variations.[2] With a higher thermal conductivity the overall operating temperature could also be reduced. Nickel aluminide is also very resistant to oxidation.[2] It has served as the major component in the "aluminide" coating on virtually all high temperature turbine blades.[2]

Nickel aluminide also suffers from a few disadvantages, little ductility at lower temperatures and low strength at higher temperatures.[2] However there are several ways in which to improve upon the disadvantages of the binary composition NiAl: solid solution strengthening, metallic-precipitate strengthening, intermetallic-precipitate strengthening, and composite strengthening.[2] It is believed that using these strengthening methods the low temperature ductility and high temperature strength can be improved. 


\subsection{High Temperature Creep}

High temperature creep is a process in which engineering materials undergo timedependent elongation under constant loading conditions at elevated temperatures. When evaluating material strength at high temperatures not only are the loading conditions important but time also becomes important.[3,4] At room temperature the material strength is independent of time and only dependent of load.[3,4] However at high temperatures the material strength becomes dependent upon strain rate and time of exposure.[3,4] Usually creep becomes of significance at $50 \%$ of the melting temperature of the material.[3,4] At elevated temperatures creep can become significant at relatively small loads. This is why creep tests are used to evaluate the high temperature deformation properties of materials.

There are several different mechanisms which contribute to creep; dislocation glide, dislocation creep, diffusion creep, grain boundary sliding, and subgrain formation.[3] The reduced Strength is due mostly to the increased mobility of dislocations. At higher temperatures new slip systems are activated. With more slip systems available less stress is required to deform the material. Dislocation climb, vacancy diffusion, and cross slip are all thermally activated processes, which means they occur more easily with increasing temperature. These processes make it easier for dislocations to move, which would in turn lower the strength of the material.

A creep test is usually conducted under constant load. Figure 1.3 shows what a typical constant load creep curve would look like. There are three stages in a constant load creep test.[3,4] The first stage, decreasing slope, occurs initially when a load is applied to the specimen.[3,4] At this stage an initial elongation occurs immediately, then 
the creep rate decreases with time.[3,4] During the second stage the creep rate becomes constant and changes very little with time. Steady State creep rate can be expressed in the form of Dorn's equation:

$$
\mathrm{d} \varepsilon / \mathrm{dt}=\mathrm{B} \sigma^{\mathrm{n}} \exp (-\mathrm{Q} / \mathrm{RT})
$$

where $\sigma$ is the applied stress, $\mathrm{n}$ is the stress exponent, $\mathrm{Q}$ is the activation energy for creep, $\mathrm{R}$ is the gas constant, $\mathrm{T}$ is the absolute temperature, and $\mathrm{B}$ is a material constant.[3] Steady state creep represents a balance between strain hardening and the thermal recovery by rearrangement and annihilation of dislocations.[3] After a period of steady state creep, the creep rate will begin to increase rapidly until fracture occurs.[3,4]

Typical creep requirements for nickel base supperalloys included stresses up to 30 ksi at temperatures as high as $1000^{\circ} \mathrm{C}$ for over 300 hours.[10] A creep strain as little as 1 to $2 \%$ often constitutes creep failure.[10]. Therefore the amount of primary creep and steady state creep must be very low to provide acceptable performance.[10] The testing for this research will be done using constant strain rate testing. This will evaluate the materials deformation behavior in the secondary creep region. The region of steady state creep. The specimens will be tested in compression at constant strain rates. In actuality, the materials will be subjected to tensile stresses when used in gas turbine engines. The materials will be tested in compression due to the brittle nature on NiAl. The results from constant strain rate compression and constant strain tension testing would provide very close results. The steady state deformation behavior would be the same. The difference in tension and compression testing would occur from the strain and time to fracture. In compression fracture never really occurs, the specimen would continue to compress. In tensile testing fracture would occur more quickly at a certain time and strain level. For 
this reason the difference from tensile creep and compression creep testing were determined to be negligible.

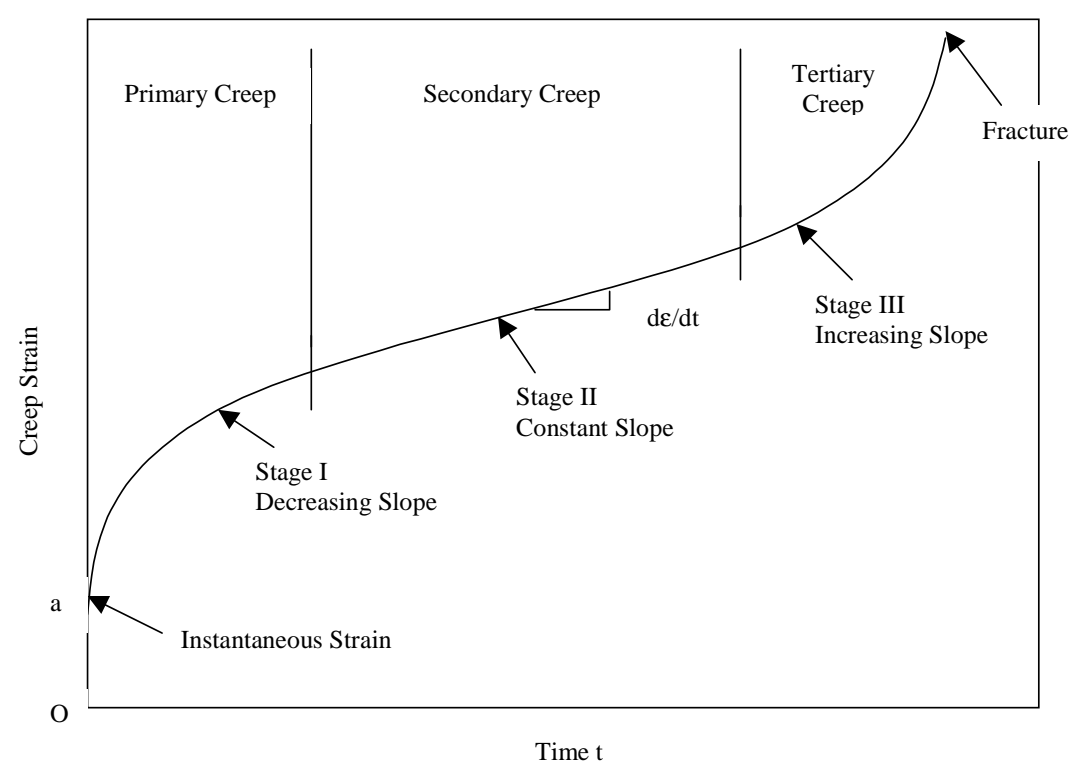

Figure 1.3: Creep Curve [3,4]

\subsection{Intermetallics}

Intermetallic compounds can be defined as ordered alloy phase formed between two metallic elements, where an alloy phase is ordered if two or more sublattices are required to describe its atomic structure.[7] The ordered structure exhibits attractive elevated temperature properties because of the long range ordered superlattice which reduces dislocation mobility and diffusion processes at elevated temperatures.[7] Reducing dislocation mobility and diffusion at elevated temperature can improve strength and creep resistance. The strong bonding that occurs in intermetallic compounds provides higher melting temperatures and can provide increased strength at high temperatures.[2] 
There are hundreds of intermetallic compounds that exist.[7] There are several intermetallic compounds being developed for structural applications: $\mathrm{Ni}_{3} \mathrm{Al}, \mathrm{NiAl}, \mathrm{Ni}_{3} \mathrm{Si}$, $\mathrm{Fe}_{3} \mathrm{Al}, \mathrm{FeAl}, \mathrm{Ti}_{3} \mathrm{Al}, \mathrm{TiAl}, \mathrm{MoSi}_{2} \cdot[7]$

Intermetallics also suffers from some disadvantages. With the increased strength from the intermetallic compounds typically results in low ductility.[2] With respect to ductility intermetallics fall between metals and ceramics.[2]

\subsection{Directional Solidification}

When a material has been directionally solidified the grain boundary orientation is different from conventionally cast materials. In conventionally cast materials equiaxed grain boundaries form. The orientation of the grain boundaries is not dependent on the direction of solidification. In directionally solidified materials the grain boundaries become elongated in the direction of solidification. This direction is referred to as the longitudinal direction. Perpendicular to the direction of solidification the grain boundaries appear to be equiaxed as the grain boundaries would be from conventional casting. This grain boundary orientation is referred to as the transverse direction.[17]

Directional Solidification is used to control the grain morphology of superalloys. This is done to help reduce creep fractures and thermal fatigue failures. In materials that have been conventionally cast with uniform grain structures, these failures are usually

associated with grain boundaries that are transverse to the applied stress. Using directional solidification to control the grain shape helps reduce the density of transverse grain boundaries. This process produces grains elongated parallel to the stress axis. This may inhibit grain boundary fracture and increase ductility.[17] 


\subsection{Solid-Solution Strengthening}

Solid solution strengthening is accomplished by introducing solute atoms into solid solution in the solvent-atom lattice.[3,4] Introduction of these atoms produces an alloy which is stronger than the pure metal.[3,4] This is accomplished by providing frictional resistance to dislocation mobility.[3] The amount of strengthening effect is related to the type solute addition and the amount of the addition.

There are two forms of solid solution strengthening substitutional and interstitial solid solution strengthening.[3] Which type of strengthening occurs is dependent upon the size difference between the solute and solvent atom. Substitutional strengthening occurs if the solvent atom and the solute atom are approximately the same size.[3] Since the atoms are approximately the same size, the solute atoms would be too large to occupy spaces between the solute atoms in the crystal lattice structure.[3] The solute atom would have to occupy positions in the crystal lattice structure of the solvent atoms.[3] The other form, interstitial solid solutions, occurs when the solute atoms are much smaller than the solvent atoms.[3] Due to their smaller size they can occupy positions between the solvent atoms in the crystal lattice structure.[3]

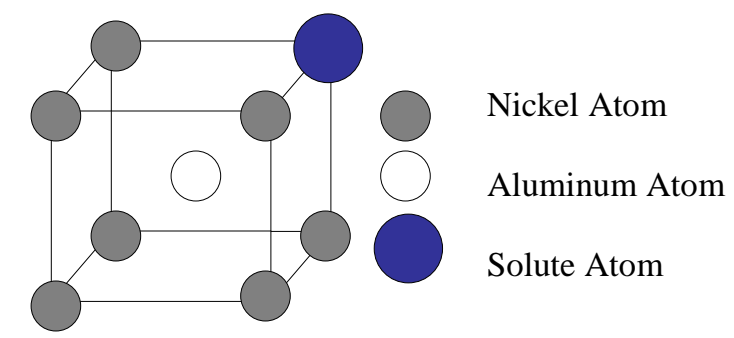

Figure 1.4: B2 BCC - Substitutional Strengthening

For this research substitutional solid solution strengthening was used. The solute atoms were comparable in size to the solvent atoms, therefor they would have been too large to occupy spaces between the lattice structure. They would have to sit in the lattice 
structure in either an aluminum or a nickel positions. Depending on which site the solute atoms would prefer has an effect on the properties of the material.[9] When selecting a solid solution strengthener it can be very important which lattice site the solute atom will prefer.[9] In order to maximize the effect of solid solution addition the solute material must be substituted for the material that it will replace in the lattice structure.[9] Not substituting the alloy addition for the site it prefer can increase site defects such as vacancies.[9]

There are several different ways in which the addition of a solute atom can increase the strength of the solvent material: elastic interaction, modulus interaction, stacking fault interaction, electrical interaction, short-range order interaction, and longrange order interaction.[3]

Elastic interaction is due to the size factor between the solute and the solvent atom.[3] The relative size difference between the solvent and solute atoms has an effect on the properties on the material. The strengthening due to elastic interaction is directly proportional to the misfit of the solute.[3] This can slow diffusion and restrict dislocation climb.[9] For this to be effective there must be a large difference between the solute and solvent atom.[9] The size difference between the solute and solvent atom will provide elastic strain on the lattice structure. This can interact strongly with dislocations.

Modulus interaction occurs if the solute atom locally alters the modulus of the crystal.[3] If the solute has a smaller shear modulus than the matrix the energy of the strain field of the dislocation will be reduced and there will be an attraction between the solute and the matrix.[3] The change in shear modulus is accompanied by a local change in bulk modulus, both edge and screw dislocations will be subject to this interaction.[3] 
Stacking fault interaction occurs due to solute atoms segregating to the stacking faults contained in extended dislocations.[3] This was first pointed out by Suzuki, so this is called Suzuki or chemical interaction.[3] For this to occur the solute must have a preferential solubility in the stacking fault.[3] The solute within the stacking fault lowers the stacking fault energy and increases the separation of the partial dislocations.[3] Therefore, the motion of the extended dislocations is made more difficult and additional work must be done to constrict the pair of partial dislocation.[3]

Electrical interaction arises from the charge of the solute atom having a dissimilar valence remaining localized around the solute atom.[3] The solute atoms become charge centers and can interact with dislocations which have electrical dipoles.[3] The electrical interaction is only significant when there is a large valence difference between solute and the matrix material and the elastic misfit is small.[3]

Short-range order interaction arises from the tendency of solute atoms arranging themselves to have more than the equilibrium number of dissimilar neighbors.[3] Strengthening occurs because the movement of a dislocation through a region of shortrange order reduces the amount of local order.[3] The resulting disordering from this process causes an increase in the energy of the alloy.[3] For energetically unfavorable dislocation motion to occur, extra work must be provided.[3]

Long-range order interaction is due to the formation of superlattices. A superlattice consists of a long range of periodically arranged dissimilar atoms. Movement of dislocations through superlattices form anti-phase boundaries. The dislocation separates into two pairs of ordinary dislocations separated by the anti-phase boundary. 
This process can resist the amount of stress required to move dislocations through these disordered regions.

\subsection{Research Objectives}

The primary objective of this research is to examine, by means of high temperature creep testing, the effect of alloying on the high temperature properties of nickel aluminide. Four different compositions were used to compare different alloying effects. The four specimens were chosen to compare how solid solution strengthening effects nickel aluminide. One specimen containing only nickel and aluminum will be used as a reference. The other three specimens each had 2 at\% of either $\mathrm{Cr}, \mathrm{Mo}$, or $\mathrm{Nb}$ added. The NiAl-2Cr and NiAl-2Mo specimens will be compared to determine the effect the atomic size factor has in solid solution strengthening. The specimens containing NiAl-2Mo and NiAl-2Nb will be compared to see the extent that chemical interaction plays in solid solution strengthening. All of the specimens were tested at temperatures ranging from $850{ }^{\circ} \mathrm{C}$ to $1200{ }^{\circ} \mathrm{C}$. Strain rate controlled compression and stress relaxation tests were performed to evaluate the high temperature deformation behavior on the specimens. Strain rate controlled compression tests ranged from $10^{-3} \mathrm{sec}^{-1}$ to $10^{-6} \mathrm{sec}^{-1}$. The results of the tests were then analyzed taking into account the composition, strain rate, and test temperature to evaluate the effect of the alloying. 


\section{Chapter 2 - Literature Review}

\subsection{Nickel Aluminide Properties}

Much research has been done to determine the properties of binary nickel aluminde and its high temperature deformation behavior. Controlling grain morphology through directional solidification and producing single crystals have shown some improvements. Strengthening through solid solution additions and with precipitates has also been used to improve binary NiAl. Table 2.1 compares some of the properties of $\mathrm{NiAl}, \mathrm{NiAl}$ alloys, and the properties of superalloys.

Table 2.1: Property Comparison between NiAl and Superalloy [7]

\begin{tabular}{|c|c|c|c|c|c|}
\hline Property & Units & $\begin{array}{c}\text { Temperature } \\
\left({ }^{\circ} \mathrm{C}\right)\end{array}$ & NiAl & $\begin{array}{c}\text { NiAl } \\
\text { alloys }\end{array}$ & $\begin{array}{c}\text { Advanced } \\
\text { Superalloys }\end{array}$ \\
\hline Crystal Structure & --- & -- & B2 & B2 & Fcc \\
\hline Bonding & --- & --- & Covalent/ Metallic & Covalent/ Metallic & Metallic \\
\hline Melting Point & ${ }^{\circ} \mathrm{C}$ & --- & 1682 & 1610 to 1676 & 1390 \\
\hline $\begin{array}{c}\text { Lattice Perimeter } \\
\text { Precipitate }\end{array}$ & $\AA$ & RT & 2.887 & 2.888 to 2.900 & 3.580 \\
\hline Lattice mismatch & $\%$ & RT & N/A & 1 to $6(ß)$ & 0 to -0.5() \\
\hline Density & $\mathrm{g} / \mathrm{cm}^{3}$ & RT & 5.9 & Up to 6.30 & 8.60 \\
\hline Young's Modulus & $\mathrm{GPa}$ & RT & 188 & 188 & 205 \\
\hline Anisotropy Factor & --- & RT & 3.25 & 3.25 & 2.72 \\
\hline Shear Modulus & $\mathrm{GPa}$ & RT & 71.5 & 71.5 & 74 \\
\hline Poisson's Ratio & --- & RT & 0.313 & 0.313 & 0.380 \\
\hline $\begin{array}{l}\text { Thermal } \\
\text { Expansion }\end{array}$ & $10^{-6} /{ }^{\circ} \mathrm{C}$ & 600 & 13.2 & 13.7 & 13.5 \\
\hline Specific Heat & $\mathrm{J} / \mathrm{g}^{\circ} \mathrm{C}$ & 600 & 0.64 & 0.61 to 0.64 & 0.46 \\
\hline Thermal & $\mathrm{cm}^{2} / \mathrm{s}$ & 600 & 0.22 & 0.10 to 0.22 & 0.033 \\
\hline $\begin{array}{c}\text { Diffusivity } \\
\text { Thermal } \\
\text { Conductivity }\end{array}$ & $\mathrm{W} / \mathrm{m}^{\circ} \mathrm{C}$ & 600 & 76 & 35 to 76 & 15 \\
\hline
\end{tabular}




\subsection{Microstructural Behavior of Alloyed Nickel Aluminide}

\begin{tabular}{|c|c|c|c|c|c|c|c|c|c|c|}
\hline IIIB & IVB & VB & VIB & VIIB & - & VIII & $\longrightarrow$ & IB & IIB & \\
\hline $\mathrm{Sc}$ & [Ti] & $\mathrm{v}$ & 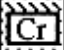 & $\mathrm{Mn}$ & $\mathrm{Fe}$ & $\mathrm{Co}$ & Ni & $\mathrm{Cu}$ & $\mathrm{Zn}$ & \\
\hline $\mathrm{Y}$ & $\mathrm{Zr}$ & $\mathrm{Nb}$ & Mo & \begin{tabular}{|l|}
$\mathrm{Tc}$ \\
\end{tabular} & Ru & Rh & $\mathrm{Pd}$ & $\mathrm{Ag}$ & $\mathrm{Cd}$ & \\
\hline $\mathrm{a}$ & $(\mathrm{Hf}$ & $\mathrm{Ta}$ & $w$ & $\mathrm{Re}$ & Os & $\frac{1 r}{I r}$ & Pt & $\mathrm{Au}$ & $\mathrm{Hg}$ & $T$ \\
\hline
\end{tabular}

Type A: Ternary Intermetallic Phase(s) Occurs

Type B: NiAl-BCC Pseudobinary Eutectic

Type C: High Solubility in NiAl

Alloying Behavior with NiAl Unknown

Figure 2.1: Alloy Addition in NiAl [12]

Figure 2.1 shows a prediction of the microstructure that may form with the addition of certain elements to nickel aluminide.[12] Accordingly, the alloying effect is expected from adding chromium as molybdenum. $\mathrm{Cr}$ and Mo have limited solubility in $\mathrm{NiAl}$ and do not form any ternary phases.[7] These elements form pseudobinary eutectic with stoichiometric $\mathrm{NiAl}$ and may strengthen $\mathrm{NiAl}$ at high temperatures and act as ductile reinforcement at low temperatures.[7] The extensive addition will form precipitates in the form of chromium or molybdenum. The addition of niobium is expected to produce intermetallic phase formation. Niobium has relatively limited solubility and form ternary ordered compounds, with nickel and aluminum.[7] The phases that may form are $\mathrm{Ni}_{2} \mathrm{AlNb}$ known as Heusler phase or NiAlNb known as Laves phase.[7] These phases are more brittle than $\mathrm{NiAl}$ and are not expected to ductilize NiAl.[7]

Elements such as chromium and molybdenum have limited low temperature solubility $(<1 \%)$ in NiAl at room temperature.[2] These elements when added beyond their solubility limit, precipitate metallic chromium and molybdenum particles which 
strengthen NiAl.[2] These particles are referred to as $\alpha$ precipitates. The $\alpha$ precipitates formed have BCC crystal structures. This type of strengthening would be referred to as metallic-precipitate strengthening.[2] The most potent form of strengthening is provide from the formation of the Heusler phase $\mathrm{Ni}_{2} \mathrm{AlX}$, (where $\mathrm{X}=\mathrm{Hf}, \mathrm{Nb}, \mathrm{Ti}, \mathrm{Zr}, \mathrm{V}$, Ta).[2] This phase is referred to as the $\beta$ ' precipitates. The $\beta$ ' precipitates for Heusler crystal structures. This type of strengthening would be referred to as intermetallic-precipitate strengthening.[2]

The first report of using $\beta$ ' as precipitate strengthening was with the addition of titanium.[9] It was found that large amounts of Ti produced either a $\beta$ matrix (NiAl) with $\beta$ ' precipitates or vice versa.[9] The strongest of these alloys, containing 15-20 at\% Ti, had creep strength approaching first generation, directionally solidified nickel-base superalloys in certain stress and temperature ranges.[9] Other alloy additions have produced similar results, Hf or Ta containing $\beta^{\prime}$ precipitates have approached the strength of the high $\mathrm{Ti}$ alloys.[9] In $\mathrm{Ta}$ and $\mathrm{Ti}$ alloys at $982{ }^{\circ} \mathrm{C}$, it is believed the primary strengthening mechanism solid solution strengthening.[9] The NiAlNb Laves phase has also been used to strengthen $\mathrm{NiAl}$, however it has been found that large addition are necessary to reach the strength of nickel-base supperalloys.[9] Directional solidification can be used to improve the properties of these alloys.[9]

Directional solidification has also been used to help improve the properties in alloys containing $\alpha$ forming precipitates, such as Mo, Cr, and Re.[9] Using directional solidification, the eutectic composition produces aligned $\alpha$ fibers $(\mathrm{Mo}, \mathrm{Cr}, \mathrm{Re})$ which can greatly improve strength.[9] It is believed that most of the strengthening that occurs from 
the addition of $\mathrm{Cr}$, is due to the dispersed $\alpha$ particles than from the solid solution addition.[9] The atomic size misfit in the addition of $\mathrm{Cr}$ is not significant.

Many different kinds of precipitates can form in the NiAl-based system.[12] Such as the ones discussed previously that for $\alpha$ or $\beta$ ' precipitates. In these cases the solubility of the precipitate increases with temperature.[12] This can be a disadvantage at elevated temperatures, since the precipitates may become dissolved at service temperature.[12] This behavior suggests that only elements with very low solubilities should be considered for high temperature applications.[12] Alternatively, dispersion strengthened alloys may be considered.[12] Ones which contain refractory particles that are essentially insoluble in the solid.[12]

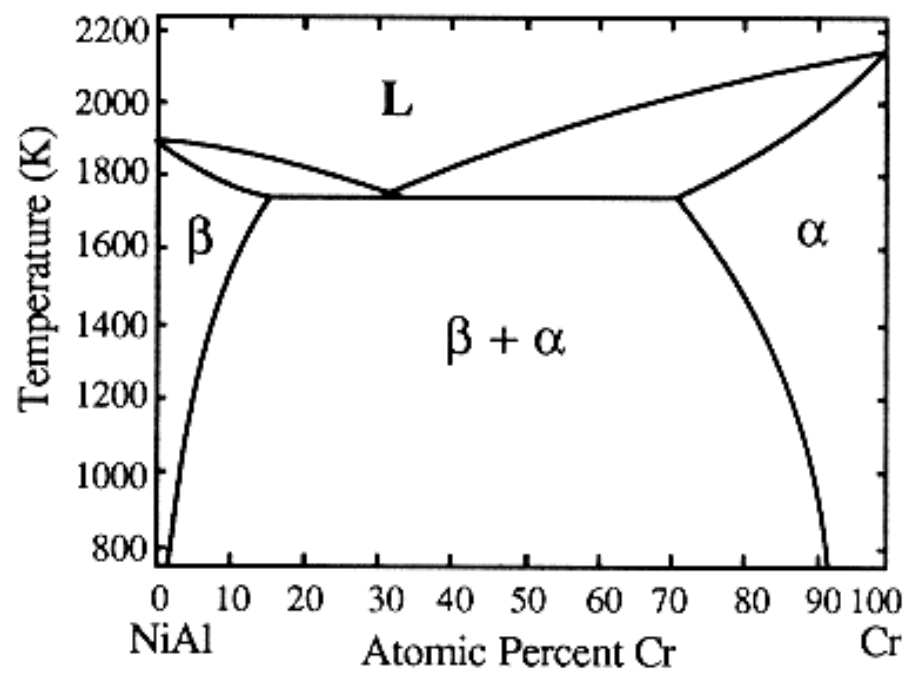

Figure 2.2: Pseudo-Binary Phase Diagram NiAlCr [12]

Illustrated in figure 2.2, the pseudo-binary phase diagram of $\mathrm{NiAlCr}$ the composition at higher temperatures can be approximated. From the diagram it can be determined that the $\alpha$ precipitates will be soluble at all the testing temperatures. 


\subsection{Alloy and Microstructure Effect on Creep Behavior}

\subsubsection{Atomic Size and Electron Number Effect on Strength Behavior of Ni-Base Superalloys}

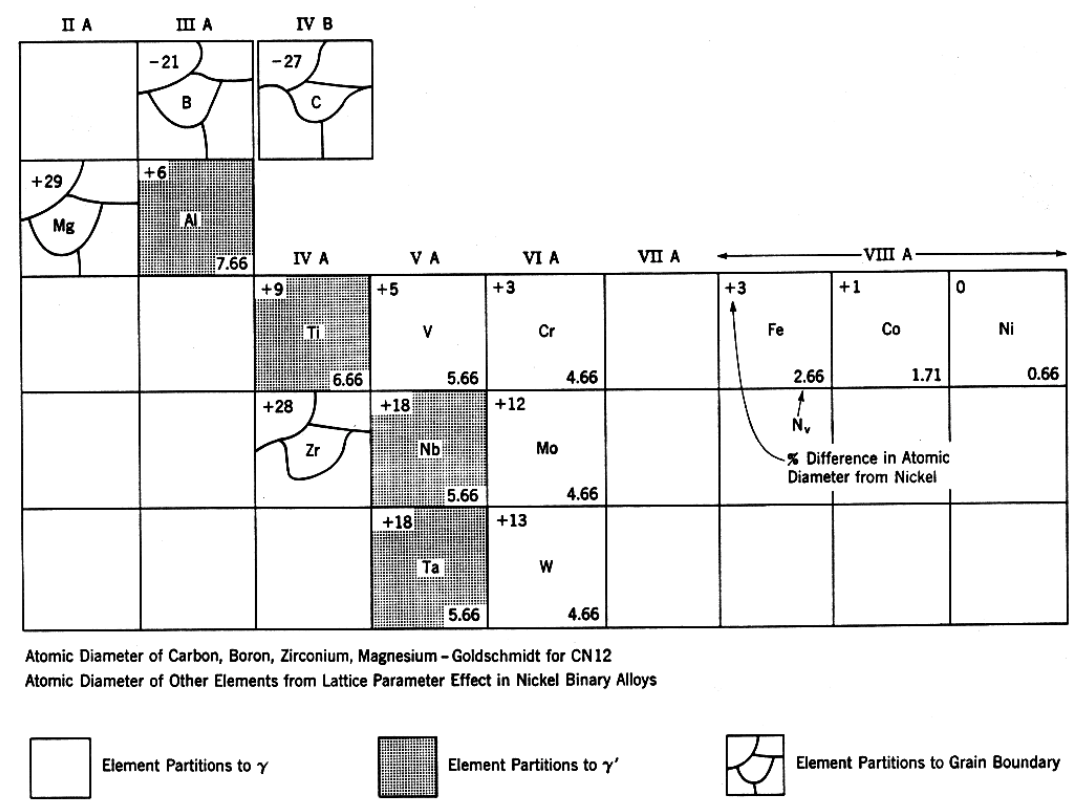

Figure 2.3: Alloying Elements in Nickel-Base Superalloys[15]

Figure 2.3 shows the alloying effects in nickel-base superalloys. From this the approximate effect on the lattice perimeter of $\mathrm{NiAl}$ from the replacement on a nickel by a solute atom can be determined. The number located in the left hand corner indicates the relative size of the solute atom to the nickel atom. This formation can offer some insight as to the improvement in strength, by adding a solid solution addition, that would sit on the nickel or aluminum sites in the lattice structure. The elements that would provide the most lattice misfit would have a larger size relative to that of the nickel atom. From the figure, chromium, molybdenum, and niobium can be compared The number in the bottom right hand corner represents the electron vacancy number $\mathrm{N}_{\mathrm{v}}$. The position the element is located on the periodic table also has a strengthening effect. The solute can 
lower stacking fault energy in extended partial dislocations. Lowering stacking fault energy would reduce the mobility of extended partial dislocations and make dislocation cross-slip more difficult.

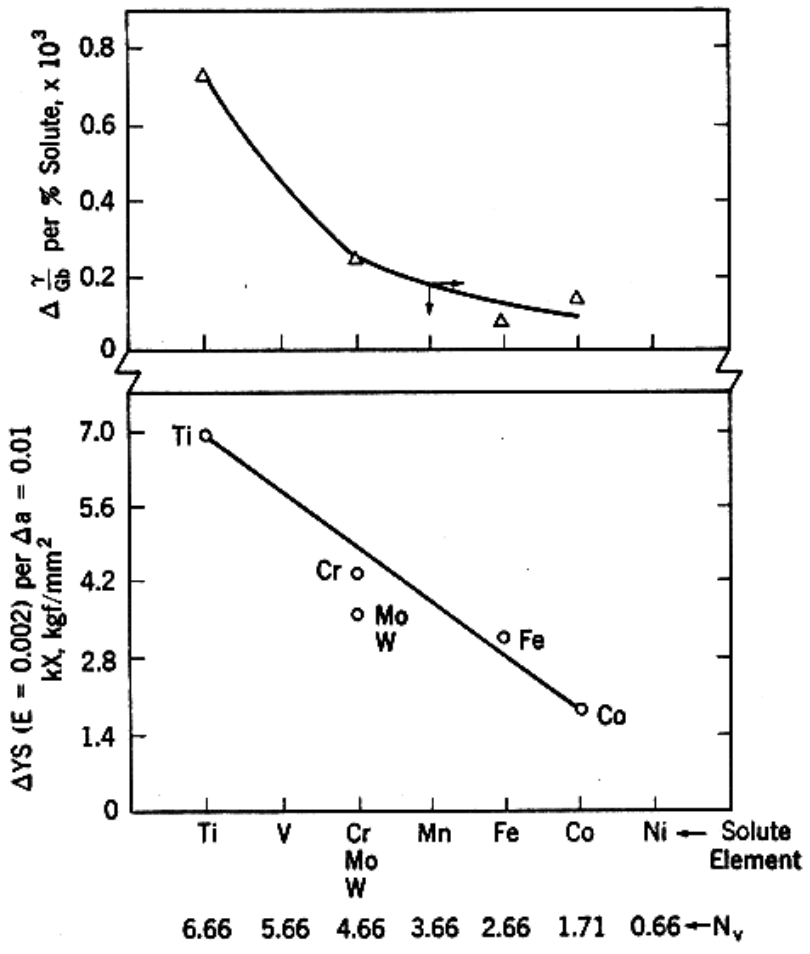

Figure 2.4: Effect of Solute Position on Periodic Table [15]

Figure 2.4 shows the effect position in the periodic table and solute $\mathrm{N}_{\mathrm{v}}$ has on nickel-base binary alloys. The top graph represents a change in stacking fault energy of nickel per percent solute. The bottom graph shows the change in room temperature yield strength per unit of lattice constant change by a given alloying element addition. 


\subsubsection{Microstructural Effect on High Temperature Deformation Behavior}

Table 2.2: Flow Stress for NiAl [001] Single Crystals [1]

\begin{tabular}{ccc}
\hline $\begin{array}{c}\text { Temperature } \\
\left({ }^{\mathbf{O}} \mathbf{C}\right)\end{array}$ & $\begin{array}{c}\text { Stress } \\
(\mathbf{k s i})\end{array}$ & $\begin{array}{c}\text { Strain Rate } \\
\left(\mathbf{s}^{\mathbf{- 1}}\right)\end{array}$ \\
\hline 1000 & 13.05 & $1.00 \mathrm{E}-03$ \\
1000 & 14.50 & $1.00 \mathrm{E}-03$ \\
1056 & 2.90 & $1.00 \mathrm{E}-06$ \\
1200 & 2.47 & $1.00 \mathrm{E}-05$ \\
1200 & 4.21 & $1.00 \mathrm{E}-04$ \\
1200 & 7.11 & $1.00 \mathrm{E}-03$ \\
\hline
\end{tabular}

Table 2.2 shows the data from high temperature compression testing. These tests were done using single crystal specimens in the [001] orientation. This will offer some comparison to the directionally solidified polycrystal NiAl specimens used for this research. The [001] single crystals should provide more creep resistance than the NiAl specimens tested for this research.[1] In this loading orientation, dislocation glide is more inhibited due to nature of the slip systems.[1] The easy slip systems for $\mathrm{NiAl}$ are $\{010\}<001>$ and $\{110\}<001>$. [1] Deformation along the [001] orientation produces no resolved shear stress for glide on the easy slip systems. For this reason the [001] loading orientation is referred to as the "hard" orientation.

Table 2.3: Flow Stress for NiAl [223] Single Crystals [1]

\begin{tabular}{ccc}
\hline $\begin{array}{c}\text { Temperature } \\
\left({ }^{\mathbf{C}} \mathbf{C}\right)\end{array}$ & $\begin{array}{c}\text { Stress } \\
(\mathbf{k s i})\end{array}$ & $\begin{array}{c}\text { Strain Rate } \\
\left(\mathbf{s}^{\mathbf{1}}\right)\end{array}$ \\
\hline 850 & 17.84 & $1.00 \mathrm{E}-02$ \\
850 & 12.18 & $1.00 \mathrm{E}-03$ \\
850 & 8.48 & $1.00 \mathrm{E}-04$ \\
850 & 6.24 & $1.00 \mathrm{E}-05$ \\
1000 & 6.15 & $1.00 \mathrm{E}-03$ \\
1000 & 5.96 & $1.00 \mathrm{E}-03$ \\
1000 & 4.06 & $1.00 \mathrm{E}-04$ \\
1000 & 2.22 & $1.00 \mathrm{E}-05$ \\
1200 & 5.24 & $1.00 \mathrm{E}-02$ \\
1200 & 3.25 & $1.00 \mathrm{E}-03$ \\
1200 & 2.35 & $1.00 \mathrm{E}-04$ \\
1200 & 1.28 & $1.00 \mathrm{E}-05$ \\
\hline
\end{tabular}


Table 2.4: Flow Stress for NiAl [111] Single Crystals [1]

\begin{tabular}{ccc}
\hline $\begin{array}{c}\text { Temperature } \\
\left({ }^{\circ} \mathbf{C}\right)\end{array}$ & $\begin{array}{c}\text { Stress } \\
(\mathbf{k s i})\end{array}$ & $\begin{array}{c}\text { Strain Rate } \\
\left(\mathbf{s}^{-\mathbf{1}}\right)\end{array}$ \\
\hline 850 & 11.46 & $1.00 \mathrm{E}-03$ \\
850 & 7.54 & $1.00 \mathrm{E}-04$ \\
850 & 4.93 & $1.00 \mathrm{E}-05$ \\
1000 & 10.3 & $1.00 \mathrm{E}-02$ \\
1000 & 6.58 & $1.00 \mathrm{E}-03$ \\
1000 & 4.05 & $1.00 \mathrm{E}-04$ \\
1000 & 2.47 & $1.00 \mathrm{E}-05$ \\
1200 & 5.25 & $1.00 \mathrm{E}-02$ \\
1200 & 3.32 & $1.00 \mathrm{E}-03$ \\
1200 & 1.99 & $1.00 \mathrm{E}-04$ \\
1200 & 1.28 & $1.00 \mathrm{E}-05$ \\
\hline
\end{tabular}

Table 2.3 and 2.4 are also for high temperature compression testing of NiAl single crystals. The loading orientations are the [111] and [223]. Due to the loading orientation of these single crystals the critical resolved shear stress is not equal to zero. This would make slip along the $\{110\}<010>$ occur easier.[1] This would make deformation along these crystal orientations less creep resistant than deformation along the [001] orientation. For this reason load in these crystal orientation is referred to as "soft" orientations.[1] Loading in these orientations should be more comparable to the polycrystal $\mathrm{NiAl}$ specimens to be tested for this research.

Table 2.5: Stress Exponent in Single Crystal NiAl [1]

\begin{tabular}{cccc}
\hline \multicolumn{4}{c}{ Stress Exponent } \\
\hline Loading Axis & $\mathbf{8 5 0}^{\circ} \mathbf{C}$ & $\mathbf{1 0 0 0}^{\circ} \mathbf{C}$ & $\mathbf{1 2 0 0}^{\circ} \mathbf{C}$ \\
\hline$[\mathbf{0 0 1}]$ & 11.4 & 5.3 & 3.9 \\
{$[\mathbf{2 2 3}]$} & 9.0 & 4.5 & 3.7 \\
{$[\mathbf{1 1 1}]$} & 5.8 & 4.7 & 4.0 \\
{$[\mathbf{0 1 1}]$} & --- & 5.5 & 4.1 \\
{$[\mathbf{0 7}$ 10] } & 7.2 & 6.0 & 4.5 \\
\hline
\end{tabular}


Table 2.5 was obtained from high temperature creep testing of NiAl single crystals. Even though microstructure from the single crystal structure is different from the directionally solidified polycrystal structure, the data may provide an approximate range that may be expected from the test data.

\subsubsection{Alloying Effect on High Temperature Deformation Behavior}

Table 2.6: Stress Exponent in Single Crystal NiAl-2.5Ti [13]

\begin{tabular}{cccc}
\hline & \multicolumn{3}{c}{ Stress Exponent } \\
\hline Specimen & $\mathbf{9 0 0}^{\circ} \mathbf{C}$ & $\mathbf{1 0 0 0}^{\circ} \mathbf{C}$ & $\mathbf{1 2 0 0}^{\circ} \mathbf{C}$ \\
\hline Nial-2.5Ti [111] & 17.3 & 5.8 & 3.7 \\
Nial-2.5Ti [100] & 11.2 & 6.8 & 5.6 \\
Nial-2.5Ti [001] & -- & 7.6 & 5.1 \\
\hline
\end{tabular}

Table 2.6 was obtained from high temperature creep testing of NiAl single crystals alloyed with titanium. Titanium forms $\beta$ ' precipitates when added to NiAl. This would offer some comparison to the alloyed specimens of $\mathrm{NiAl}$.

Table 2.7:Flow Stress [001] Single Crystal NiAl-1Hf [16]

\begin{tabular}{ccc}
\hline $\begin{array}{c}\text { Temperature } \\
\left({ }^{\mathbf{C}} \mathbf{C}\right)\end{array}$ & $\begin{array}{c}\text { Stress } \\
(\mathbf{k s i})\end{array}$ & $\begin{array}{c}\text { Strain Rate } \\
\left(\mathbf{s}^{\mathbf{- 1}}\right)\end{array}$ \\
\hline 1027 & 47.89 & $1.32 \mathrm{E}-04$ \\
1027 & 34.01 & $2.00 \mathrm{E}-05$ \\
1027 & 15.75 & $2.00 \mathrm{E}-06$ \\
1027 & 16.74 & $1.35 \mathrm{E}-06$ \\
1027 & 13.92 & $3.31 \mathrm{E}-07$ \\
1027 & 60.96 & $1.99 \mathrm{E}-04$ \\
1027 & 27.37 & $1.99 \mathrm{E}-05$ \\
1027 & 17.71 & $1.66 \mathrm{E}-06$ \\
1027 & 20.39 & $1.31 \mathrm{E}-06$ \\
1027 & 16.07 & $1.63 \mathrm{E}-07$ \\
\hline
\end{tabular}

Table 2.7 contains flow stress values for NiAl-1Hf [001] single crystals. This data will offer some comparison to the alloyed directionally solidified specimens. The testing was don in compression and the testing temperature was $1027^{\circ} \mathrm{C}$, 


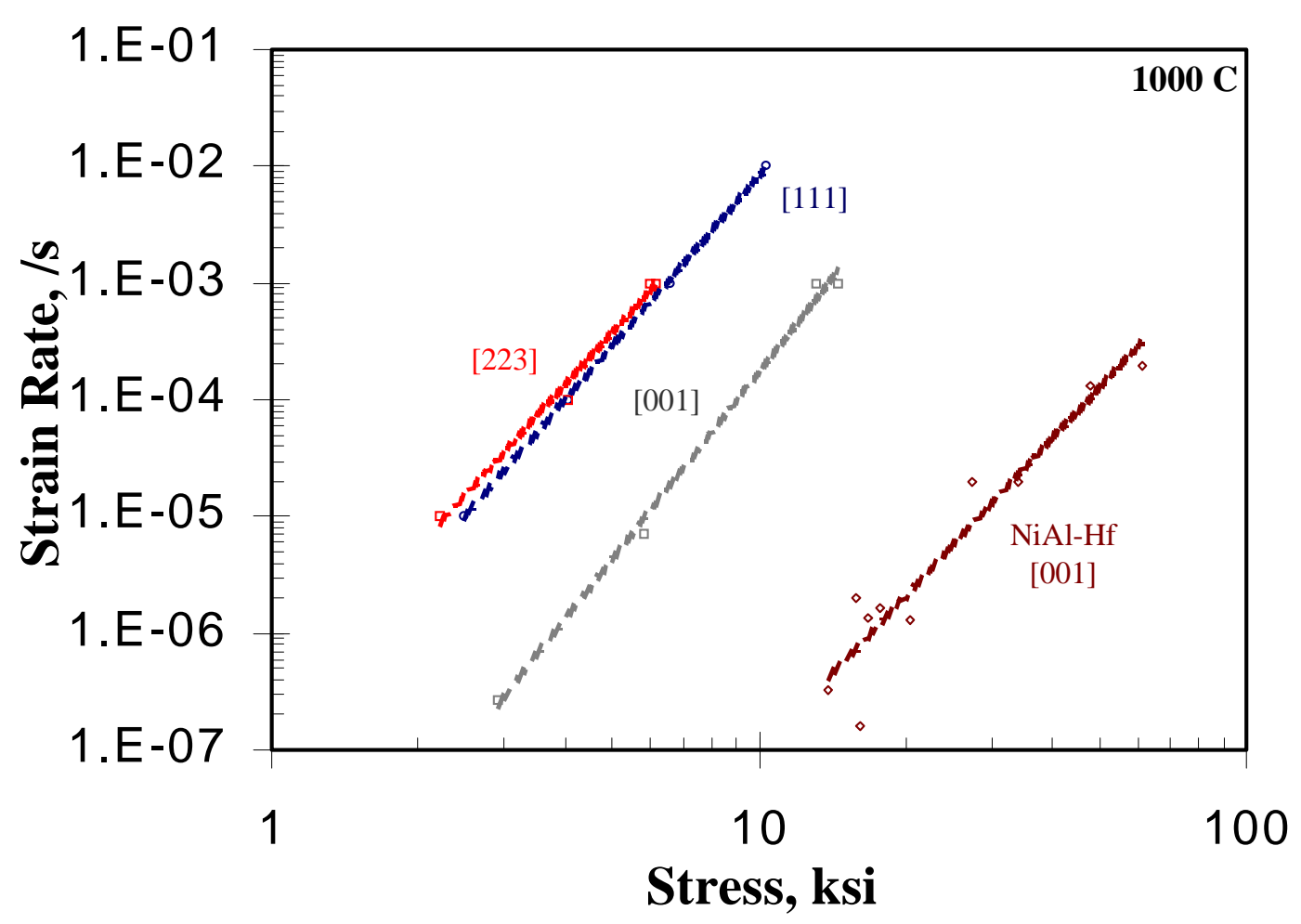

Figure 2.5:Compression Results from Single Crystal Testing[1,16]

Figure 2.7 display the results from single crystal data. Unalloyed specimens in [223], [111], and [001] can be compared to illustrate the effect crystal loading orientation would have on the specimens. The DS NiAl specimens will be closely related to the behavior displayed from the [223] and [111] "soft" crystal orientations. The [001] "hard" crystal orientation will provide more creep resistance than the DS NiAl specimen. Also included, a [001] single crystal NiAl-1Hf specimen, for comparison to the alloyed DS specimens. This material will provide superior creep behavior when compare to the alloyed DS NiAl specimens. 


\section{Chapter 3 - Experimental Procedures}

\subsection{Material}

The four designed compositions, listed in table 2, were prepared by GE Corporate Research and Development Center, Schenectady, New York. The ingots were made by vacuum induction melting using high purity laboratory materials. The materials were directionally solidified to reduce intergranular fractures. Thin plates 6 in X 1-3/8 in $\mathrm{X} 5 / 16$ in were drawn at a rate of $6 \mathrm{in} / \mathrm{hr}$ in a directional solidification furnace. Table 3.1 lists the specimens and their compositions used for evaluation. The materials were designed based on the expected lattice site preference of the alloying elements in the NiAl B2 BCC structure. It was expected that chromium would prefer nickel sites, niobium aluminum sites, and molybdenum would have no site preference. Using the information from the expected lattice site preference, the designed material compositions were determined.

Table 3.1: Chemical Composition of NiAl-base Intermetallic alloys

\begin{tabular}{|c|c|c|c|c|c|c|}
\hline Alloy ID & & $\mathrm{Ni}$ & Al & $\mathrm{Cr}$ & Mo & Nb \\
\hline CCK-1 & $\begin{array}{l}\text { Wt.\% } \\
\text { (at.\%) }\end{array}$ & $\begin{array}{c}\text { Balance } \\
(50)\end{array}$ & $\begin{array}{l}31.5 \\
(50)\end{array}$ & -- & -- & -- \\
\hline CCK-2 & $\begin{array}{l}\text { Wt.\% } \\
\text { (at.\%) }\end{array}$ & $\begin{array}{c}\text { Balance } \\
\quad(48)\end{array}$ & $\begin{array}{l}31.6 \\
(50)\end{array}$ & $\begin{array}{c}2.45 \\
(2)\end{array}$ & -- & -- \\
\hline CCK-3 & $\begin{array}{l}\text { Wt.\% } \\
\text { (at.\%) }\end{array}$ & $\begin{array}{c}\text { Balance } \\
(49)\end{array}$ & $\begin{array}{l}30.1 \\
(49)\end{array}$ & - & $\begin{array}{c}4.40 \\
(2)\end{array}$ & -- \\
\hline CCK-4 & $\begin{array}{l}\text { Wt.\% } \\
\text { (at.\%) }\end{array}$ & $\begin{array}{c}\text { Balance } \\
\quad(50)\end{array}$ & $\begin{array}{l}29.3 \\
(48)\end{array}$ & -- & - & $\begin{array}{c}4.20 \\
(2)\end{array}$ \\
\hline
\end{tabular}

Once the materials were processed they were cut into specimens to be used for compression testing. Figure 3.2 shows the shape and the dimensions that the specimens were produced for compression testing. 


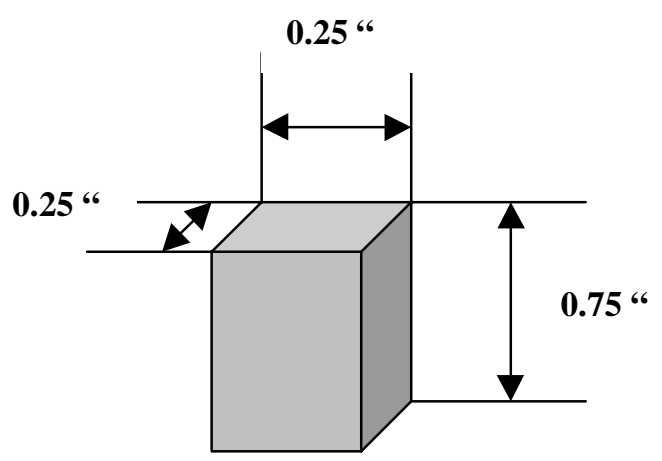

Figure 3.1: Compression Specimen

\subsection{Microstructural Evaluation Procedure}

To evaluate the microstructure both the optical and scanning electron microscope was used. The scanning electron used was a JEOL JSM-6400. The optical microscope used was a Leitz Laborlux 12ME with a COHU high performance CCD camera. The optical microscope was connected to a personal computer and used Optima's imaging software. The Optima imaging software provided the ability to transform images taken from the digital camera to files that could be altered for observation and comparison.

\subsubsection{Optical Microstructural Evaluation Procedure}
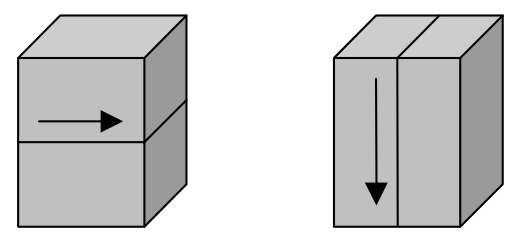

Figure 3.2: Specimen Cutting for Microstructural Evaluation

Before the Microstructure of the specimens could be viewed they had to first be polished and etched to provide suitable surface for viewing. To polish the specimens they first had to be cut using a Buehler Isomet low speed diamond saw. This was done to provide a surface both parallel and perpendicular to the direction of solidification. As can be seen from figure 3, each specimen was cut to view both the longitudinal and transverse 
grain boundary orientations. It was also done to provide a damage free surface to begin the polishing process. To polish the specimens it was required that they were mounted in a polymer mold. To mount the specimens Buehler Sampl-Kwick mold was used. This was done to make the polishing process less difficult. The polishing system required that the specimens be mounted in the molds to be used in the machine.

Once the specimens were mounted in the molds the polishing process could begin. To begin the polishing process the specimens were first sanded using 240 grit sandpaper to remove the damaged area from cutting. After they were sanded with the 240 grit paper the sanding process continued using sandpaper with decreasing particle size until they had been sanded with 600 grit paper. The specimens were sanded using a Buehler Automet 2 power head with a Buehler Ecomet 2 two-speed grinder-polisher. To polish the specimens a special superalloy polishing cloth was used with alpha micropolish II deagglomerated alumina to provide a 1.0-micron finish. This provided a scratch free surface for viewing the microstructure of the specimens.

Once the polishing process had been completed, the specimens were etched to bring out the grain boundaries and secondary particles for viewing. They were etched using a solution containing $45 \%$ concentrated $\mathrm{HCL}, 45 \% \mathrm{H}_{2} \mathrm{O}$, and $10 \% \mathrm{H}_{2} \mathrm{O}_{2}$. All the specimens were placed in the solution for approximately 10-15 seconds. They were then placed in water to stop the etching process. After etching the specimen surfaces were cleaned with methanol and dried with hot air to remove any spots from the specimen surface. 


\subsubsection{SEM Microstructural Evaluation Procedure}

Before the Microstructure of the specimens could be viewed they had to first be polished to provide suitable surface for viewing. The specimens were polished using the same process as used in the optical viewing procedure. To view the specimens with the scanning electron microscope it was not required that they were etched. However it was necessary that they be removed from the polymer molds.

\subsection{Microstructural Analysis Procedure}

The compositions of the secondary particles were analyzed using the Energy Dispersive Spectroscopy (EDS) function on the scanning electron microscope. Using the EDS the approximate composition of the secondary particles could be determined and compared to that of published data. The EDS graphs displayed the composition at any point on the specimen. A point was selected within the secondary phase and one was selected on the matrix material.

EDS is a chemical microanalysis technique performed in conjunction with a scanning electron microscope.[14] The technique utilizes $\mathrm{x}$-rays that are emitted from the sample during bombardment by the electron beam to characterize the elemental composition of the analyzed volume.[14] When a sample is bombarded by the electron beam from the SEM, electrons are ejected from the atoms on the specimen surface.[14] An electron from a higher shell fills the resulting vacancies, and an x-ray is emitted to balance the energy between the two electrons.[14] The EDS measures the number of emitted x-rays versus their energy.[14] The energy of the x-ray is characteristic of the element from which the x-ray was emitted.[14] A spectrum of the energy versus relative 
counts of the detected $\mathrm{x}$-rays is obtained and evaluated for analysis to determine the elements present.[14]

Another technique called elemental mapping was also used. This technique was very effective for analyzing the elemental concentrations in the materials that contained secondary phases that consisted of only one composition. The characteristic x-ray intensity is measured relative to lateral position on the sample surface.[14] Variations in $\mathrm{x}$-ray intensity then indicate the relative elemental concentrations across the surface.[14] Maps are recorded using image brightness intensity as a direct function of the local concentrations of the elements present.[14]

\section{Optical Microstructural Viewing Equipment}

- Buehler LTD Grinder-Polisher System

Automet 2 Power Head

Ecomet 2 Two-Speed Grinder-Polisher

Buehler Polishing Wheel

Buehler Microcloth Polishing Cloth

Buehler Alpha Micropolish II Deagglomerated Alumina

- Buehler LTD Diamond Saw

Isomet low speed saw

Buehler Isocut Fluid

- Buehler LTD Rollgrinder

Handimet 2 Rollgrinder

Sandpaper Grit: 240, 320, 400, 600

- Buehler LTD Sample Mold

Sampl-Kwick Mold

- Leitz Laborlux $12 \mathrm{ME}$

COHU High performance CCD Camera

Optima Imaging Software

- JEOL JSM-6400 Scanning Electron Microscope 


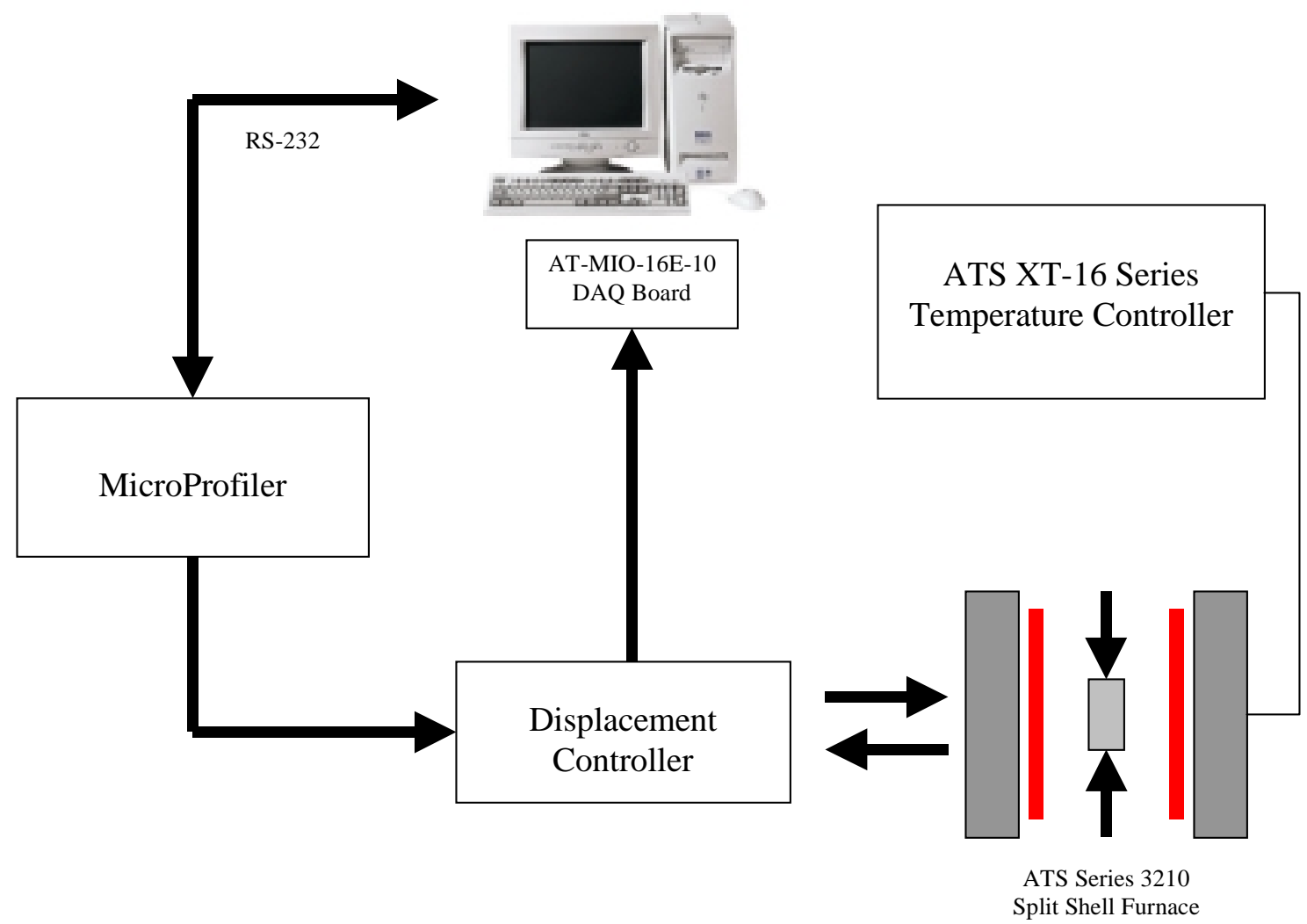

Figure 3.3: Schematic for Mechanical Test Setup

\subsection{Mechanical Testing Setup}

The nickel aluminide specimens were tested using two methods to evaluate their high temperature properties: strain rate controlled compression test and stress relaxation tests. The testing was done at temperatures ranging from $850{ }^{\circ} \mathrm{C}$ to $1200{ }^{\circ} \mathrm{C}$. The specimens were cut with a height of 0.75 inches and a cross-section of $0.25 \times 0.25$ inches.

The samples were tested using an 810 Material Testing System (MTS). The MTS was computer controlled using National Instruments LabView Software. The computer controlled test setup was used to monitor the testing, record the data, and maintain consistency between each individual test. Using the computer, a constant displacement rate of the crosshead on the MTS 810 testing frame could be maintained. While the 
displacement rate was being maintained, the computer could record the data from the load cell and linear variable displacement transducer (LVDT) located on the MTS.

\subsubsection{Constant Strain Rate Compression Testing}

The constant strain rate compression tests were done using a hydraulic driven Model 810 MTS testing machine. Samples were placed between two flat ATS MARM246 compression platens coated with boron nitride to allow slip between the specimen and the platens. The test was performed in air in a model ATS 3210 split shell furnace, capable of temperatures up to $1200^{\circ} \mathrm{C}$. The ATS 3210 split shell furnace was controlled by an ATS Series XT-16 Three-Zone Temperature Control System. The set point temperature was set on the ATS temperature controller. The ATS controller performed the feedback loop to maintain a constant temperature during testing. Displacement was translated using two ATS MAR-M246 liquid cooled pull rods. Displacement was measured using the MTS linear variable displacement transducer (LVDT). The full-scale range could be selected for each specimen so the resolution could be improved. The fullscale range was selected to \pm 0.5 inches to maximize the resolution. However the resolution of the displacement was limited by the National Instruments AT-MIO-16E-10 data acquisition board. The resolution was limited to $2.44 \times 10^{-4}$ inches. The load cell used was a MTS model 318.10B load unit. The load unit was attached to the crosshead on the MTS test frame. To measure the load the upper pull rod was threaded into the load unit using an adapter made by ATS. The load cell was capable of measuring loads up to 22 kip. The full-scale range could also be selected to improve the resolution. The fullscale range of the load cell was adjusted between 2 kip and $10 \mathrm{kip}$, depending on the maximum expected load from each test. The resolution was limited by the MTS 458.20 
MicroConsole. The resolution ranged from 0.1 pounds for the 2 kip full-scale setting to 0.5 pounds for the $10 \mathrm{kip}$ full-scale setting.

A National Instruments AT-MIO-16E-10 DAQ board along with an SCB-68 connector block was used to monitor the system. The data acquisition board was wired to the MTS microconsole to control the crosshead motion and record the displacement and load from the test. A Pentium $133 \mathrm{MHz}$ computer was used to control the data acquisition system. The temperature within the ATS split shell furnace was maintained by the ATS series XT-16 temperature control system. The uniform heated zone provided by the ATS furnace was 3" x 3". Strain rates from $10^{-6}$ to $10^{-3}$ were performed on the specimens. All of the compression tests were performed at temperatures ranging from $850{ }^{\circ} \mathrm{C}$ to $1200{ }^{\circ} \mathrm{C}$.

\subsubsection{Stress Relaxation Testing}

Some samples were tested using a technique call stress relaxation. The MTS testing system was also used to perform the stress relaxation tests. The stress relaxation test were also conducted at high temperatures ranging from $850{ }^{\circ} \mathrm{C}$ to $1200{ }^{\circ} \mathrm{C}$. The testing was done by loading the specimen in compression at a specified strain rate. Once the point of steady-state creep was reached the crosshead displacement was stopped. The position of the crosshead was maintained with a feedback loop while the load was

allowed to drop. The data acquisition system monitored the time and loads, then stored the data from the test.

\subsubsection{Mechanical Testing Error}

Observed in the mechanical testing setup were several areas of possible errors: DAQ system in the MTS 458.20 MicroConsole and the National Instruments AT-MIO- 
16E-10 DAQ Board. Using the estimated errors from data recording system the approximate error from the electronic equipment used can be determined.

The accuracy of the MTS MicroConsole, $\pm 0.05 \%$ full-scale, was provided from the MTS manual. For the mechanical testing the $\pm 2, \pm 4$, and \pm 10 kip range cards were used to measure the load. From this information the error in the load measurement was determined to be $\pm 1 \mathrm{lb}, \pm 2 \mathrm{lb}$, and $\pm 5 \mathrm{lb}$ depending on the range card selected. The displacement card used for testing, \pm 0.5 in, produced an error of 0.00025 in.

There was also some error produced by the DAQ board. The estimated error obtained from the manual was $\pm 0.5 \mathrm{LSB}- \pm 1.5 \mathrm{LSB}$. Since the card used provided 12 bit resolution the error was calculated to be $0.0366 \%$. The largest error in measurement is produced by the MTS MicroConsole. The error in the measurement data can be viewed table 3.2. The relative error changes depending on the magnitude of the measurement. Illustrated in the table, the error decreases as the magnitude of the measurement increases.

Table 3.2: Measurement Error in DAQ System

\begin{tabular}{cc}
\hline Error & Measurement Error (ksi)/(strain) \\
\hline Error @ 1 ksi & \pm 0.0804 \\
Error @ 10 ksi & \pm 0.0837 \\
Error @ 1\% Elongation & \pm 0.000337 \\
Error @ 5\% Elongation & \pm 0.000352 \\
\hline
\end{tabular}

\section{Mechanical Testing Equipment}

- High Temperature Deformation Testing

Controlled strain rate

Stress Relaxation Test

Temperature up to $1200^{\circ} \mathrm{C}$

- $\quad$ MTS model 810 Testing Frame 
- MTS 318.10B Load Unit (force rating: 22kip; displacement: 6 in)

- MTS 458.20 MicroConsole TM $^{\mathrm{TM}}$

458.11 DC force controller

458.13 AC displacement controller

458.91 MicroProfiler ${ }^{\mathrm{TM}}$ (12 to 18-bit resolution)

- Instrumentation Control \& Data Acquisition System

Pentium 133 Computer

Communicate with MTS MicroProfiler ${ }^{\mathrm{TM}}$ using RS-232 interface

- National Instruments AT-MIO-16E-10 Board

Interface with $\mathrm{DC}$ force controller, $\mathrm{AC}$ displacement controller, temperature Controllers, and temperature transmitter

Analog Input: 16 single-ended, 8 differential channels, 12-bit resolution; 100kS/s Sampling rate; analog output: 2 channels, 12-bit resolution

- National Instruments AT-GPIB/TNT Board

IEEE 488.2 compatible; maximum transfer rates: $1.5 \mathrm{Mbytes} / \mathrm{s}$

Interface with HP power supply \& multimeter

- National Instruments Shielded Connector Block 68

Provided means of connecting equipment to DAQ board

- National Instruments LabView Software

- Environmental Control Chamber

- ATS Series 3210 Split Tube Furnace

Three heated zones; heated length: 3 x 3"

Temperature: up to $1200^{\circ} \mathrm{C}$

- ATS Series XT-16 Three-Zone Temperature Control System

Temperature range: 25 to $1200^{\circ} \mathrm{C}$, type $\mathrm{K}$

Sampling rate: $0.1 \mathrm{sec}$

With RS-485 serial communications link

- Upper Pull Rod: 3/4" Diameter, Threaded 3/4-10-2B

Radiation Shields

Water cooling collar

Length: $15-1 / 2 "$

Material: MAR-M246

- Lower Pull Rod: 3/4" Diameter, Threaded 3/4-10-2B

Radiation Shields

Water cooling collar

Length: 15-1/2"'

Material: MAR-M246 
- Compression Platens

Material: MAR-M246

- Double pivot mounting assembly

Mounts furnace to MTS model 810 test frame

- Pull-rod adapters

Connects upper and lower pull-rods to MTS model 810 test frame

Material: 1045 steel

\subsection{Mechanical Testing Data Analysis}

\subsubsection{Compression Data Analysis}

The compression data was collected in the form of time, load, and displacement. For this data to be interpreted in had to be transformed into true stress and true strain. From that the flow stress could be found that corresponded to the steady state creep rate of the compression test. The first step in the data analysis was to graph load vs. displacement. This was done to aid in the removal of the elastic displacement. Once the data was graphed linear regression analysis could be done on the linear region of the data. Once the regression analysis was done to find the slope and intercept of the linear region the plastic deformation could be calculated. The equation used to calculate the plastic deformation was:

$$
\mathrm{P}=\mathrm{D}-\mathrm{L} / \mathrm{m}-\mathrm{b} / \mathrm{m}
$$

where $\mathrm{P}$ is the plastic displacement, $\mathrm{D}$ is the total displacement, $\mathrm{L}$ is the load, $\mathrm{m}$ is the slope, and $\mathrm{b}$ is the intercept. This equation could be used to calculate the plastic displacement at every point from the total displacement given from the testing data. Illustrated in figure 3.4, the first two steps in the compression data analysis, linear regression to remove elastic displacement and the resulting curve after removal. 


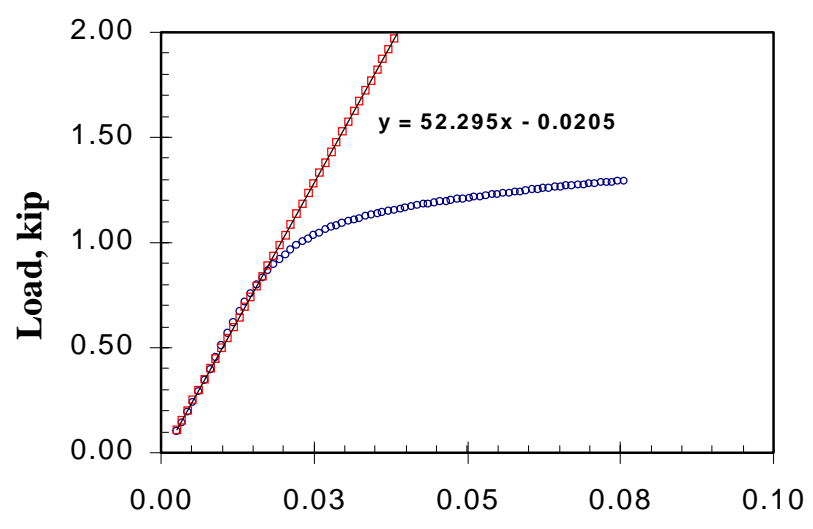

Dis., in.

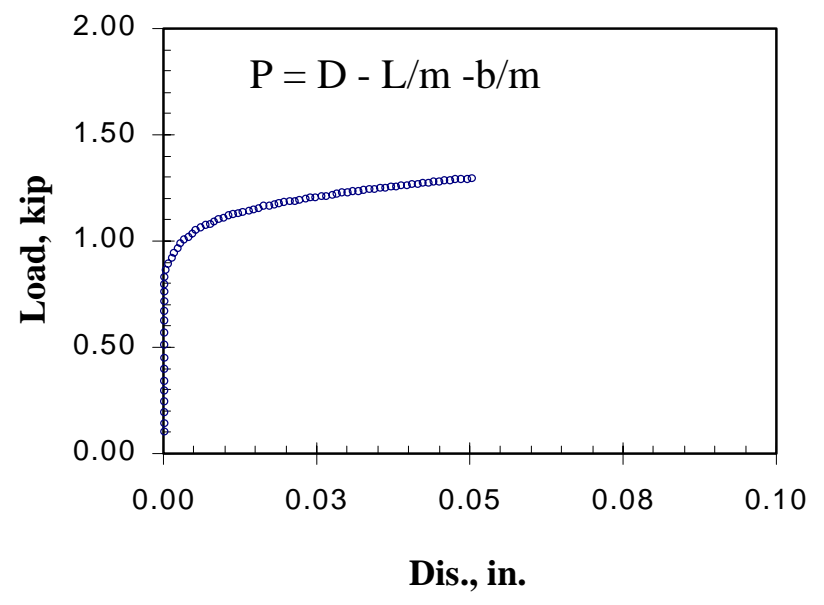

Figure 3.4: Compression Data Analysis Example

Once the plastic displacements were calculated the stress and strains could be calculated. First the engineering stresses and strains needed to be calculated. The equations used were:

$$
\begin{aligned}
& \mathrm{e}=\mathrm{P} / \mathrm{h} \\
& \mathrm{s}=\mathrm{L} / \mathrm{A}
\end{aligned}
$$

where $\mathrm{e}$ is the engineering strain, $\mathrm{P}$ is the plastic displacement, and $\mathrm{h}$ is the starting height. The second equation was used to calculate the engineering stress where $\mathrm{s}$ is the engineering stress, $\mathrm{L}$ is the load, and $\mathrm{A}$ is the beginning cross-sectional area.

After the engineering stresses and strain were found the true stresses and strains needed to be found. The equations used for finding the true stress and strain were:

$$
\begin{aligned}
& \varepsilon=\operatorname{Ln}(1+e)[3] \\
& \sigma=\mathrm{s}(1+\mathrm{e})[3]
\end{aligned}
$$

where $\varepsilon$ is the true strain and e is the engineering strain. The second equation was used for finding the true stress where $\sigma$ is the true stress, $\mathrm{s}$ is the engineering stress, and $\mathrm{e}$ is the engineering strain. From the true stress and strain the flow stress could be calculated. 
The flow stress was found by taking the average true stress from the region of steady state creep on the stress-strain curve. Once the flow stress was found at certain strain rates the data could be graphed on a log-log scale in the form of strain rate vs. flow stress. This is the typical method of preparation for creep data to be analyzed. This process is further illustrated in figure 3.5 , the transformation from engineering stress-strain to true stress-strain and the average flow stress taken from the steady state region.
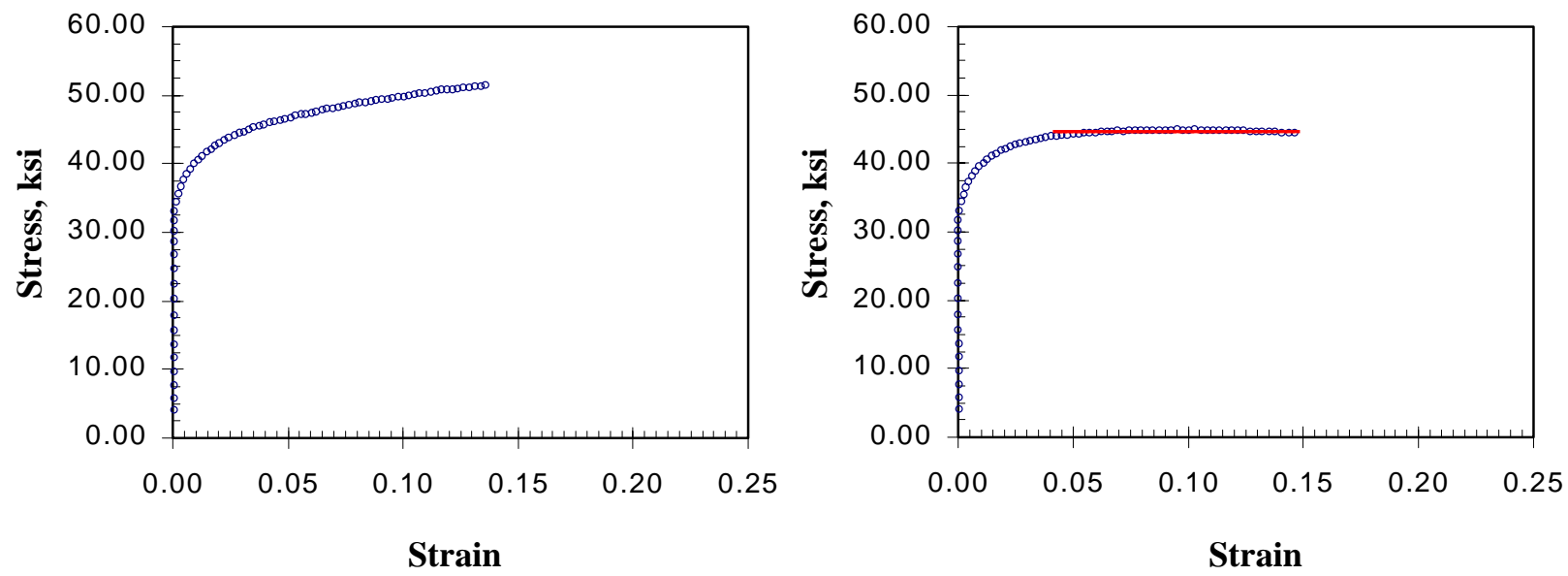

Figure 3.5: Compression Data Analysis Example

\subsubsection{Stress Relaxation Data Analysis}

The stress relaxation data was collected in the form of load and time. It was necessary to transform this data in the form of strain rate vs. stress to be compare to the compression data. To analyze the stress relaxation data, first the normalized load was plotted against time on a log-log scale. Regression analysis was then done with a power law fit:

$$
\mathrm{y}=\mathrm{kt}^{\mathrm{m}}
$$

where $\mathrm{y}$ is the normalized load, $\mathrm{k}$ is a constant, $\mathrm{t}$ is time, and $\mathrm{m}$ is the slope. The data fit was then graphed with the original data to confirm that a sufficient fit was done. This was done to calculate the strain rate from the test data. 


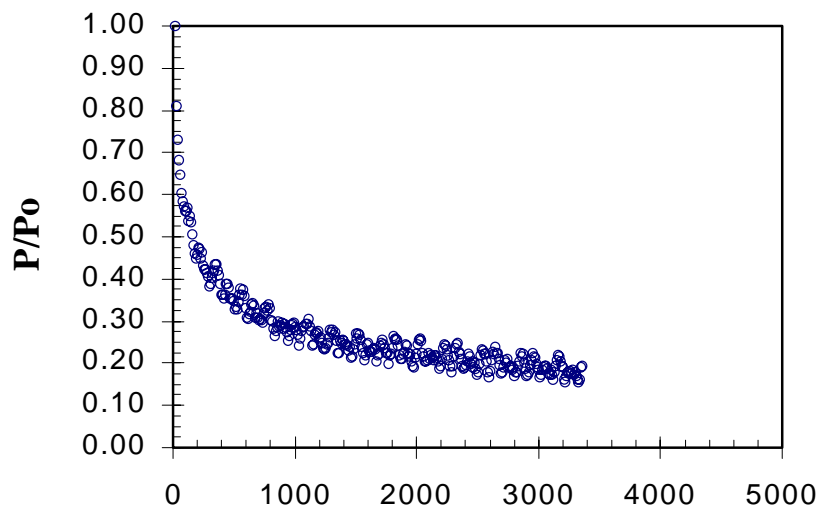

Time, $\min$

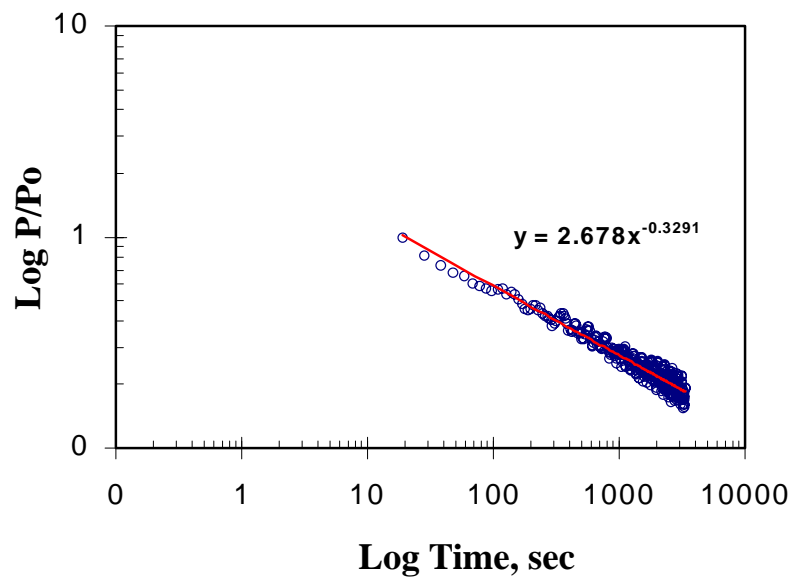

Log Time, sec

Figure 3.6: Stress Relaxation Data Analysis Example

To begin a stress relaxation test the specimen was first loaded under constant strain rate until a condition of steady state creep was achieved. Then the crosshead displacement was stopped to begin the stress relaxation test. To calculate the stress it was assumed the when the stress relaxation test began the cross-sectional area of the specimen remained unchanged, since the position of the crosshead was maintained. Since the initial stress and strain rate was known the following values could be found. This was done by using the equation:

$$
\sigma_{\text {new }}=\sigma_{\text {previous }}\left(\mathrm{P}_{\text {new }} / \mathrm{P}_{\text {previous }}\right)
$$

where the next stress value could be calculated by multiplying the previous value of stress by the ratio of the new load to the previous load. This method would give the values for the stress at every data acquisition interval during the stress relaxation test.

The strain rate could be calculated also by using the initial starting values for the stress relaxation test. This was done by relating the change in stress to the change in strain rate. The equation found from the regression analysis performed on the normalized load vs. time graph could be used to find the strain rate. The equation from the regression analysis could be represented in the form: 


$$
\mathrm{y}=\mathrm{kt}^{\mathrm{m}}
$$

where $\mathrm{y}$ is the normalized stress, $\mathrm{k}$ is a material constant, $\mathrm{t}$ is time, and $\mathrm{m}$ is the slope of the line. To find the strain rate from the normalized stress a relationship can be made between the elastic and plastic deformation.[3,5] Before the stress relaxation part of the testing begins; the displacement on the crosshead is not equal to zero.[3] This can be represented by the equation:

$$
\mathrm{v}=\mathrm{L}_{\mathrm{E}}+\mathrm{L}_{\mathrm{P}}[3]
$$

where $\mathrm{v}$ is the displacement rate of the crosshead, $\mathrm{L}_{\mathrm{E}}$ is the elastic displacement rate, and $L_{P}$ is the plastic displacement rate.[3] At the point where the stress relaxation test begins $\mathrm{v}$, the crosshead displacement rate becomes equal to zero.[3] The equation can then be divide by $\mathrm{L}_{\mathrm{o}}$ the equation will become:

$$
\dot{\epsilon}_{\mathrm{E}}+\dot{\epsilon}_{\mathrm{P}}=0[3]
$$

where $\dot{\epsilon}_{\mathrm{E}}$ is the elastic strain rate and $\dot{\epsilon}_{\mathrm{P}}$ is the plastic strain rate.[3] To find the plastic strain rate from the stress rate the equation that relates elastic strain rate to stress rate can be substituted in to the equation.[3] For the elastic region of a stress-strain curve equation:

$$
\dot{\epsilon}=(1 / \mathrm{E}) \mathrm{d} \sigma / \mathrm{dt}[3,5]
$$

where $\dot{\epsilon}$ is the strain rate, $E$ is the elastic modulus of elasticity, and $d \sigma / d t$ is the stress rate. Substituting this into the equation you are left with and equation to relate the stress rate to the strain rate.

$$
\mathrm{d} \sigma / \mathrm{dt}=\mathrm{B} \dot{\epsilon}[3,5]
$$

Where $d \sigma / d t$ is the stress rate, B is a constant, $\dot{\epsilon}$ is the strain rate. From this equation it can be seen that the strain rate and stress rate differ only by a constant multiple.[3,5] 
From this equation the strain rate can be calculated at any point.[3,5] To find the values for the strain rate from the initial value the following equation was used:

$$
\dot{\epsilon}_{\text {new }}=\dot{\epsilon}_{\text {previous }}\left(\mathrm{d} \sigma_{\text {new }} / \mathrm{dt}\right) /\left(\mathrm{d} \sigma_{\text {previous }} / \mathrm{dt}\right)
$$

where the strain rate could be found by multiplying the previous strain rate by the ratio of the new stress rate to the previous stress rate. Using this method the strain rate values that correspond to the stress values could be found.
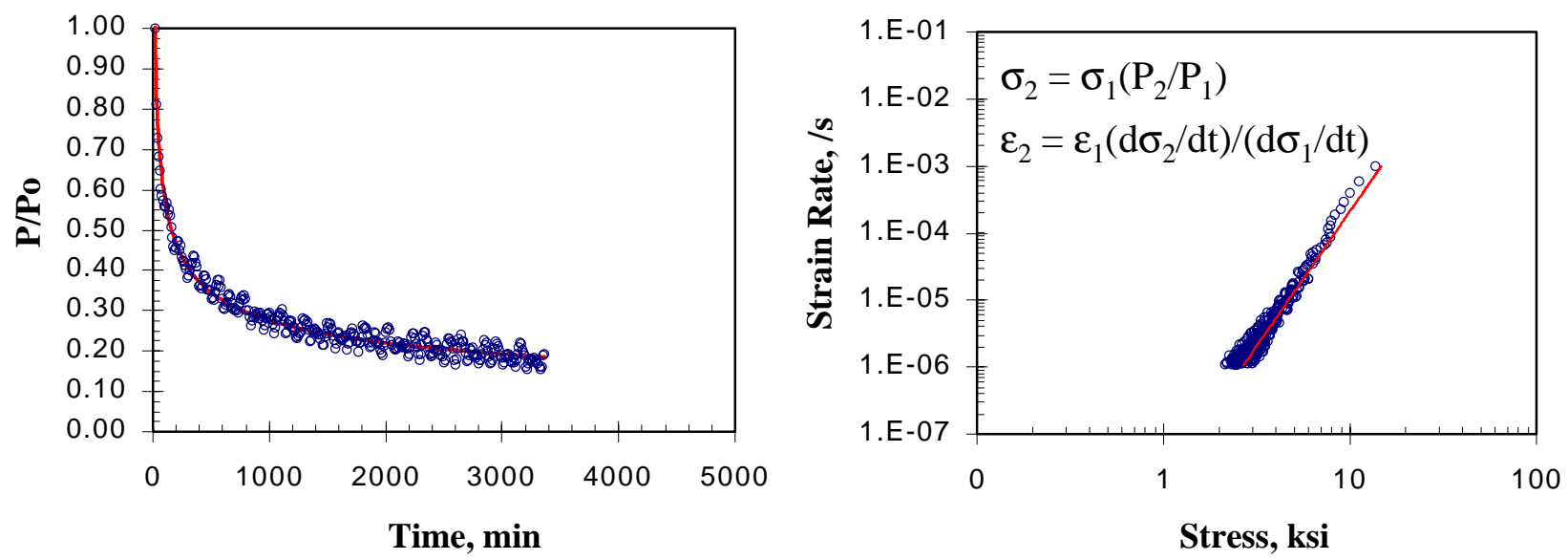

Figure 3.7: Stress Relaxation Data Analysis Example 


\section{Chapter 4 - Results}

The results are divided into three main categories: Microstructural Evaluation, Compression Testing Results, and Relaxation Testing Results. Within the microstructural evaluation section, optical and SEM pictures were included to compare the DS structure and determine the composition of the matrix material and any precipitates formed during solidification. Included in the compression testing section were the temperature and alloying effect on high temperature deformation behavior from constant strain rate compression testing. Included in the stress relaxation testing section were the temperature and alloying effect on high temperature deformation behavior from stress relaxation testing.

\subsection{Microstructural Evaluation}

Displayed below are the results from the Optical and SEM microstructures. From the optical microstructure the DS structure formed in the materials can be viewed. The SEM analysis provided some insight into the composition of the matrix and phases formed in the material used for testing.

Using the optical microscope provides excellent means for viewing grain structure and secondary phases. From the analysis of the optical pictures the effects on the microstructure from directional solidification can easily be seen. Using DS grains were produced elongated in the longitudinal direction, while they appeared to be equiaxed in the transverse direction. From the optical microstructures $\mathrm{NiAl}$ and $\mathrm{NiAl}-2 \mathrm{Cr}$ revealed no secondary phases present in the matrix material. The specimens containing NiAl-2Mo and $\mathrm{NiAl}-2 \mathrm{Nb}$ revealed many secondary phases present. 


\subsubsection{Optical Microstructures}

Figure $4.1-4.4$ are the optical microstructures of nickel aluminide alloy studied. From these the Directional Solidification (DS) structure can be seen clearly. The specimens were cut longitudinal and transverse to the direction of solidification to show the DS structure. From figure 4.1 the $\mathrm{NiAl}$ specimen shows the difference in grain structure between the transverse and longitudinal directions. There were no secondary phases present within the matrix. Subsequently the NiAl specimen was not analyzed with the scanning electron microscope.
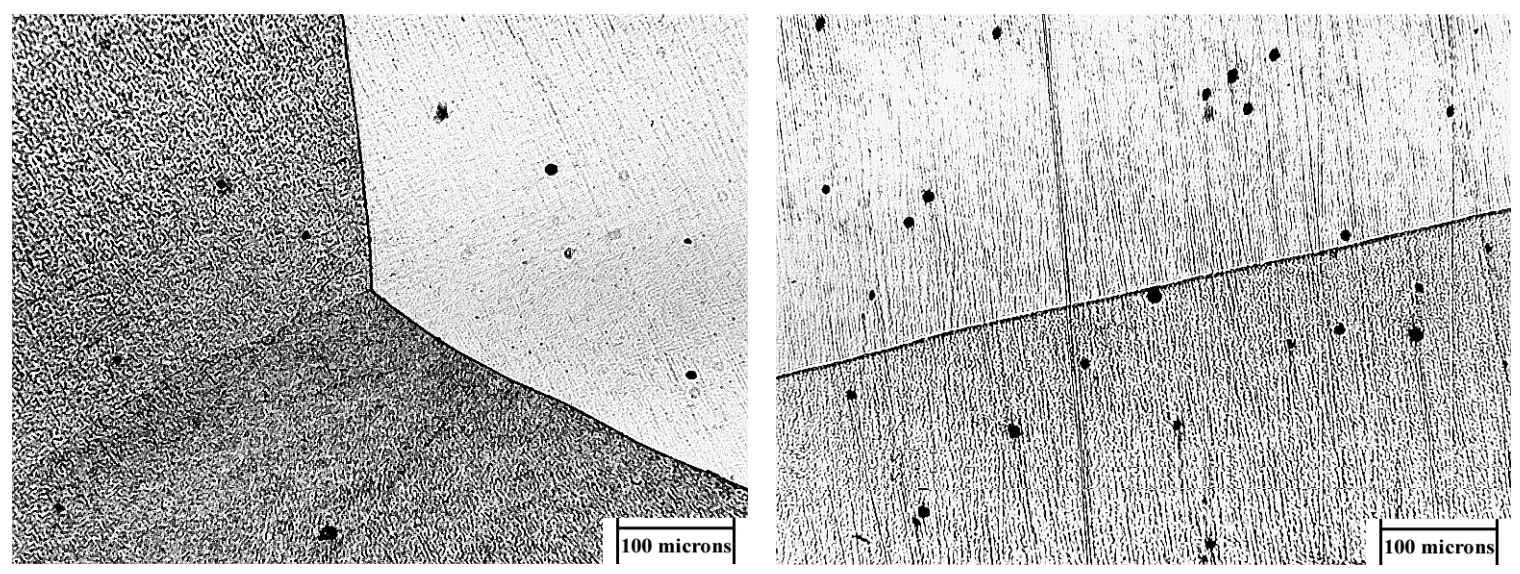

Figure 4.1: NiAl Optical Microstructure Transverse and Longitudinal Direction

Illustrated in figure 4.2 the optical NiAl-2Cr specimen the DS structure in NiAl$2 \mathrm{Cr}$ can easily be identified. From the optical picture it appears that no secondary phases were present. Based on the information from chromium additions to NiAl, this may be normal since chromium can be more soluble at solidification temperature than molybdenum in NiAl. If the chromium had been added beyond its solubility limit, metallic precipitates would have been present in the form of chromium. 

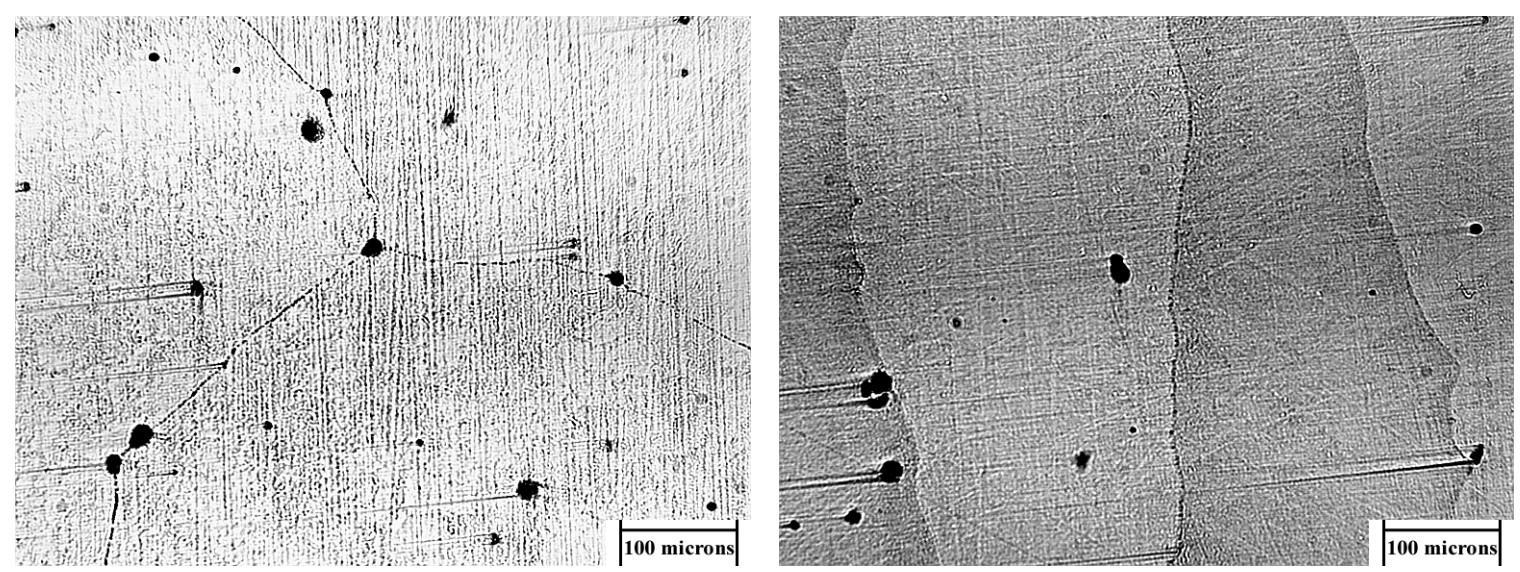

Figure 4.2: NiAlCr Optical Microstructure Transverse and Longitudinal Direction

From figure 4.3 the optical NiAl-2Mo specimen also reveals the DS structure. However there are secondary phase particles present in the matrix. From information in the literature review molybdenum will have limited solubility at solidification temperature in $\mathrm{NiAl}$ and will form metallic particles in the form of molybdenum during solidification.
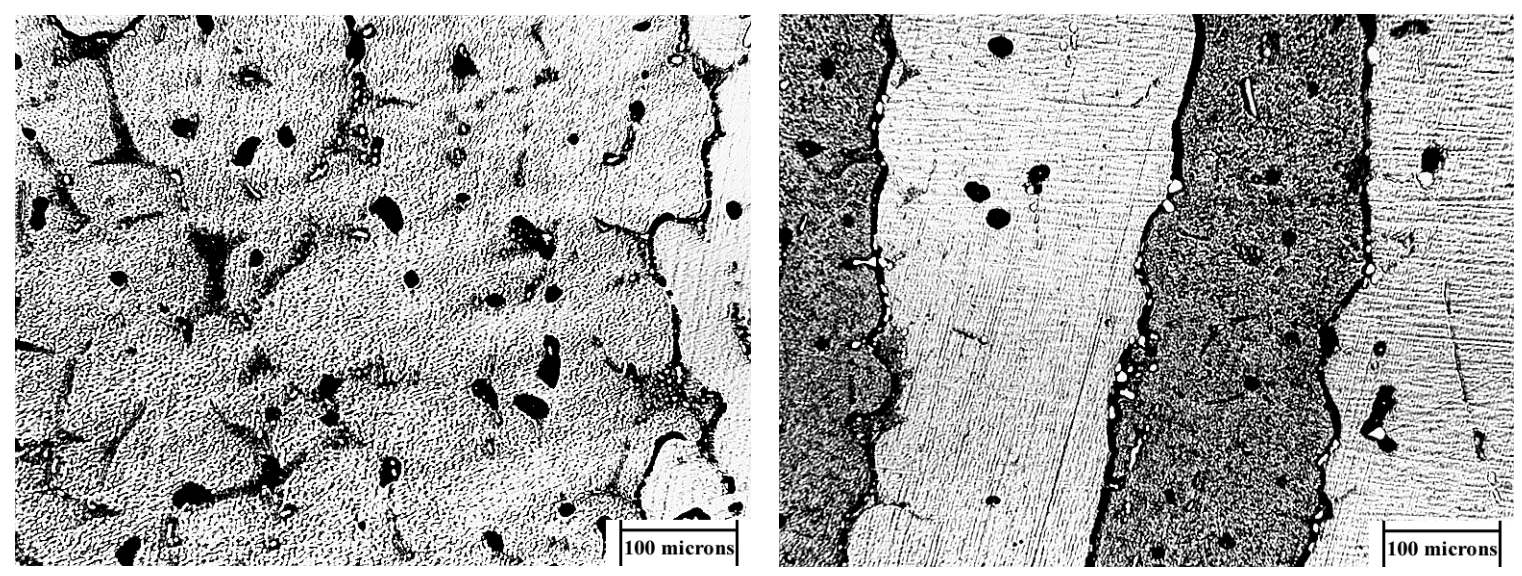

Figure 4.3: NiAIMo Optical Microstructure Transverse and Longitudinal Direction

Displayed in figure 4.4 the NiAl-2Nb specimen can be seen. From the transverse and longitudinal microstructures the DS structure can be observed. There are many secondary phase particles present in the matrix material. Based on information from the 
literature review, niobium will form intermetallic phases in the form $\mathrm{Ni}_{2} \mathrm{AlNb}$, Heusler phase.
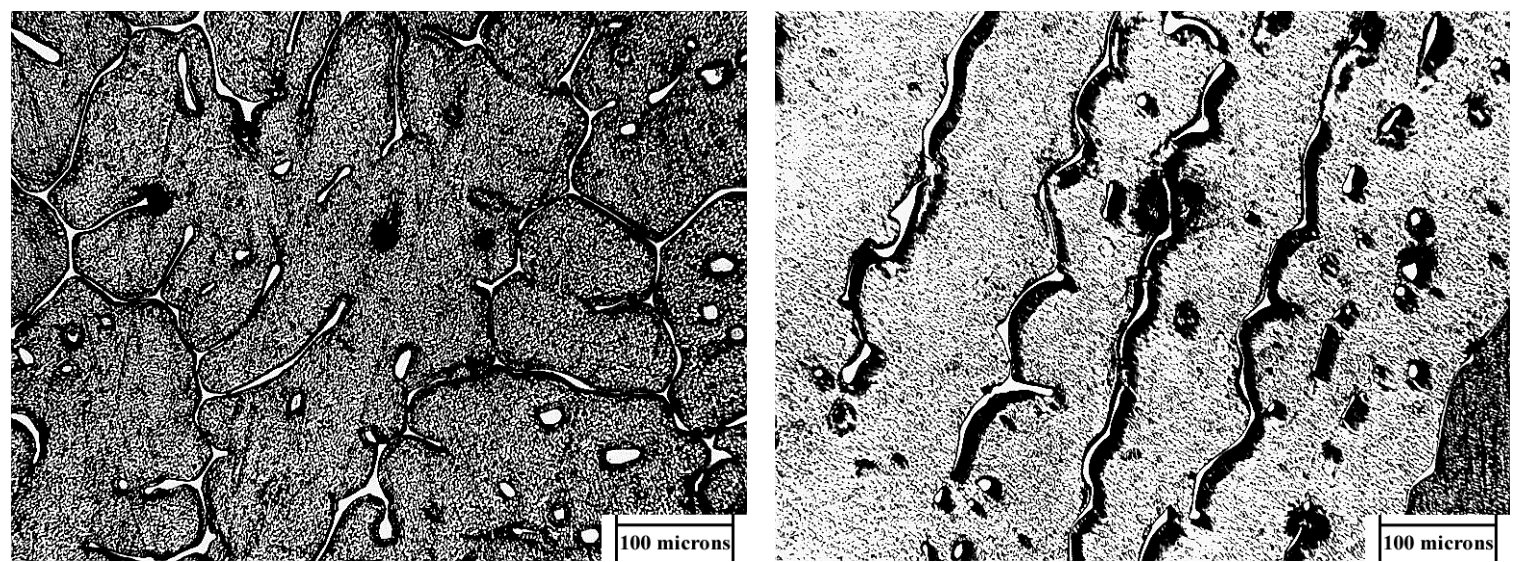

Figure 4.4: NiAINb Optical Microstructure Transverse and Longitudinal Direction

\subsubsection{SEM Microstructure}

Figure 4.5 is an SEM image of NiAl-2Cr. Some dark particles were found in SEM images, even though optical microstructures did not reveal this. An Energy Dispersive Spectroscopy (EDS) was done to determine the composition of the dark particles and the matrix material. The EDS results can be viewed in figure 4.6. The EDS suggests that the dark particles may contains a little more chromium. They are probably chromium particles formed during solidification. It is possilble that they may be impurities within the specimen. An EDS was also performed on the matrix material to determine the composition.The EDS confirmed that nickel, aluminum, and chromium were present in the matrix material. Theoretically the two at $\%$ of chromium added to the material is abble to completely disolve in the matrix material. 


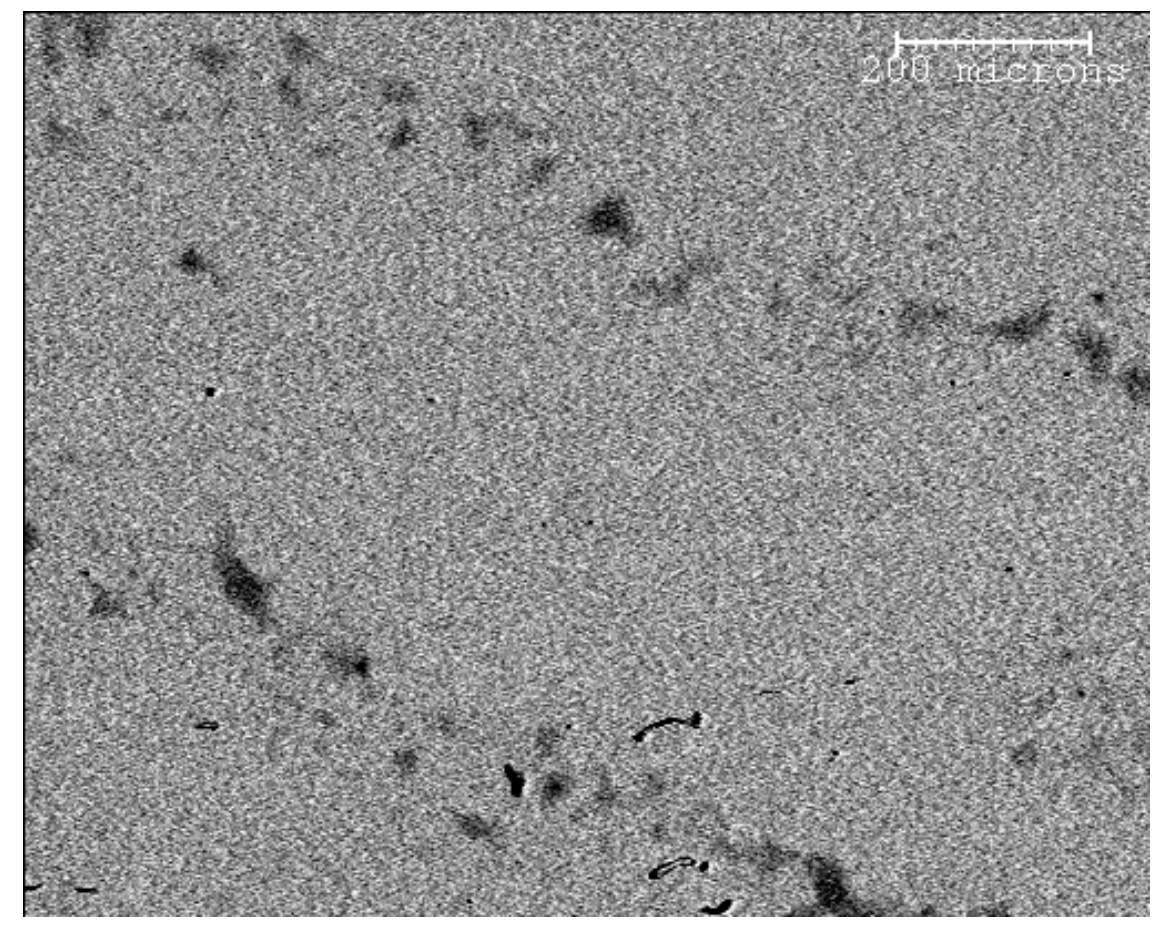

Figure 4.5: SEM of NiAl-2Cr Alloy

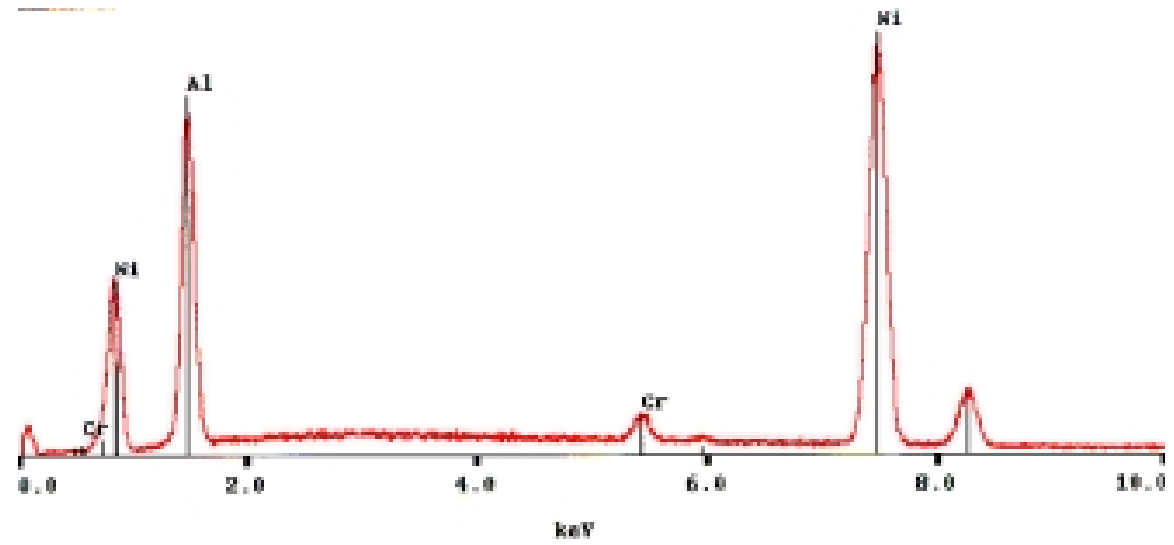

Figure 4.6: EDS of NiAl-2Cr Matrix

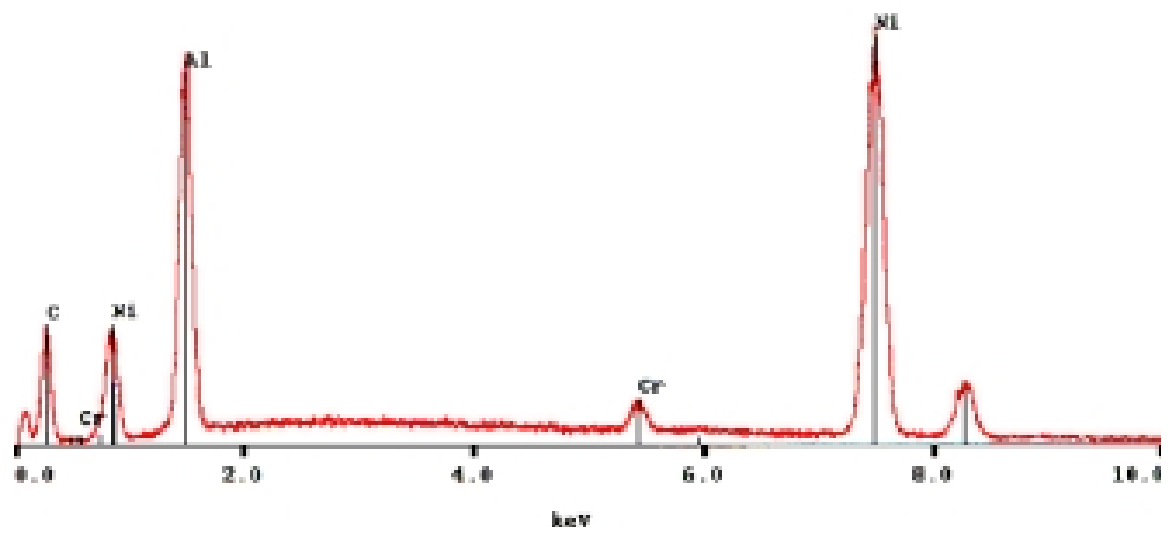

Figure 4.7: EDS of NiAl-2Cr Dark Phase 
Figure 4.7 is an SEM image of the specimen containing NiAl-2Mo. From the SEM of the NiAlMo specimen it can be see that the specimen contain some eutectic precipitates. A technique called elemental mapping was usd to determine the composition of the precipitates and the matrix material. From figure 4.8, the X-ray mapping of the structure, the matrix was found to be high in nickel and aluminum. The percipitates were found to be rich in molybdenum $\alpha$ precipitates. It would seem from the elemental mapping that molybdenum has very limited solubility at solidification temperature in nickel aluminide. This would agree from the information from the literature review. Due to the limited solubility of molybdenum in nickel aluminide the formation of $\alpha$ precipitates in enevitable. When molybdenum is added to nickel aluminide in excesive amounts metallic $\alpha$ precipitates form that are rich in molybdenum.

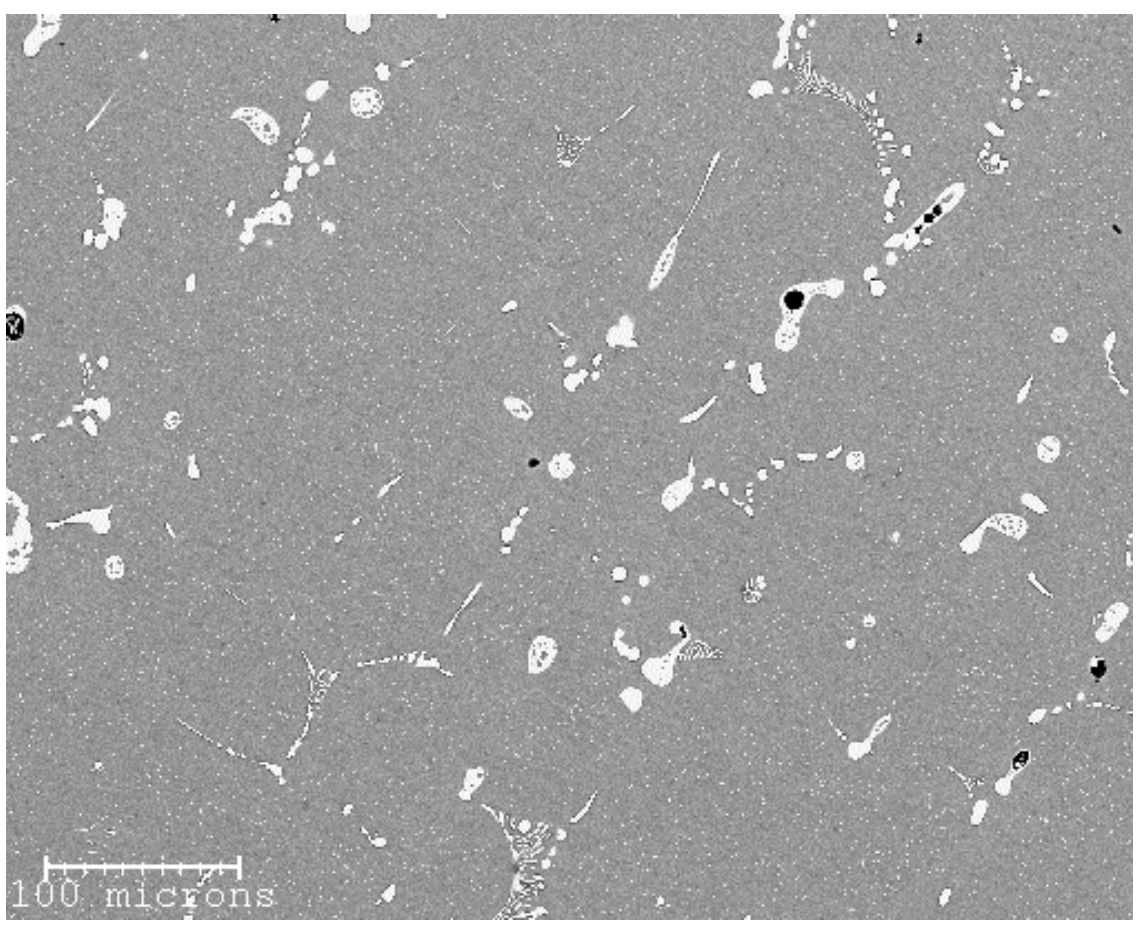

Figure 4.8: SEM of NiAl-2Mo Alloy 

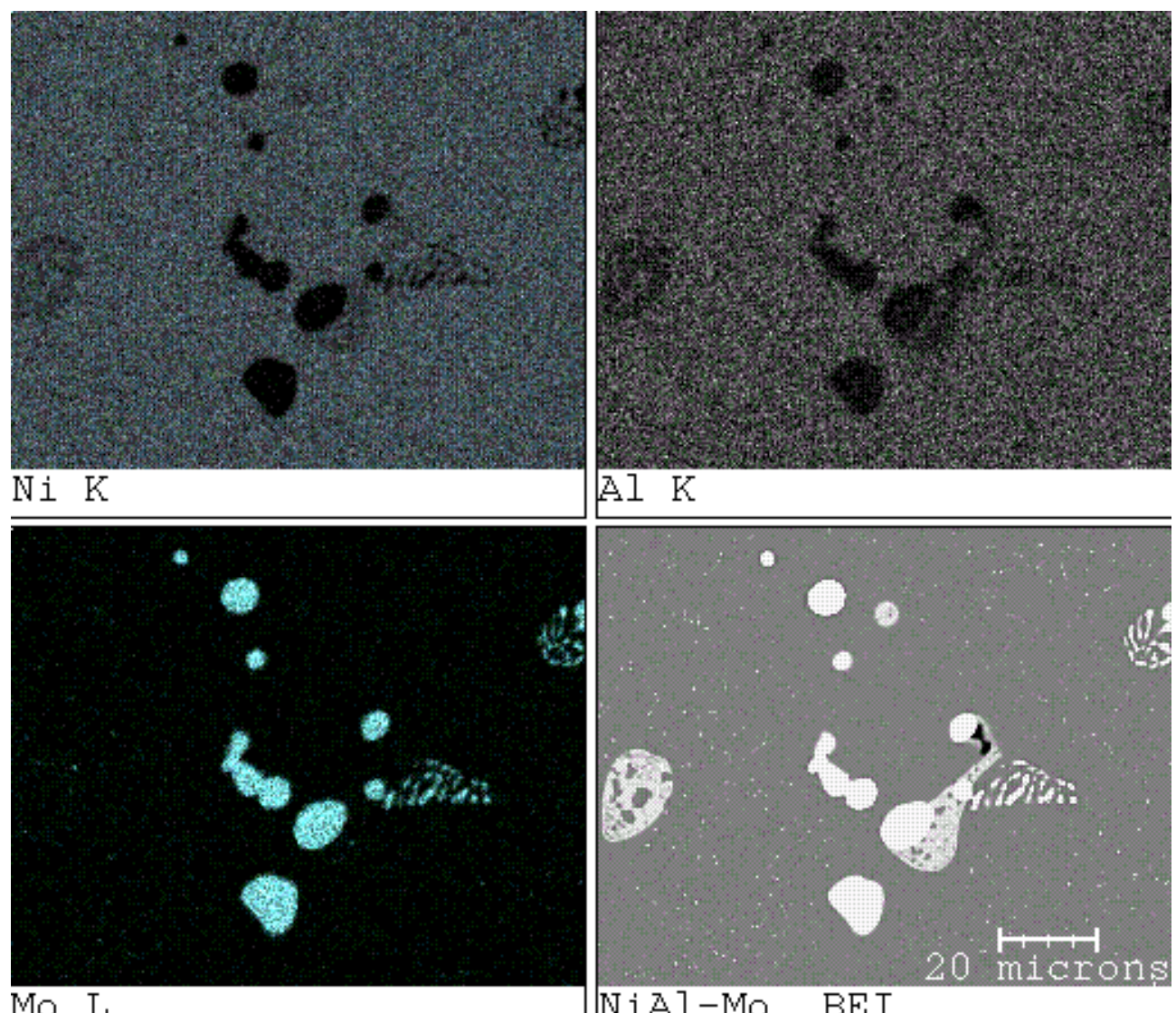

$\mathrm{Al} \mathrm{K}$

Mo L

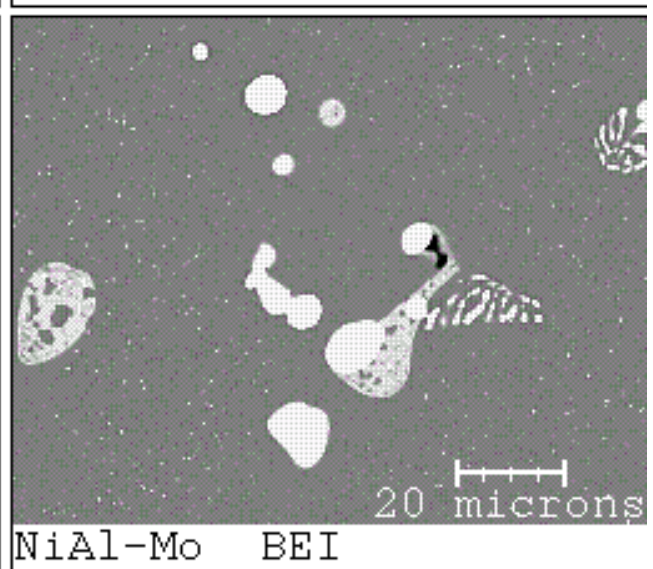

Figure 4.9: X-ray Mapping of NiAl-2Mo Alloy

Illustrated in figure 4.9 is an SEM image of the $\mathrm{NiAl}-2 \mathrm{Nb}$ specimen. The matrix material and the precipitates were analyzed using EDS. The results from the EDS can be seen in figure 4.10. The matrix material was found to contain nickel, aluminum, and a small trace of niobium. The precipitates were found to contain niobium, nickel, and aluminum, where Niobium is much higher than nickel and aluminum. Therefore, $\mathrm{t}$ was determined that the precipitates consisted of $\mathrm{Ni}_{2} \mathrm{AlNb}$, the $\beta^{\text {‘ Heusler phase }}$ 


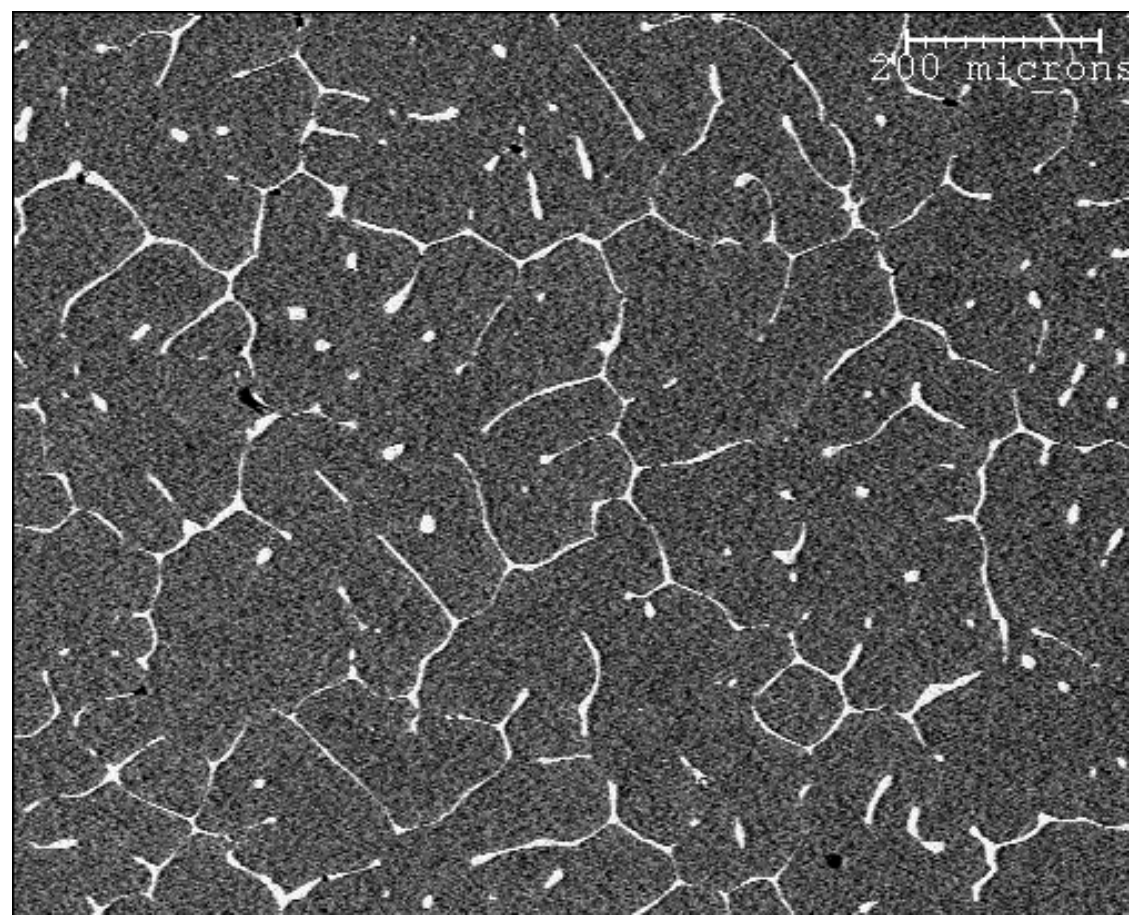

Figure 4.10: SEM of NiAINb

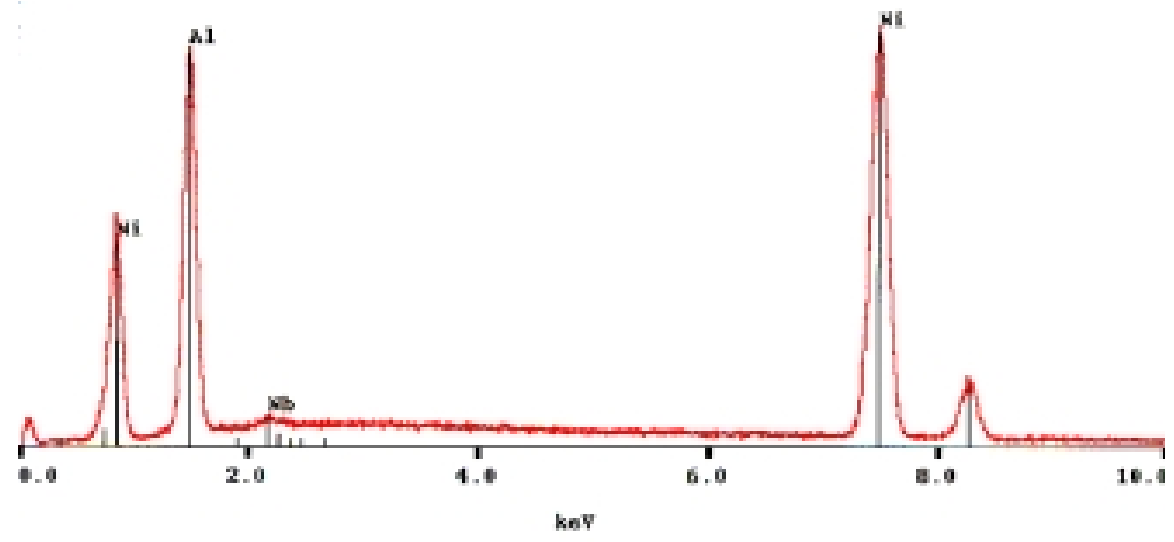

Figure 4.11: EDS of NiAl-2Nb Matrix

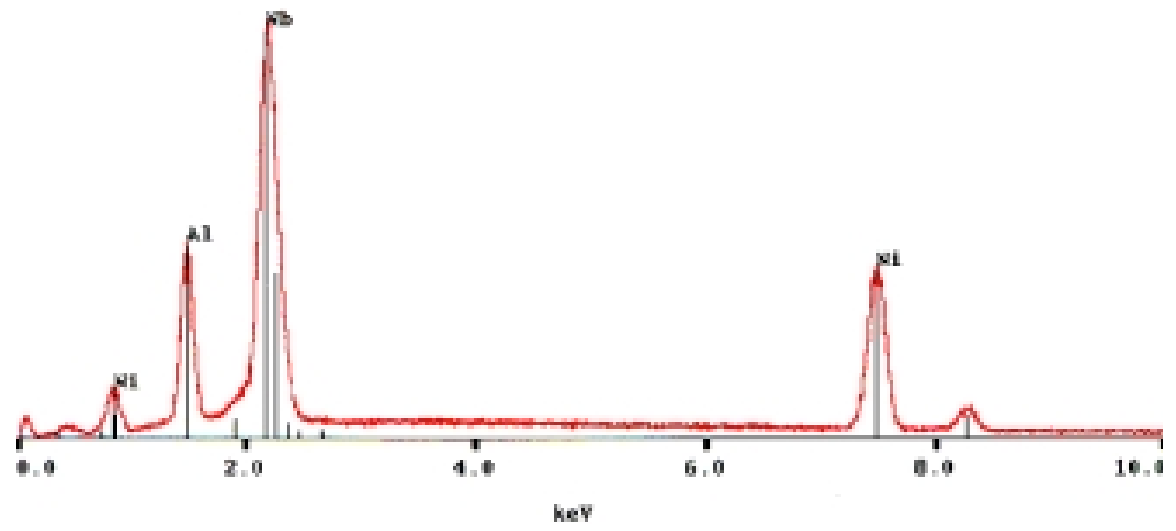

Figure 4.12: EDS of NiAl-2Nb Dark Phase 


\subsection{Compression Test}

The compression testing section will be separated into two sections: temperature effect and alloy effect. The figures included in the temperature effect provide figures with material composition constant. This will reveal the effect different testing temperatures have on the testing specimens. The figures included in the alloy effect provide figures displayed at one temperature. This will provide a way to compare the effect from alloying.

The graphs shown below compare the temperature and strain rate effect on the high temperature deformation properties of NiAl, NiAl-2Cr, NiAl-2Mo, and NiAl-2Nb. The data are measured by constant strain rate compression testing. There were four testing temperatures completed for comparison, $850{ }^{\circ} \mathrm{C}, 1000{ }^{\circ} \mathrm{C}, 1100{ }^{\circ} \mathrm{C}$ and $1200{ }^{\circ} \mathrm{C}$. Strain rates ranged from $10^{-6} \mathrm{~s}^{-1}$ to $10^{-2}$.

Flow stress is a function of both temperature and strain rate. As temperature increases flow stress becomes increasingly sensitive to changes in strain rate. Each data point represents a compression test preformed at a certain strain rate for a given temperature. Regression analysis on the measured flow stress, as a function of a given strain rate, has been preformed using a power law fit. The equation used for the fit was:

$$
\dot{\epsilon}=\mathrm{k} \sigma^{\mathrm{n}}
$$

where $\dot{\epsilon}$ is the strain rate, $\mathrm{k}$ is a material constant, $\sigma$ is the flow stress, and $\mathrm{n}$ is the stress exponent. On the log-log graph $\mathrm{n}$ is actually the slope of the line from the regression analysis. The value for $\mathrm{n}$ usually decreases as temperature increases. This is because the steady state creep rate becomes less dependent on the applied stress as temperature increases. 


\subsubsection{Temperature Effect}

As illustrated in figures 4.13-4.16, the plastic flow curves for $\mathrm{NiAl}, \mathrm{NiAl}-2 \mathrm{Cr}$, $\mathrm{NiAl}-2 \mathrm{Mo}$, and NiAl-2Nb at $1000{ }^{\circ} \mathrm{C}, 1100{ }^{\circ} \mathrm{C}$, and $1200{ }^{\circ} \mathrm{C}$. The curves were generated from a strain rate of $10^{-3} \mathrm{~s}^{-1}$. These figures illustrate the effect of temperature on the plastic flow curves of the materials tested. All of the materials exhibited similar deformation behavior. There appeared to be little or no work hardening in the curves from the testing specimens. This can be observed from the steady state deformation region of the plastic flow curve. The stress level remains constant as the strain level increases. For this reason the effects from strain hardening were determine to be negligible and ignored. As the testing temperature was increased, the level the steady state flow stress level reduced, monotonically.

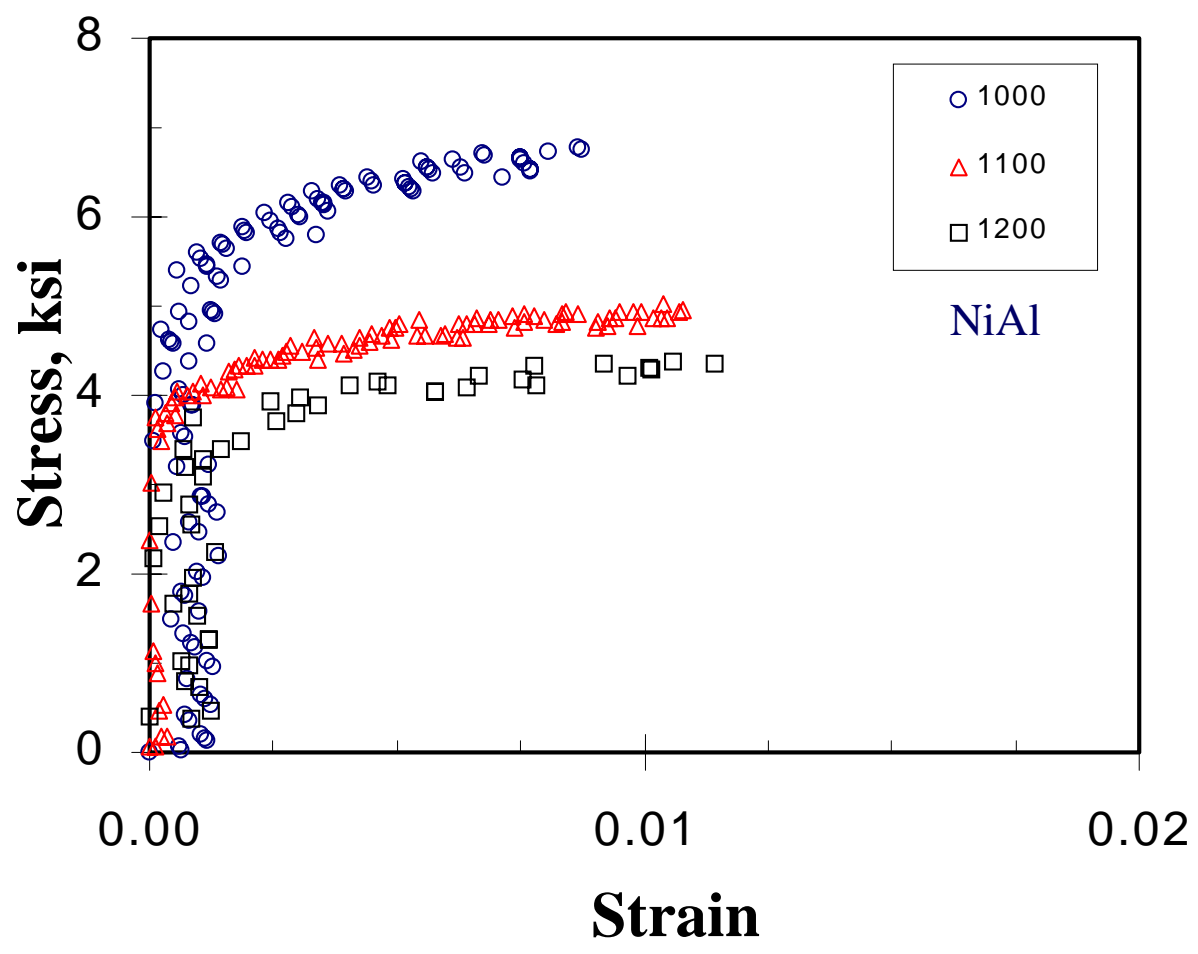

Figure 4.13: Compression Plastic Flow Curve NiAl 


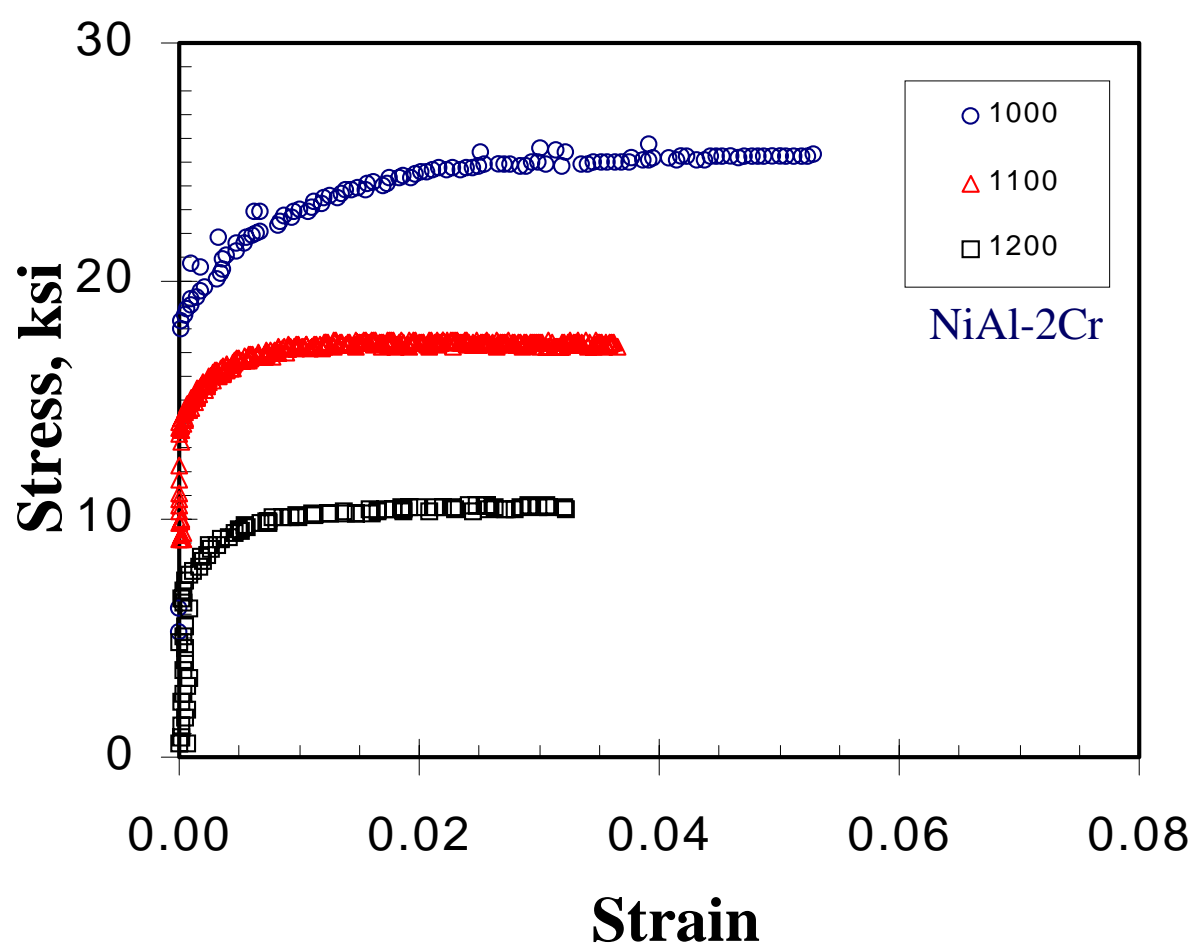

Figure 4.14: Compression Plastic Flow Curve NiAl-2Cr

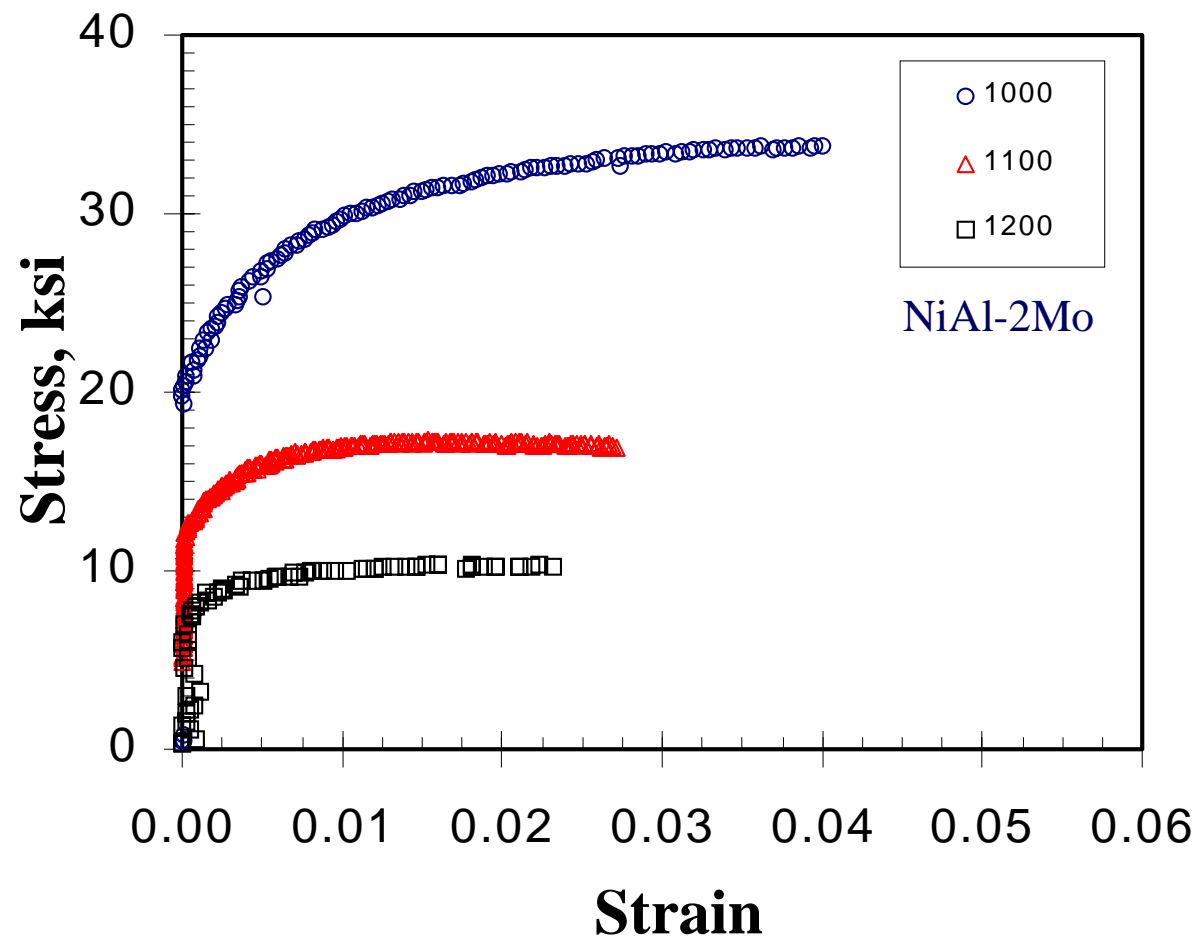

Figure 4.15: Compression Plastic Flow Curve NiAl-2Mo 


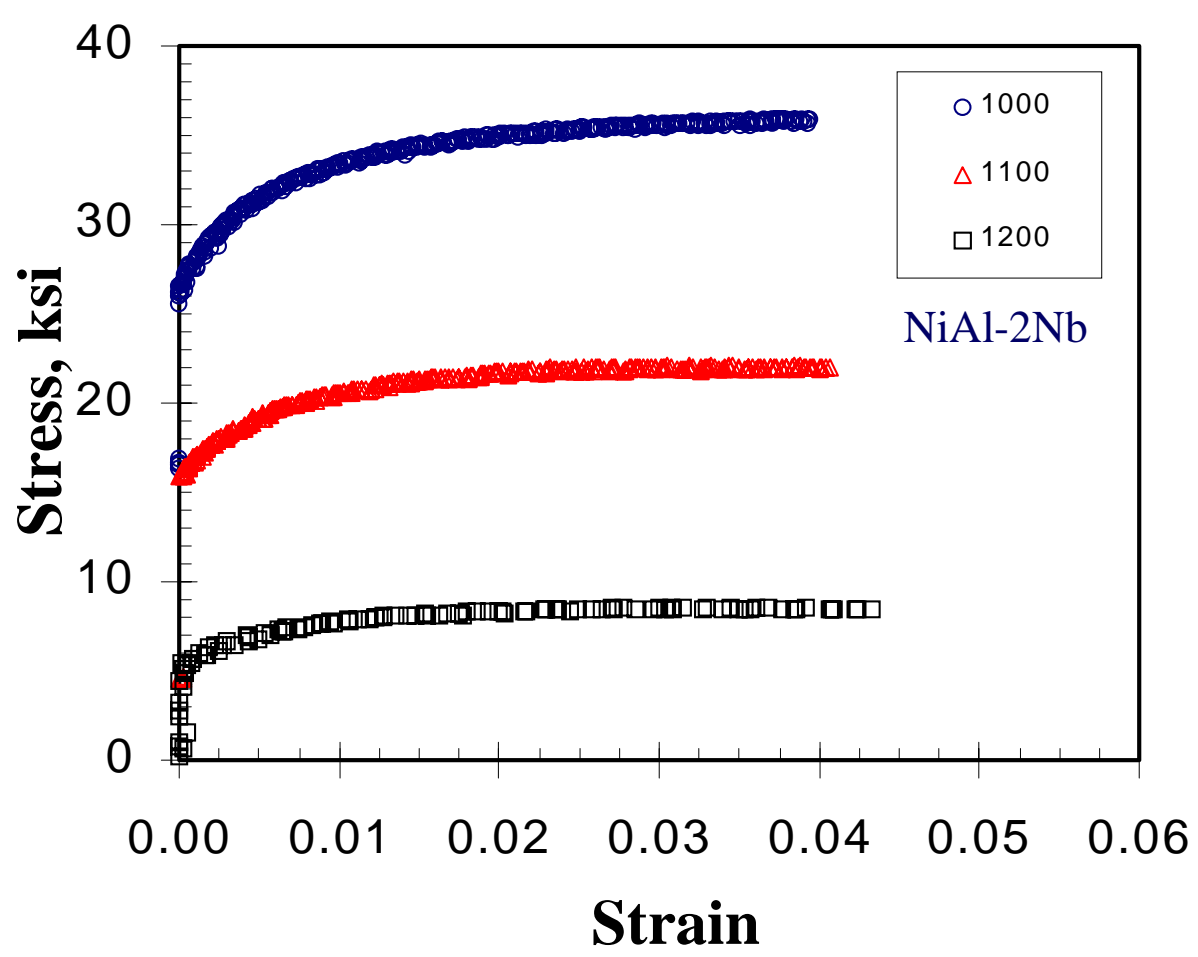

Figure 4.16: Compression Plastic Flow Curve NiAl-2Nb

Illustrated in figures 4.17-4.20 are the temperature effects on creep behavior on nickel aluminide alloys. The figures are from constant strain rate compression testing at temperatures $850^{\circ}$ to $1200^{\circ} \mathrm{C}$. The data points are from plastic flow curves. The average stress value was taken at the region of steady state deformation as describe in the experimental section. The figures illustrate how temperature and strain rate affect the plastic flow stress. The data for the figures are shown in tabular form in Appendix A. This will provide a comparison for the temperature and strain rate deformation behavior of the testing materials

As seen in the figures, the flow stress level decreases as testing temperature was increased. This was the same pattern shown above in the plastic flow curves. Using regression analysis to perform a power law fit, the slope from the data was found. From comparing the change in slope and viewing the trend from the figure, the flow stress 
becomes increasingly sensitive to changes in strain rate as temperature increases. With increasing temperature there is an increase in flow stress dependence on strain rate.

Illustrated by the figures, the alloys suffer from reduction in creep resistance as testing temperature increases. Shown in figure 4.17 the results from increasing temperature. Comparing the values from $850{ }^{\circ} \mathrm{C}$ to $1000{ }^{\circ} \mathrm{C}$ the creep resistance has been reduced significantly with increasing temperature. By extending a vertical line from one data set to the next, the difference in steady state creep rate can be determined. The steady state creep rate has increased by a factor of 1000x from the increase in testing temperature from $850{ }^{\circ} \mathrm{C}$ to $1000{ }^{\circ} \mathrm{C}$.

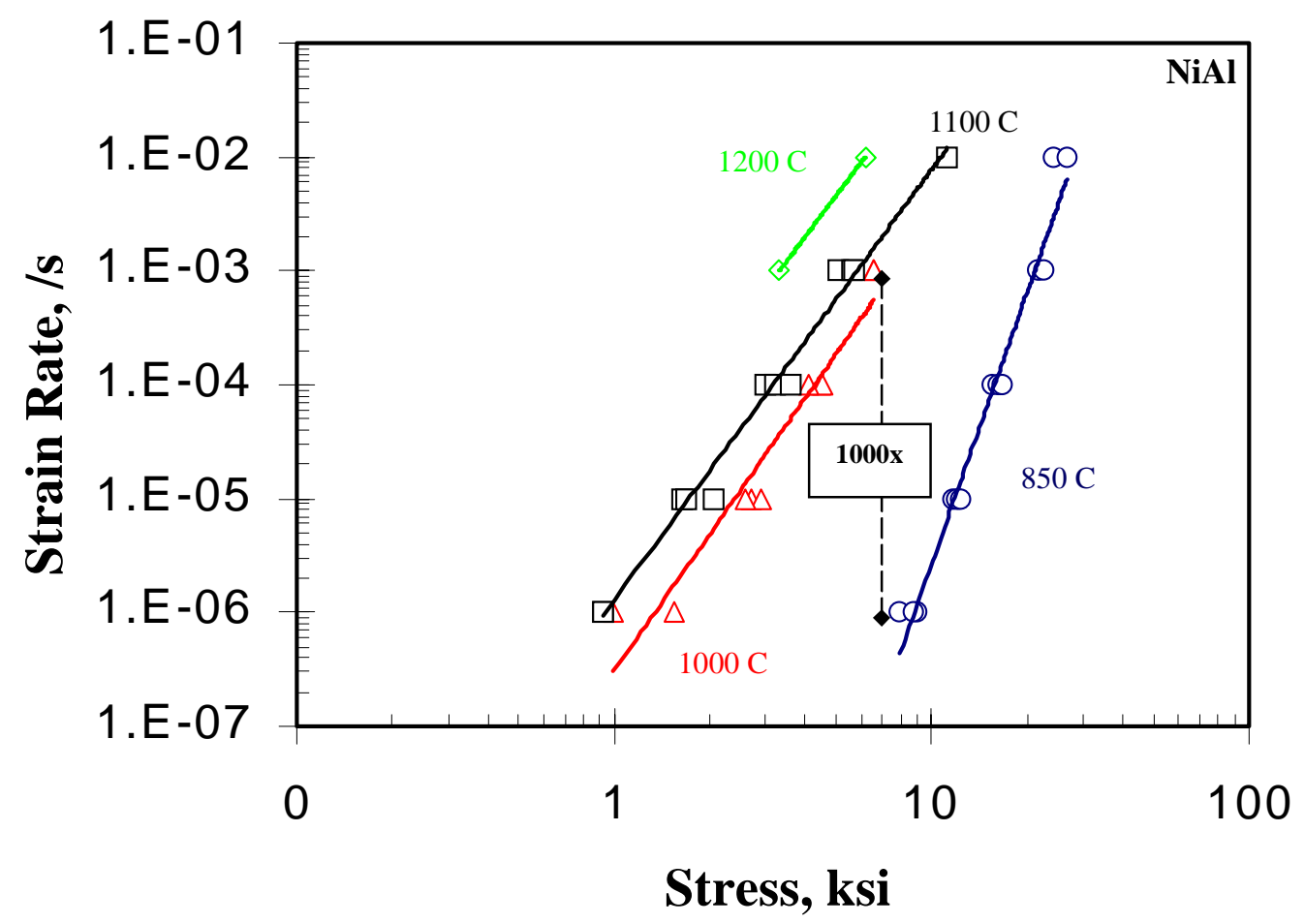

Figure 4.17: Compression Test NiAl 


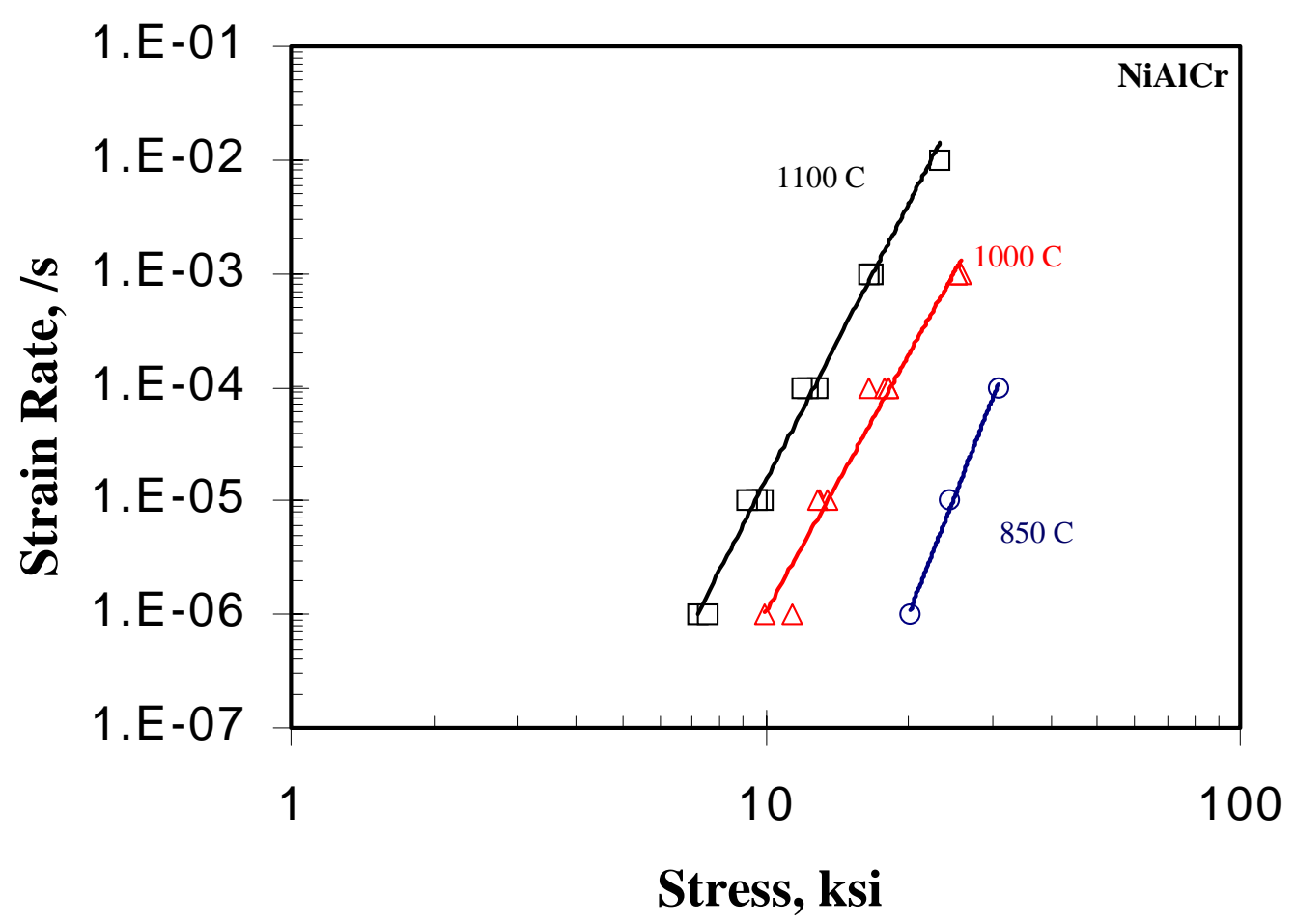

Figure 4.18: Compression Test NiAlCr

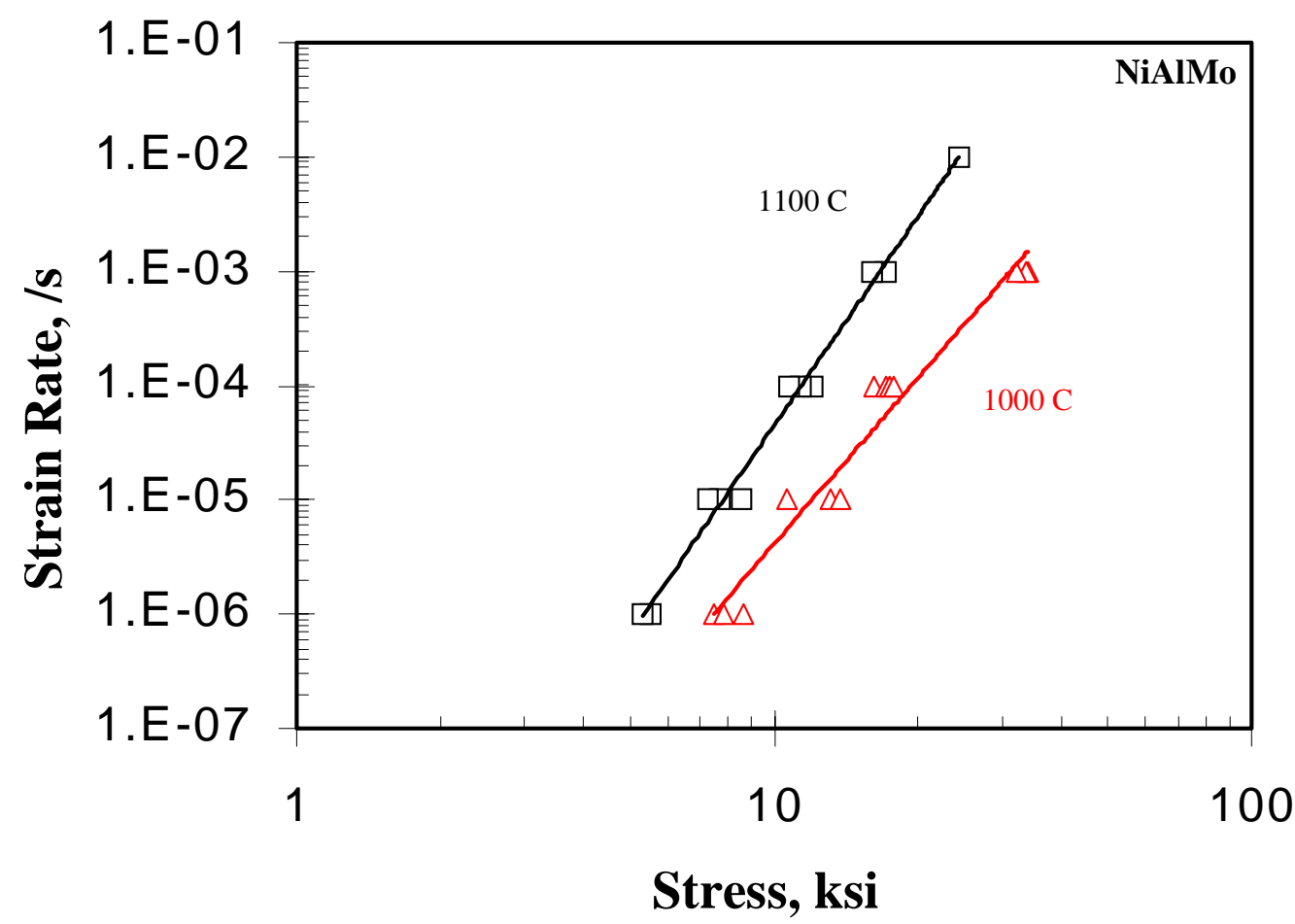

Figure 4.19: Compression Test NiAIMo 


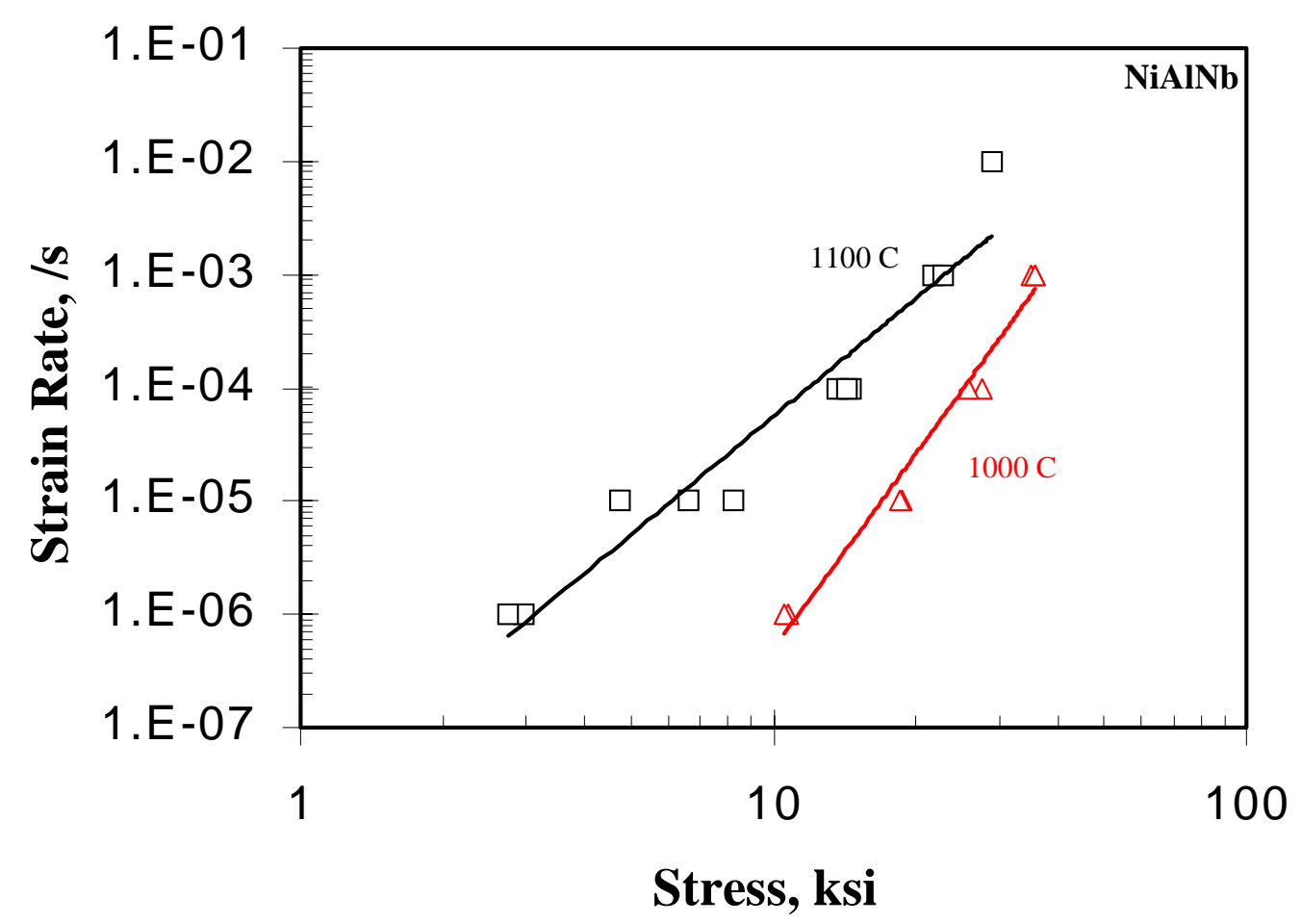

Figure 4.20: Compression Test NiAlNb

\subsubsection{Alloying Effect}

Illustrated in figures 4.21-4.26 are compression results displayed to show the alloying effect on the creep behavior of nickel aluminide. From the figures the difference in high temperature deformation behavior at constant temperature can be compared The different alloys and microstructures provide distinct characteristics in creep behavior. Shown in the figures the improvements over unalloyed NiAl from alloying addition.

Figures 4.21-4.23 display a comparison of the effects that alloying produced on the plastic flow curves on $\mathrm{NiAl}$ alloys. The curves were generated from constant strain rate compression tests at a strain rate of $10^{-3} \mathrm{~s}^{-1}$. From the figure it was observed that the alloyed specimen provided significant improvements in strength over the unalloyed binary NiAl specimen. There was little or no work hardening in any of the curves. Observed from the curves was the absence of any yield point effect and serrations in the 
plastic flow curves. This would indicate the solid solution strengthening additions affect the entire flow curve. From this it can be concluded that the strengthening provided from alloying additions provided a frictional resistance to dislocation mobility rather than static locking of dislocations.

At $1000{ }^{\circ} \mathrm{C}$ and $1100{ }^{\circ} \mathrm{C}$ niobium addition was found to produce the most significant improvement over binary $\mathrm{NiAl}$ in the flow curve. However at $1200{ }^{\circ} \mathrm{C}$, chromium addition provided superior deformation properties. At $1100^{\circ} \mathrm{C}$ and $1200^{\circ} \mathrm{C}$ it was observed that chromium and molybdenum additions provided very similar deformation properties.

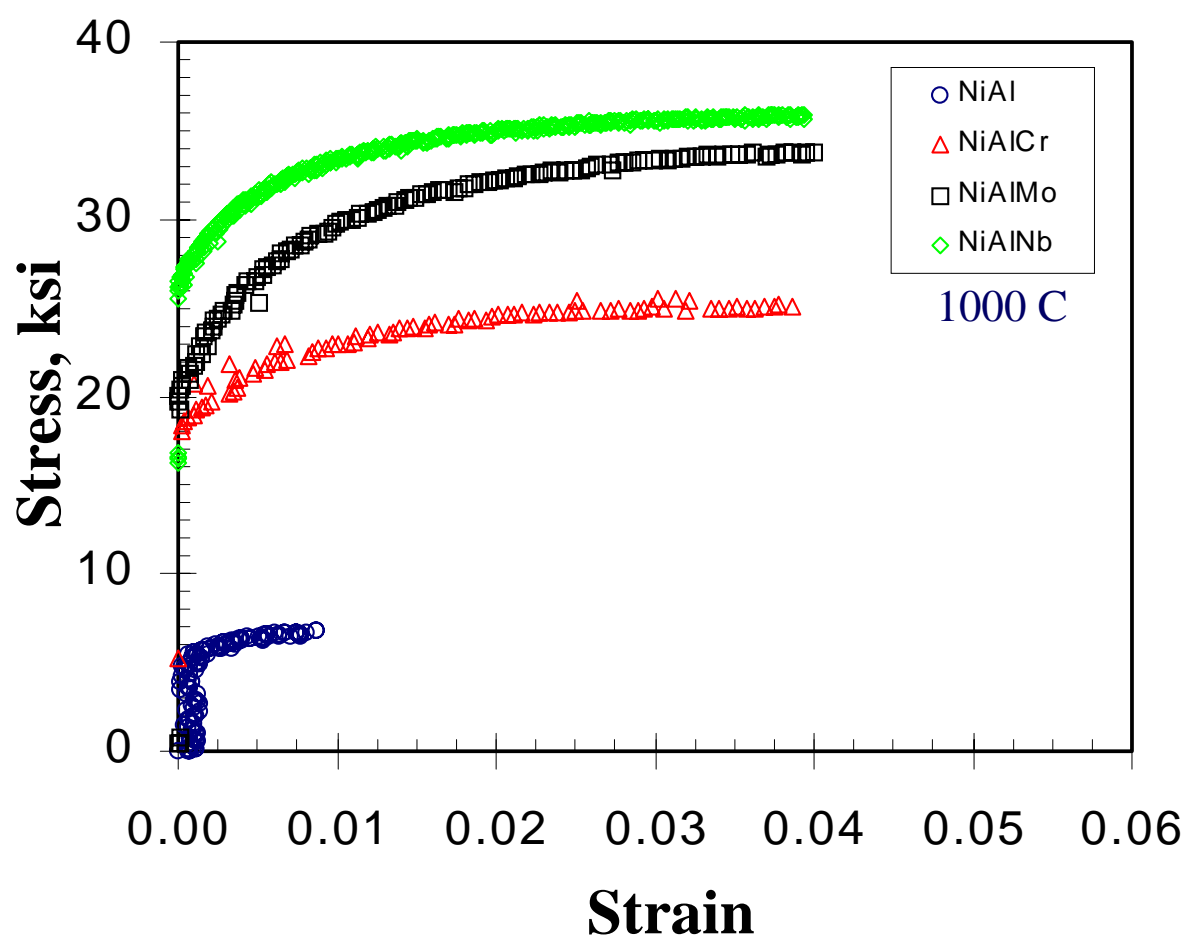

Figure 4.21: Compression Plastic Flow Curve $1000 \mathrm{C}$ 


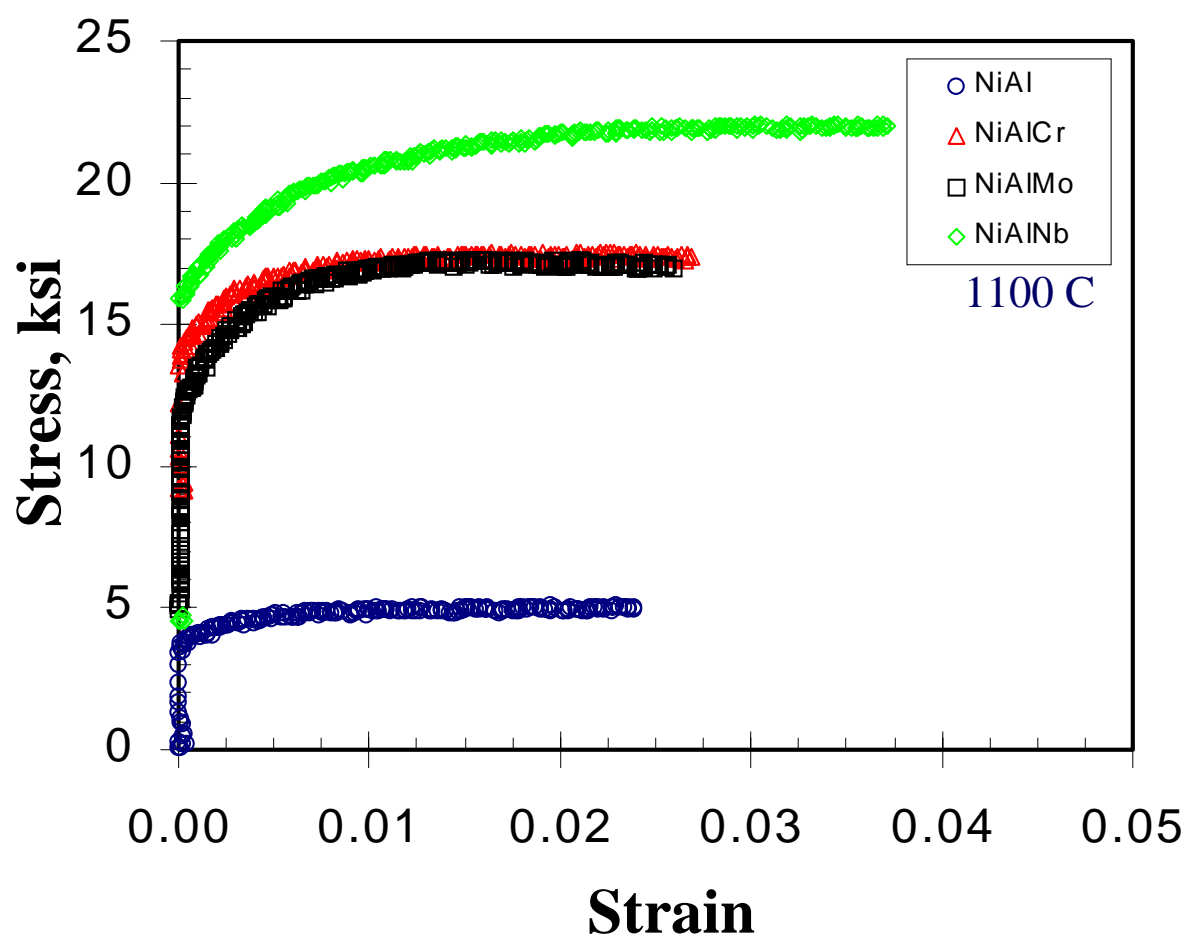

Figure 4.22: Compression Plastic Flow Curve 1100 C

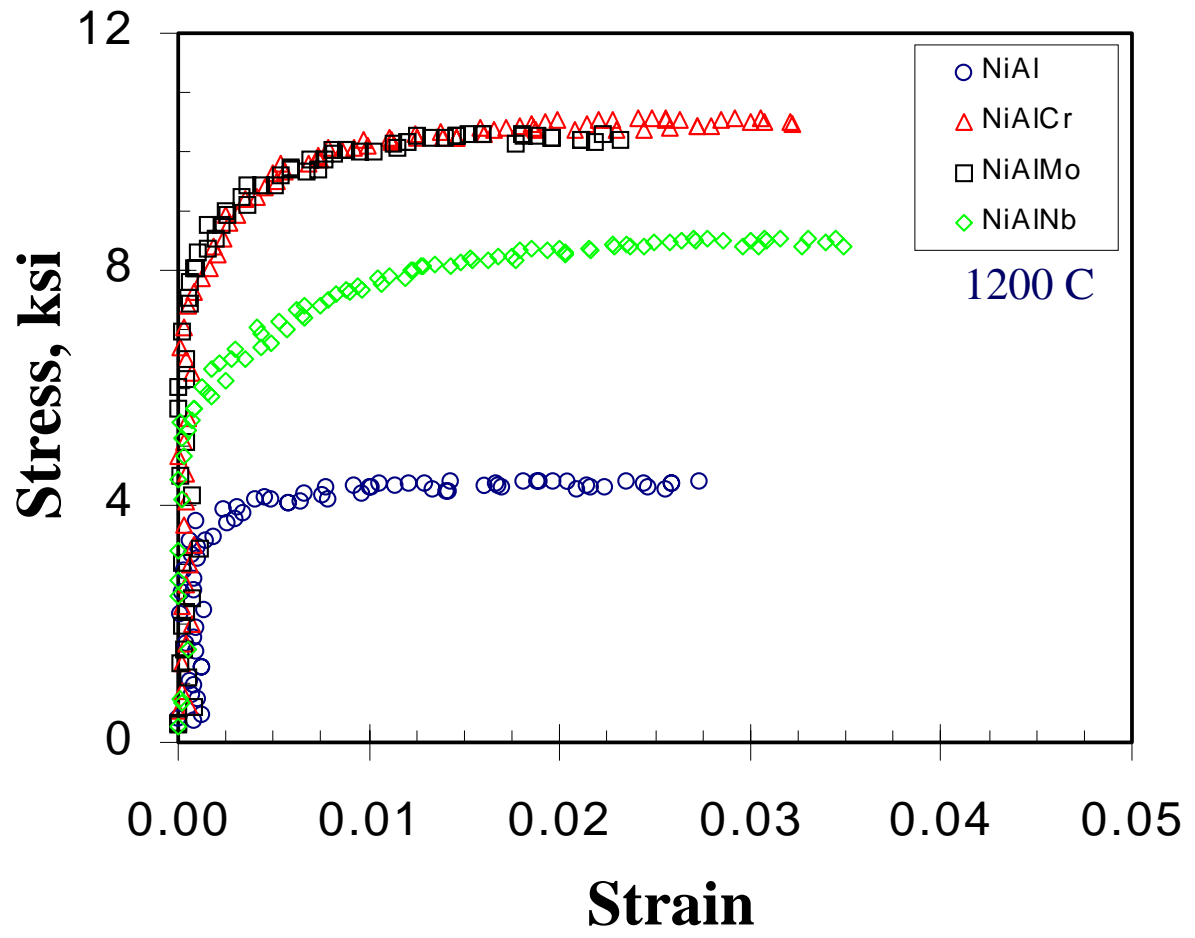

Figure 4.23: Compression Plastic Flow Curve 1200 C 
Figures 2.24-2.26 include the strain rate vs. flow stress data to compare the alloy effect at different temperatures and stain rates. Observed in the figures the alloyed materials provided significant improvements at all strain rates and temperatures over binary NiAl. At $1000{ }^{\circ} \mathrm{C}$ niobium additions provided the most significant improvement over the entire strain rate testing region. At $1100{ }^{\circ} \mathrm{C}$ the niobium additions was superior at higher strain rates, however at lower strain rates chromium additions provided more creep resistance.

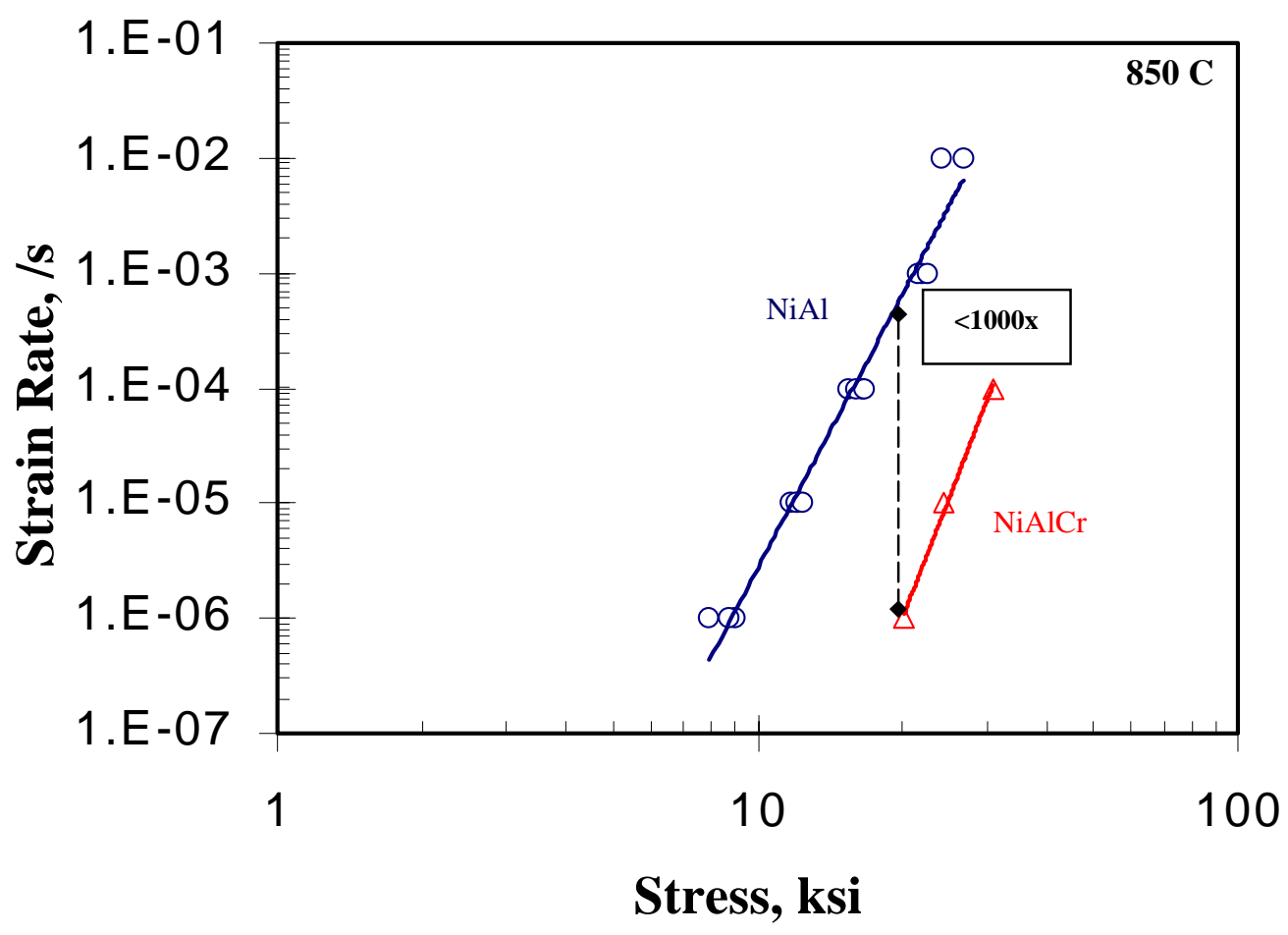

Figure 4.24: Compression Testing $850 \mathrm{C}$ 


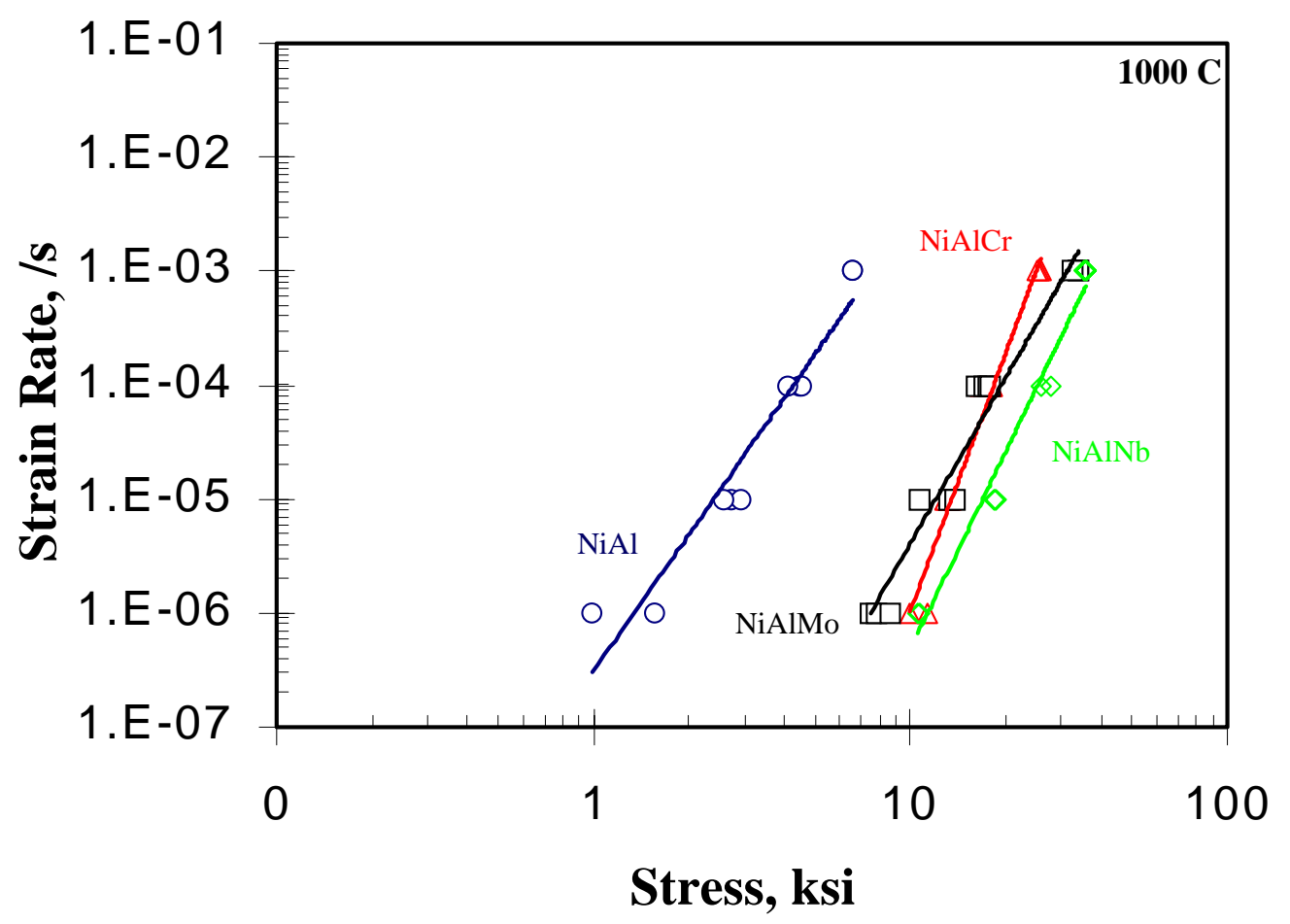

Figure 4.25: Compression Testing $1000 \mathrm{C}$

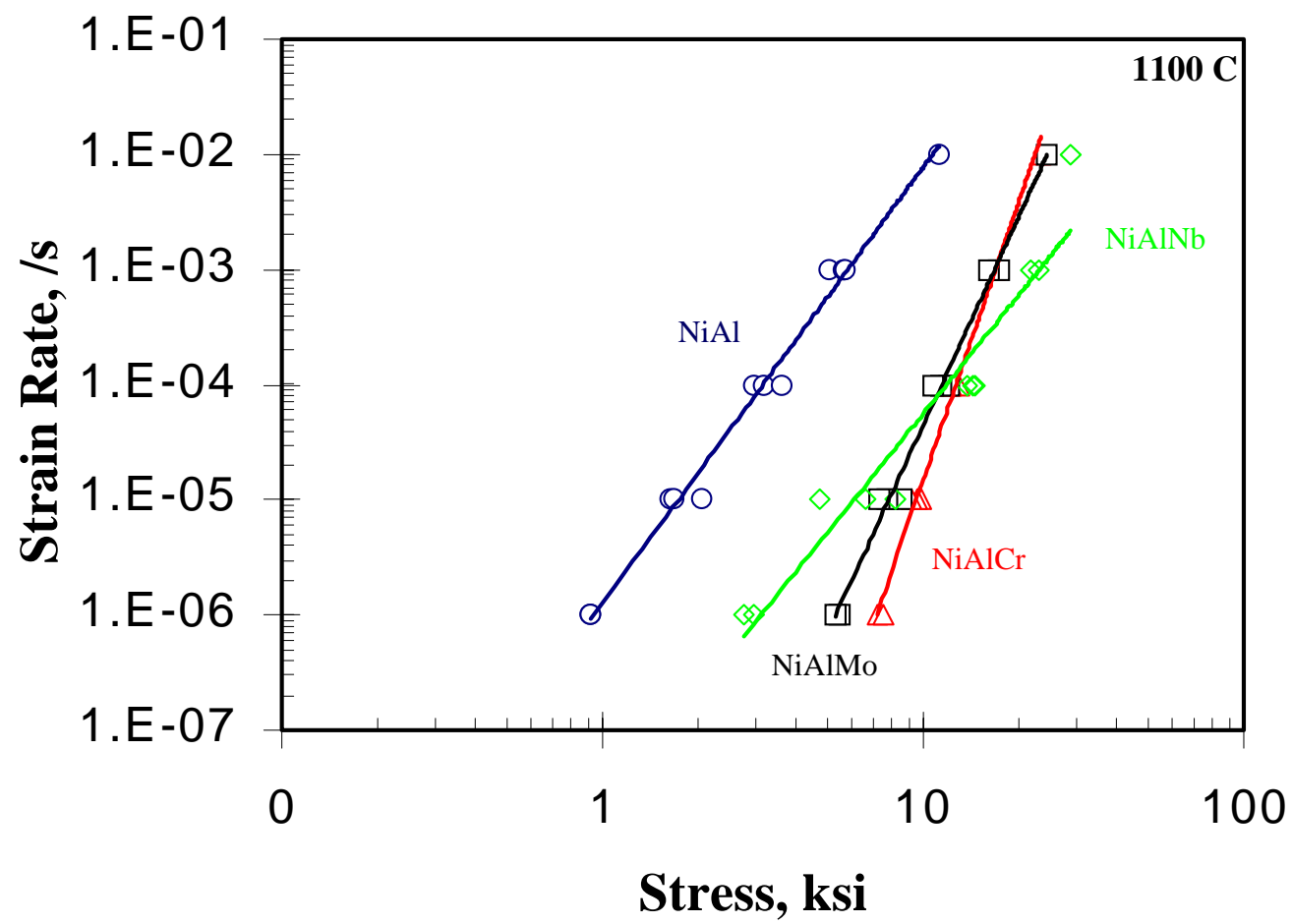

Figure 4.26: Compression Testing $1100 \mathrm{C}$ 
Table 4.1 lists the stress exponents from the constant strain rate compression testing for comparison. The stress exponent reveal the materials creep rate sensitivity to a change in applied stress. The stress exponent is sometime referred to as the stress dependency. The stress dependency decreases with increasing temperature. All materials will experience a reduction in the stress exponent value with increasing temperature. A material can be evaluated or compared to other materials by the extent and rate at which the stress dependency changes.

Table 4.1: Stress Exponents from Compression Tests

\begin{tabular}{cccc}
\hline \multicolumn{4}{c}{ Stress Exponent } \\
\hline Specimen & $\mathbf{8 5 0}^{\circ} \mathbf{C}$ & $\mathbf{1 0 0 0}^{\circ} \mathbf{C}$ & $\mathbf{1 1 0 0}^{\circ} \mathbf{C}$ \\
\hline NiAl & 7.92 & 3.98 & 3.78 \\
NiAlCr & 10.73 & 7.52 & 8.11 \\
NiAlMo & -- & 4.82 & 6.06 \\
NiAlNb & --- & 5.75 & 3.46 \\
\hline
\end{tabular}

\subsection{Stress Relaxation Test Results}

The following graphs are from stress relaxation testing preformed on the specimens. From stress relaxation testing, the steady state creep rate and flow stress can be found at each testing temperature. This provided another testing method for comparison to the compression testing. The specimens were tested at temperatures ranging from $850{ }^{\circ} \mathrm{C}$ to $1200{ }^{\circ} \mathrm{C}$. The results were very similar to the compression tests. The stress relaxation results will be broken into two sections for comparison: Temperature Effect and Alloying Effect. A section displaying the stress relaxation test data will also be in included for comparison.

The following graphs, generated from the stress relaxation data, reveal the same pattern as the results from the compression testing. With increasing temperature the flow stress and the stress dependency decrease. Also at higher stress levels the creep rate is faster. 


\subsubsection{Stress Relaxation Curves (Stress vs. Time)}

Stress relaxation is a type of creep testing in which decreasing stress is observed. The specimen was initially deformed at a constant strain rate $\mathrm{d} \varepsilon$ to a stress $\sigma_{\mathrm{o}}$. The displacement of the crosshead is the stopped and the specimen allowed to creep under the initial stress $\sigma_{\mathrm{o}}$.[5] Each extension $\mathrm{d} \varepsilon$ unloads the specimen by $\mathrm{d} \sigma=\mathrm{Bd} \varepsilon$ whereupon the creep rate again decreases. The behavior of the material $d \varepsilon(\sigma)=d \sigma(t) / B$ is obtained from the measured time dependence of the relaxation $\sigma(t)$.

Figures 4.27-4.30 include data from stress relaxation testing. The data is plotted in the form of stress vs. time. For comparison to the compression data, the stress vs. time curves were converted to strain rate vs. stress by the methods described in section 3.5.2. From the figures shown below, the stress relaxation behavior at different testing temperatures can be seen. Observed in the figures stress relaxation occurs very rapidly initially and gradually reduces during the test. Testing temperature and alloy composition determine the decreasing stress rate. At lower temperatures the stress rate and amount of stress relaxation is much lower than at higher testing temperatures. The stress rate is also significantly different from alloy to alloy. These differences can be observed in the stress relaxation graphs included latter in this section. 


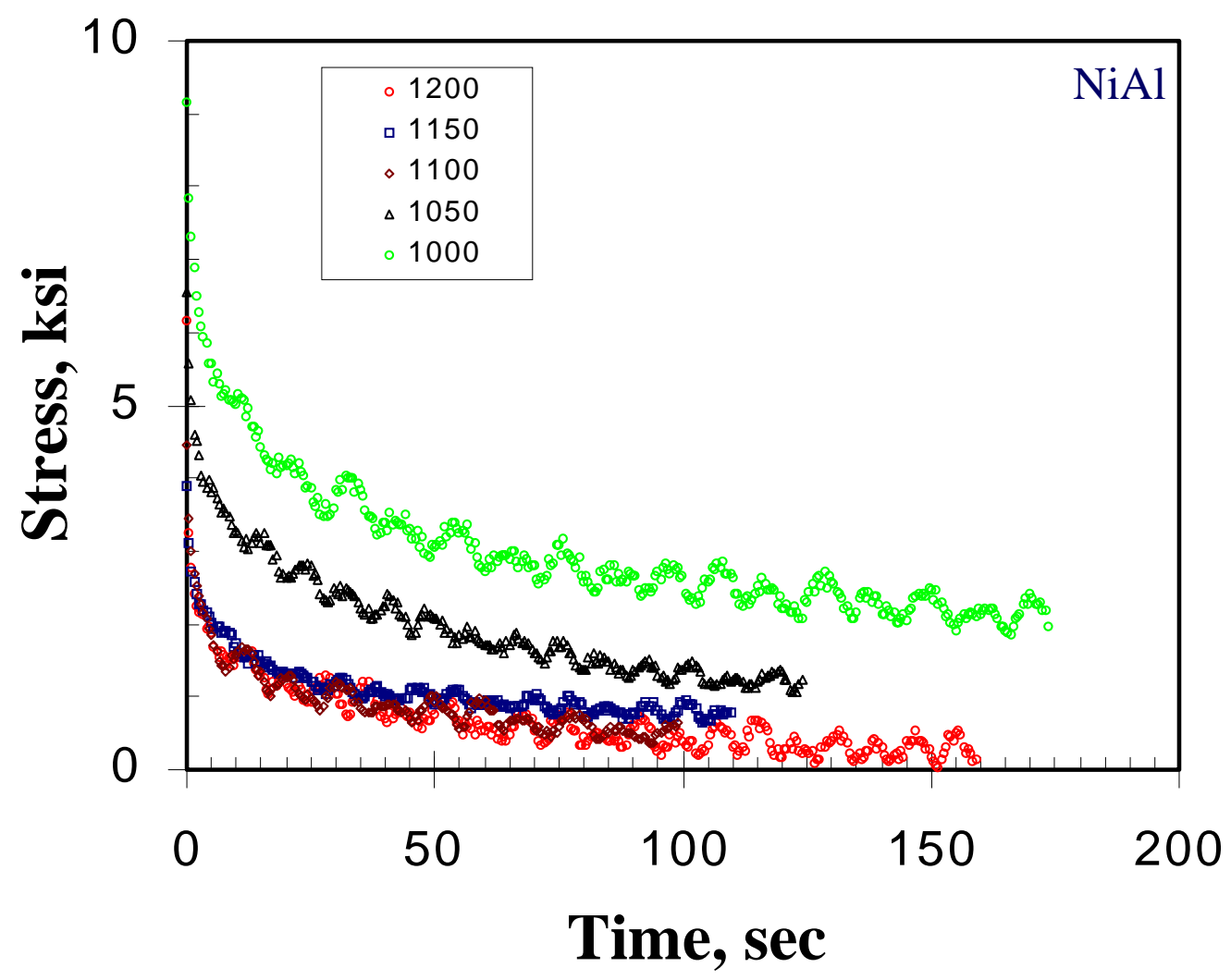

Figure 4.27: Stress Relaxation Curves NiAl

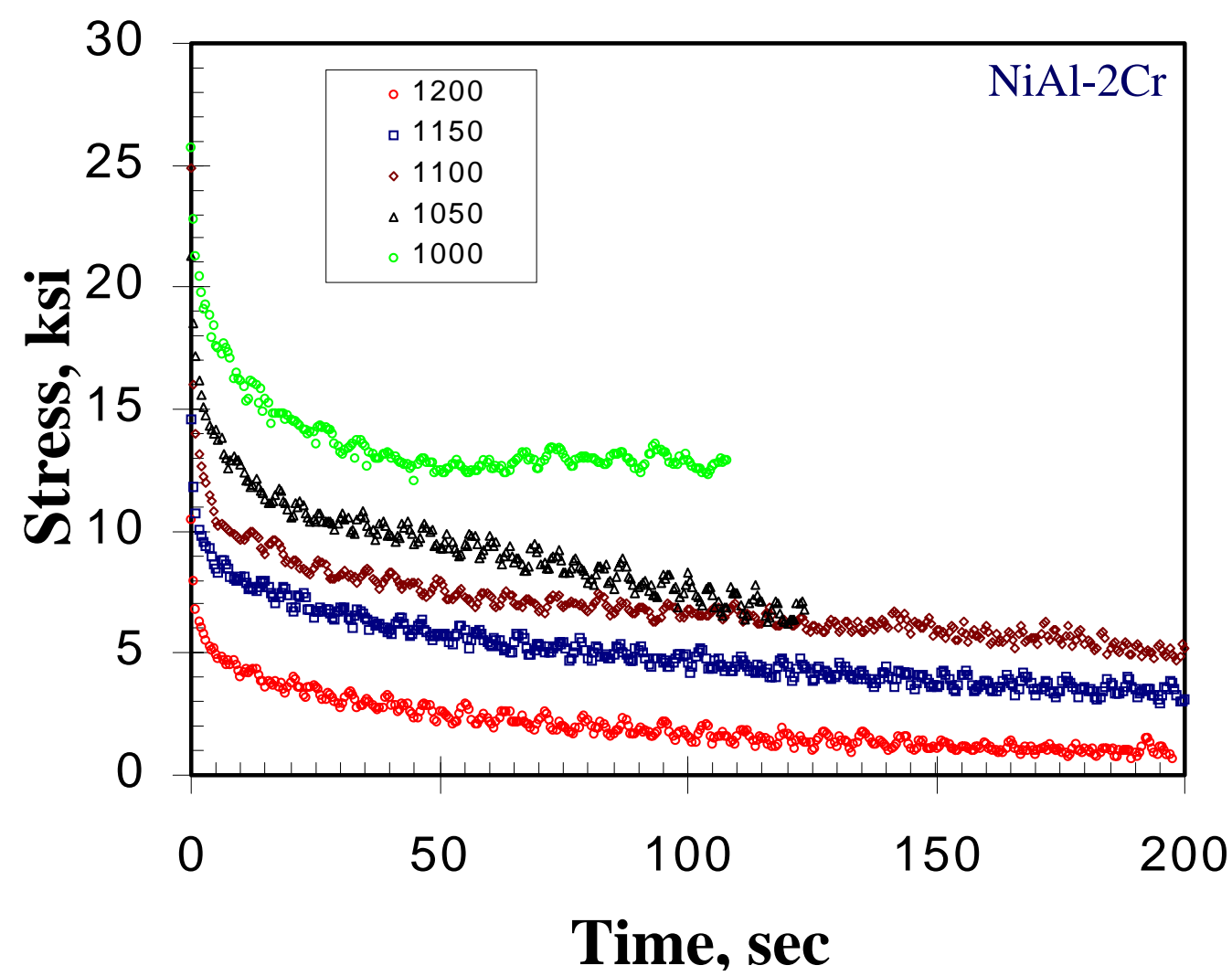

Figure 4.28: Stress Relaxation Curves NiAl-2Cr 


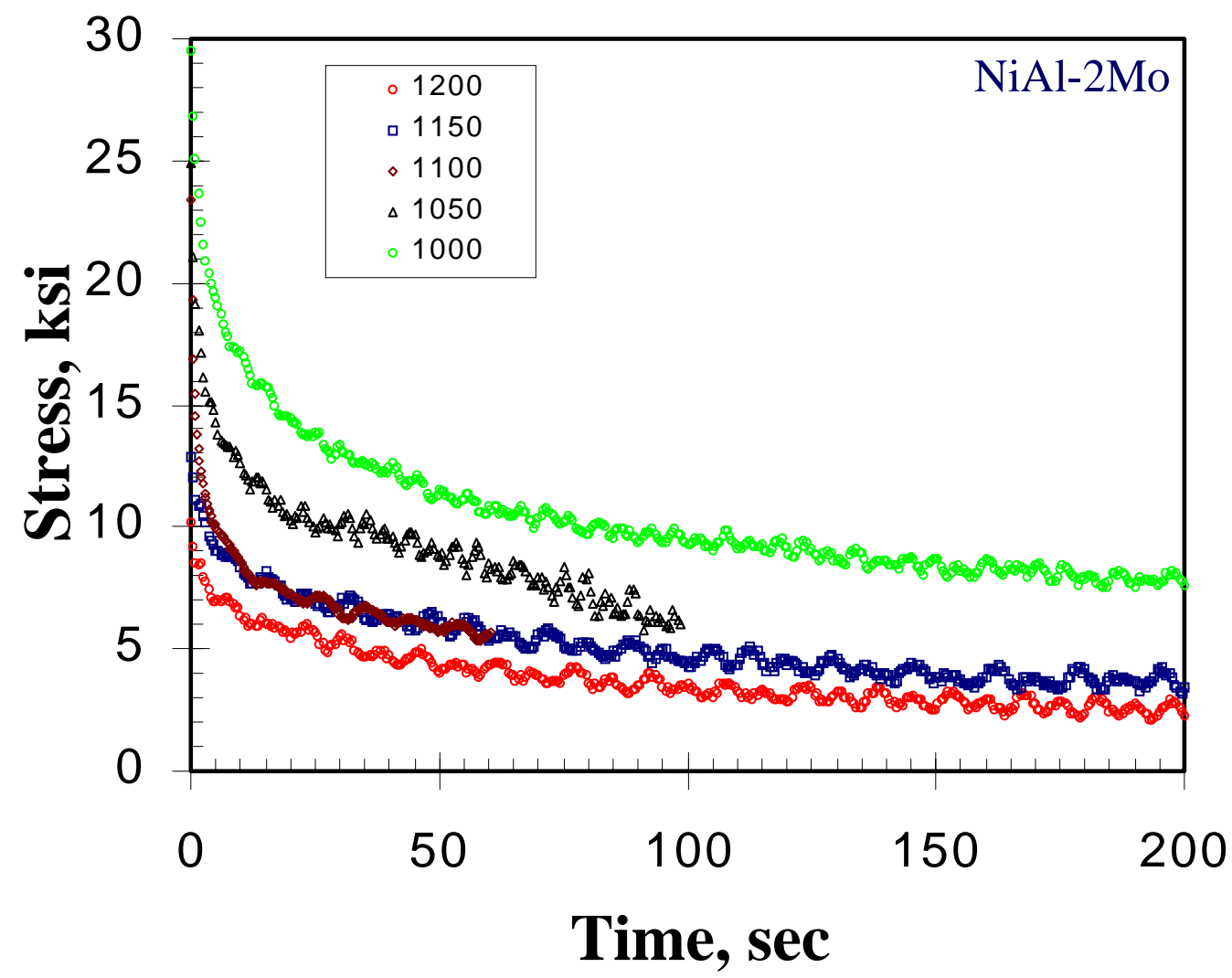

Figure 4.29: Stress Relaxation Curves NiAl-2Mo

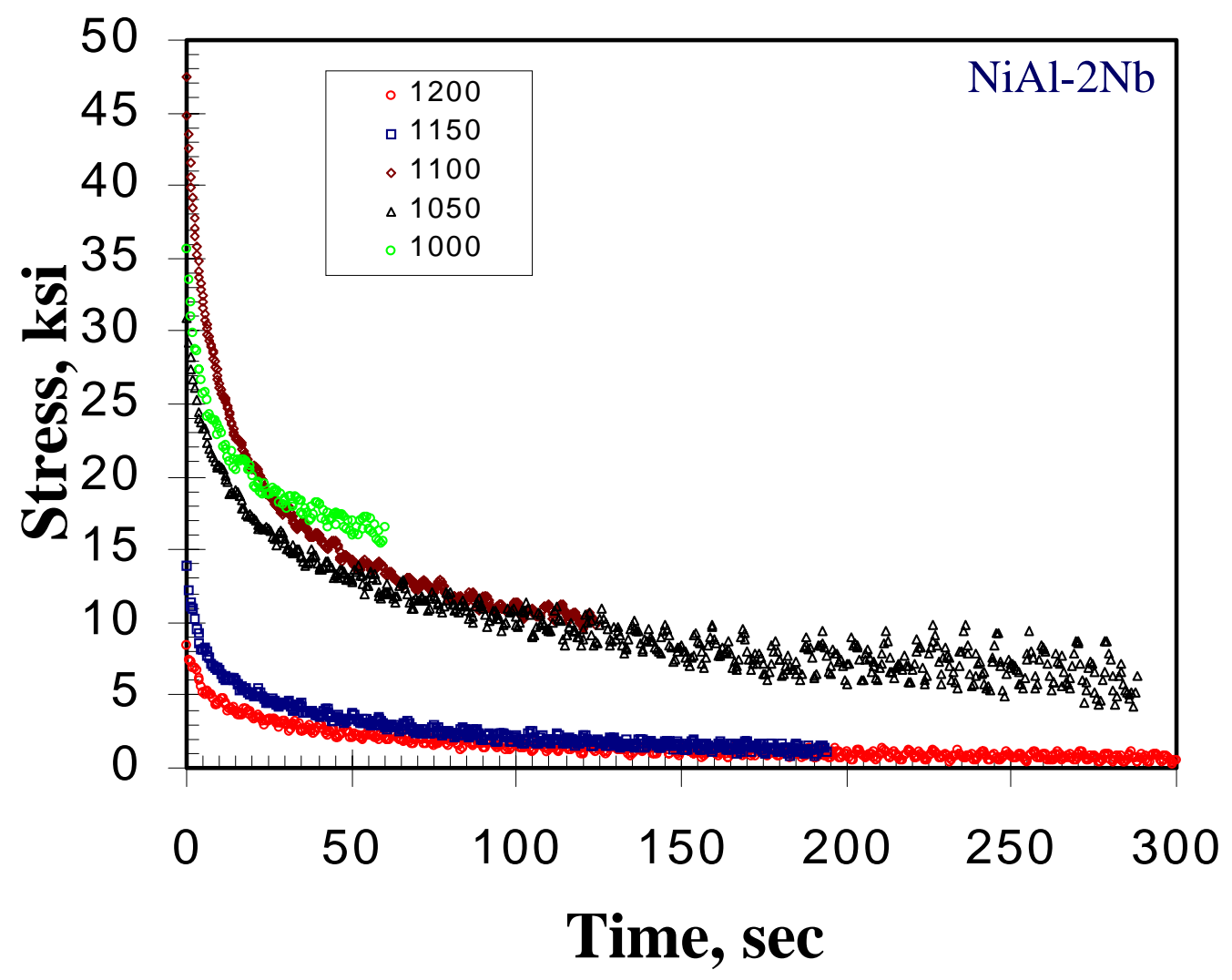

Figure 4.30: Stress Relaxation Curves NiAl-2Nb 


\subsubsection{Stress Relaxation Temperature Effect}

Figures 4.31-4.34 show the results from the stress relaxation testing at temperatures ranging from $850{ }^{\circ} \mathrm{C}-1200{ }^{\circ} \mathrm{C}$. The data was converted to strain rate vs. stress from the stress vs. time format to simplify the high temperature behavior comparison. The results from the stress relaxation testing were consistant from the behavior observed in the compression testing.

Observed in the stress relaxation data at lower stress levels, $1 \mathrm{ksi}$ and below, were an increase in the scatter of the testing data. This flucuation in data is due to changes in the force data obtained from testing. The magnitude of the flucuations were observed to be constant at all stress levels. This is why the error becomes increasingly visible at lower stress levels.

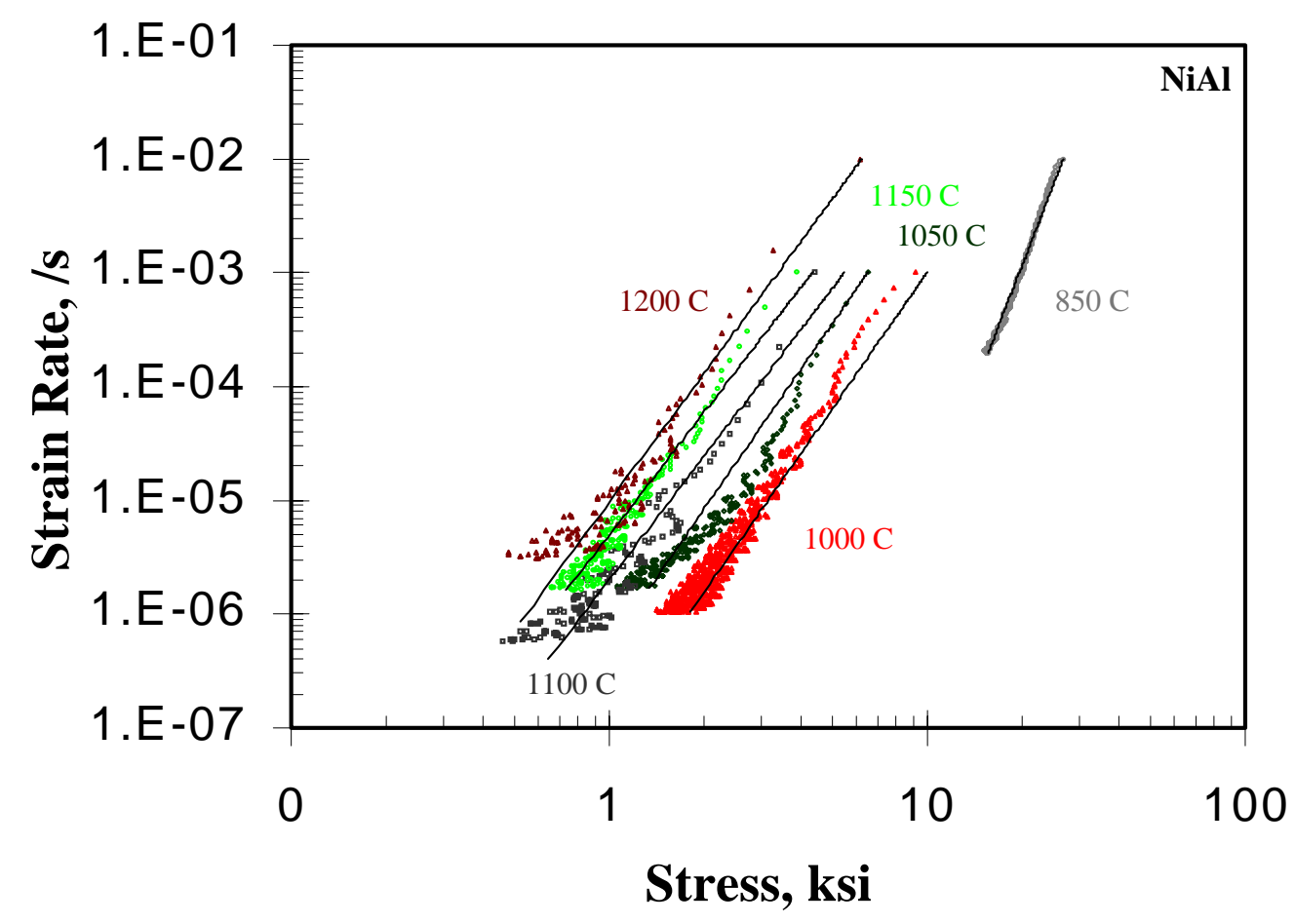

Figure 4.31: Stress Relaxation Tests NiAl 


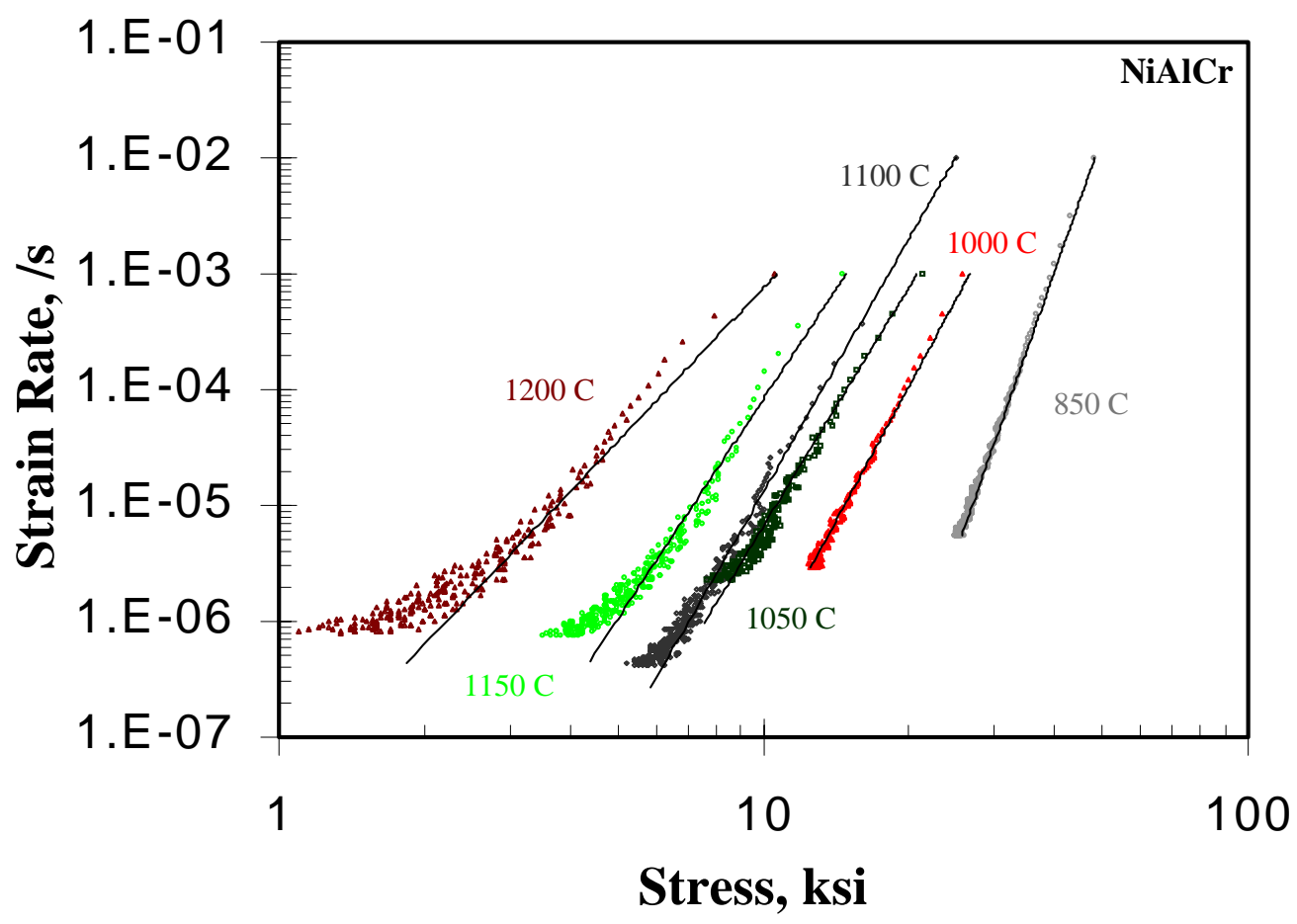

Figure 4.32: Stress Relaxation Tests NiAICr

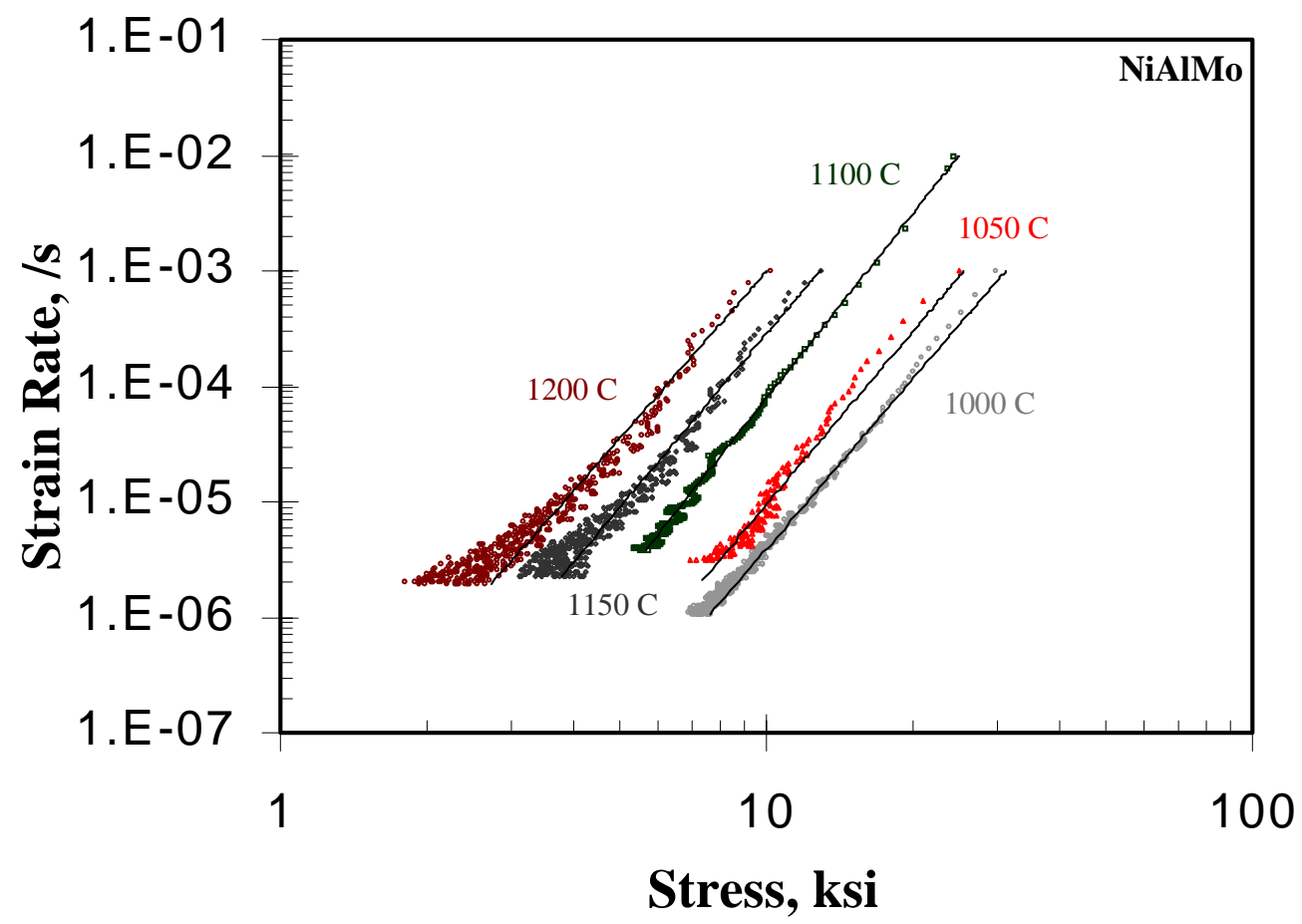

Figure 4.33: Stress Relaxation Tests NiAIMo 


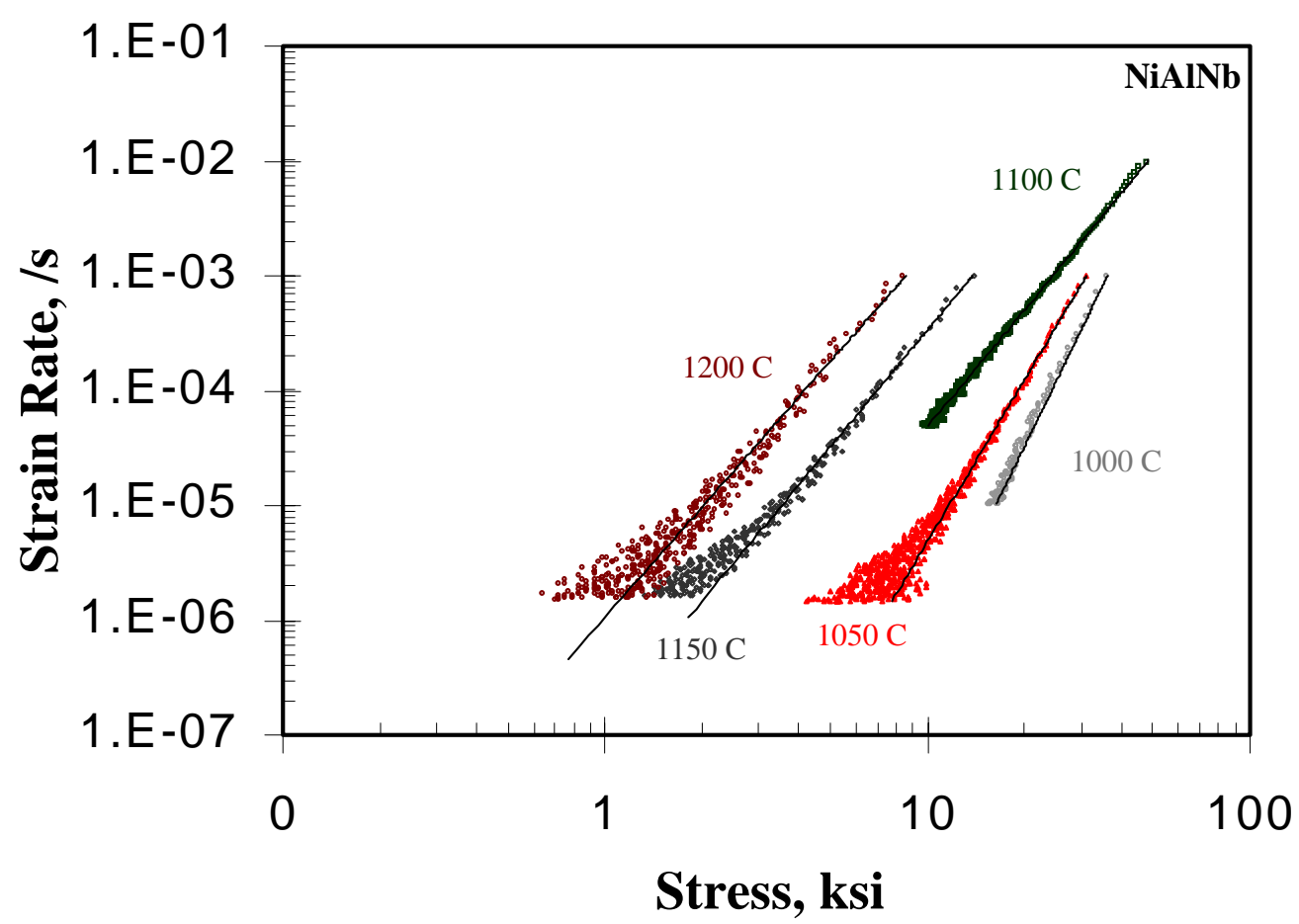

Figure 4.34: Stress Relaxation Tests NiAINb

\subsubsection{Stress Relaxation Alloying Effect}

The alloy effect for $1000{ }^{\circ} \mathrm{C}, 1050{ }^{\circ} \mathrm{C}, 1100{ }^{\circ} \mathrm{C}, 1150{ }^{\circ} \mathrm{C}$, and $1200{ }^{\circ} \mathrm{C}$ are shown below. These charts will provide a comparison to the results found in the compression data. All of the alloyed specimens provided significant improvements over the unalloyed NiAl specimen. A power law fit using regression analysis was applied to determine the stress exponent. The results were found to be consistent with the results from the compression testing. 


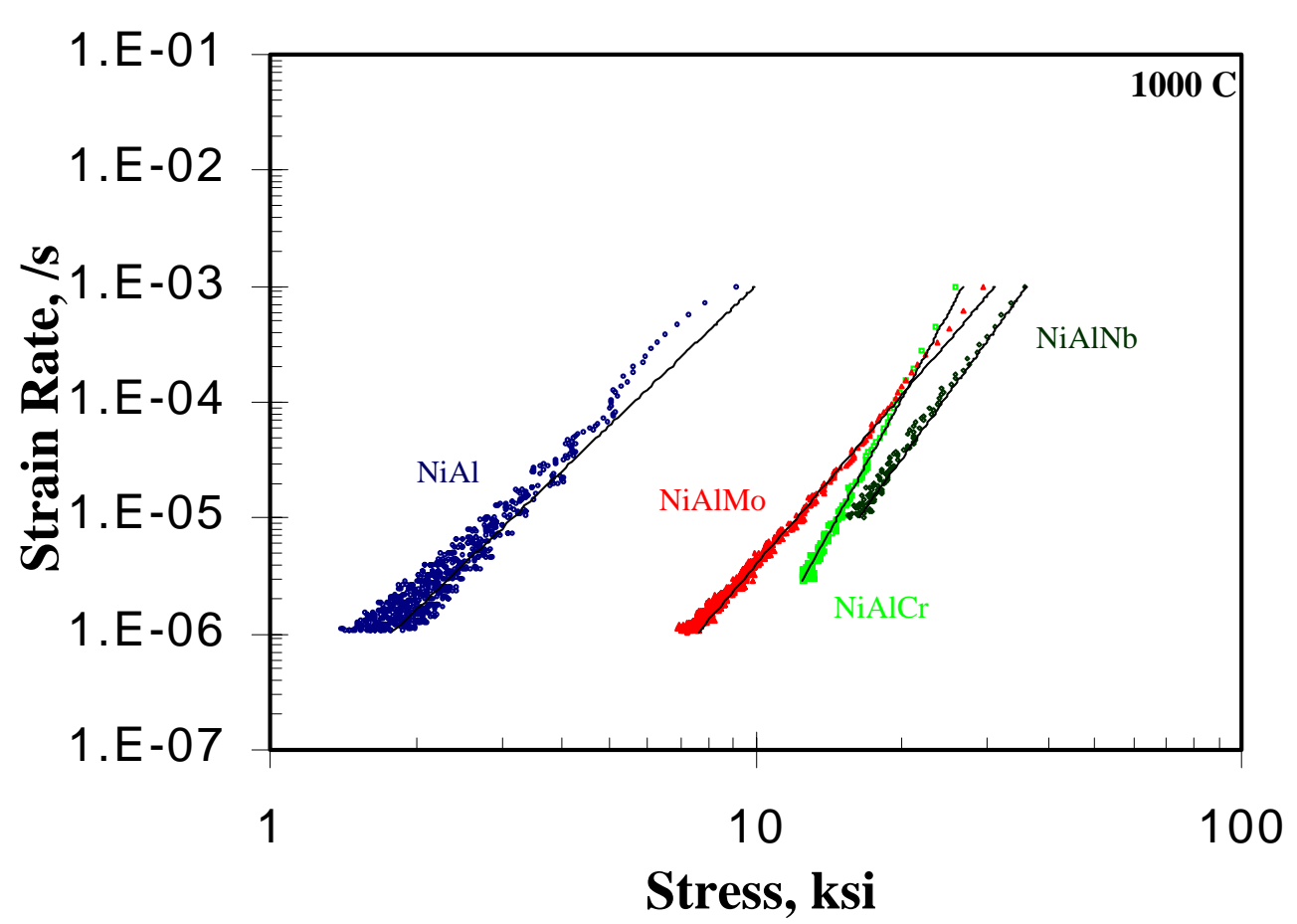

Figure 4.35: Stress Relaxation Tests $1000 \mathrm{C}$

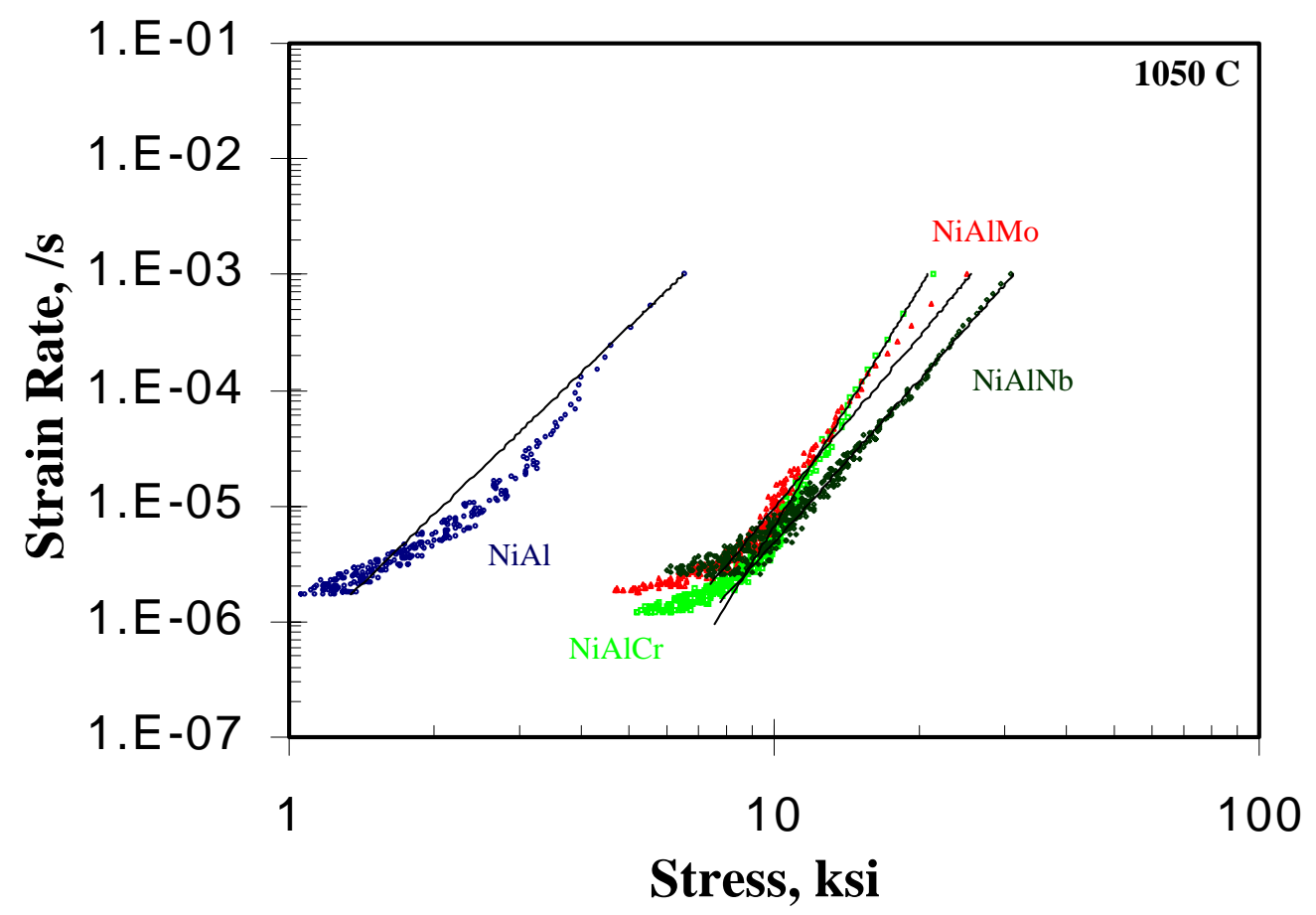

Figure 4.36: Stress Relaxation Tests $1050 \mathrm{C}$ 


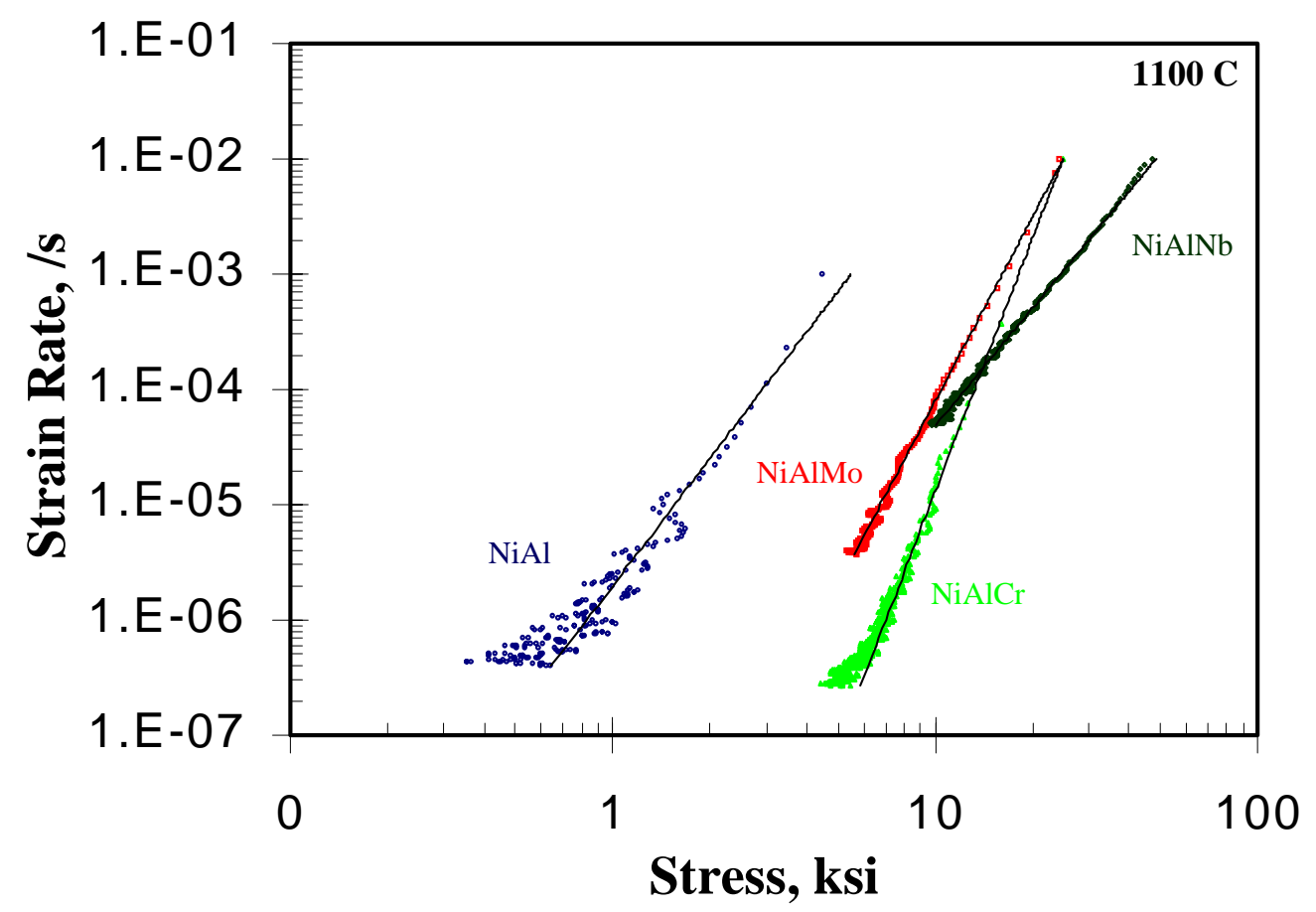

Figure 4.37: Stress Relaxation Tests $1100 \mathrm{C}$

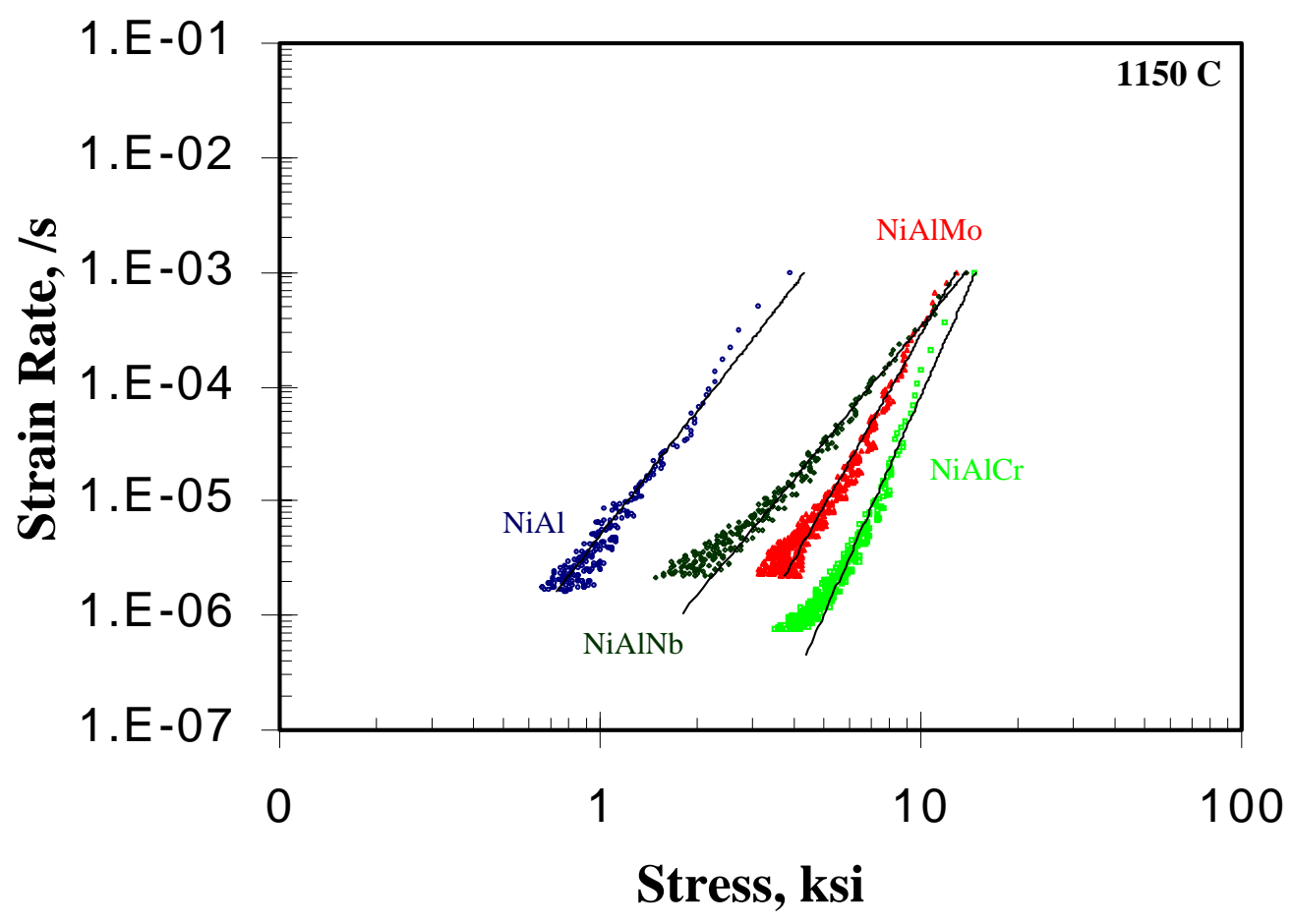

Figure 4.38: Stress Relaxation Tests 1150 C 


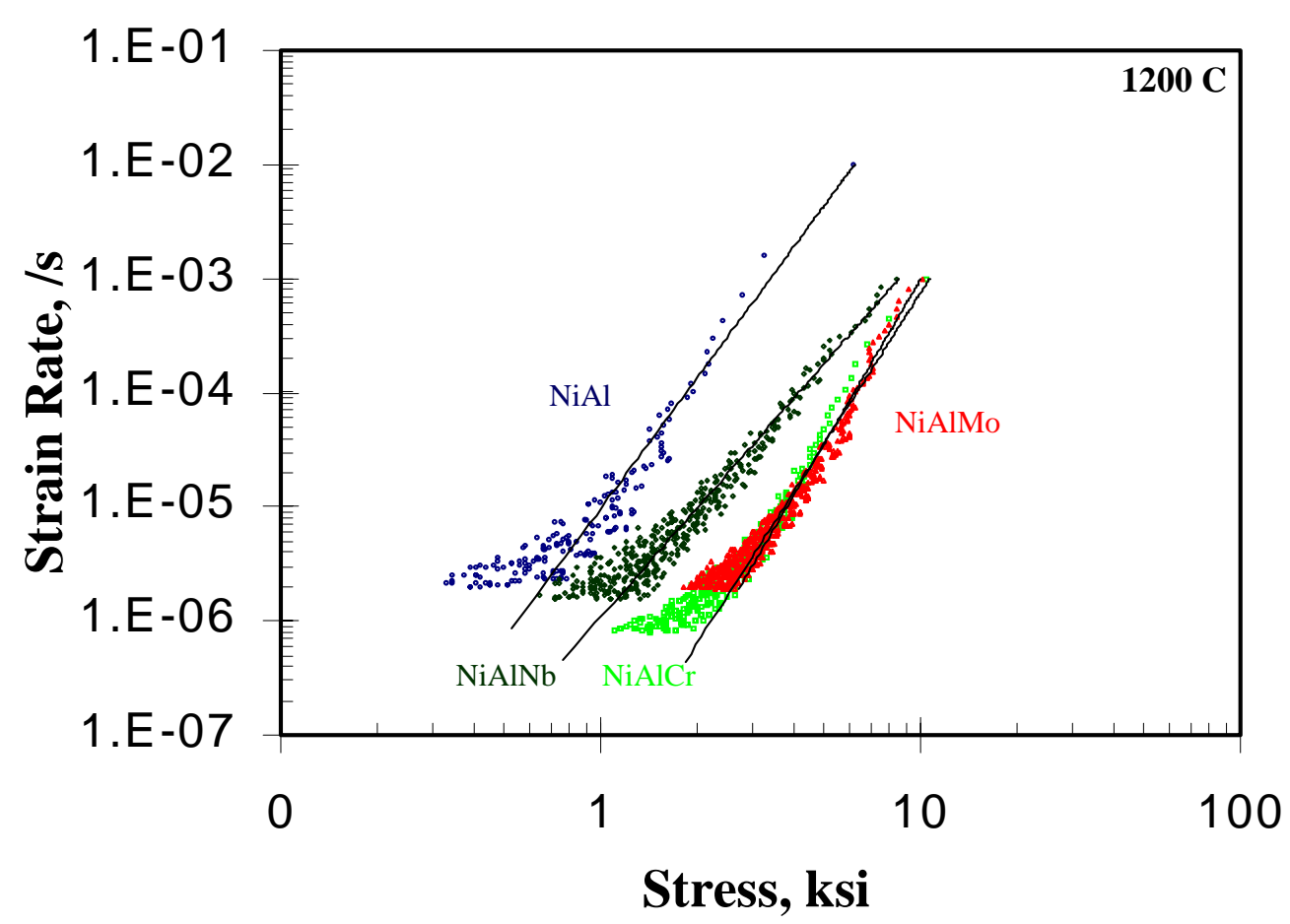

Figure 4.39: Stress Relaxation Tests 1200 C

Table 4.2 lists the stress exponents from stress relaxation testing for comparison. The stress exponent reveal the materials creep rate sensitivity to a change in applied stress. As can be seen the stress exponent decreases with increasing temperature. All materials will experience a reduction in the stress exponent value with increasing temperature. A material can be evaluated or compared to other materials by the extent and rate at which the stress sensitivity changes.

Table 4.2: Stress Exponent Stress Relaxation Tests

\begin{tabular}{ccccccc}
\hline & \multicolumn{5}{c}{ Stress Exponent } \\
\hline Specimen & $\mathbf{8 5 0}^{\circ} \mathbf{C}$ & $\mathbf{1 0 0 0}^{\circ} \mathbf{C}$ & $\mathbf{1 0 5 0}^{\circ} \mathbf{C}$ & $\mathbf{1 1 0 0}^{\circ} \mathbf{C}$ & $\mathbf{1 1 5 0}^{\circ} \mathbf{C}$ & $\mathbf{1 2 0 0}^{\circ} \mathbf{C}$ \\
NiAl & 7.22 & 4.00 & 4.03 & 3.65 & 3.61 & 3.80 \\
NiAlCr & 11.88 & 7.71 & 6.87 & 7.27 & 6.32 & 4.40 \\
NiAlMo & --- & 4.89 & 4.98 & 5.30 & 4.98 & 4.77 \\
NiAlNb & --- & 5.78 & 4.69 & 3.38 & 3.37 & 3.19 \\
\hline
\end{tabular}




\section{Chapter 5 - Discussion}

\subsection{Alloy Effect}

There were many differences observed between the alloyed and unalloyed NiAl specimens. To compare the observed differences in creep resistance and microstructure based on the different alloying editions, two sections will be discussed to compare the alloying element properties. The two sections will include a comparison of the atomic size factor and the electron number difference.

\subsubsection{Mechanical Testing Comparison}

The following graphs, figures 5.1-5.4, provides a comparison of the flow stresses obtained from the alloys at various strain rates and temperatures. The data is from the constant strain rate compression testing. The figures illustrate the typical pattern found when comparing the alloyed and unalloyed specimens. NiAl-2Cr and NiAl-2Mo seemed to have very similar results at most of the strain rates and temperatures. However this was not always the case case. Usually at higher strain rates the $\mathrm{NiAl}-2 \mathrm{Nb}$ specimen outpreformed the other materials and at lower strain rates the NiAl-2Cr specimen was superior. As temperature increased the strengthening provided by niobium additions diminished, while chromium and molybdenum additions continued to provide significant strengthening. This pattern is shown in figures 5.1-5.4, at lower temperatures the niobium provided the most strengthening, while at higher tempeatures chromium provided the most strengthening. The differences and simularities between the testing material can be explained by comparing the atomic size factor and the electron number effect. 


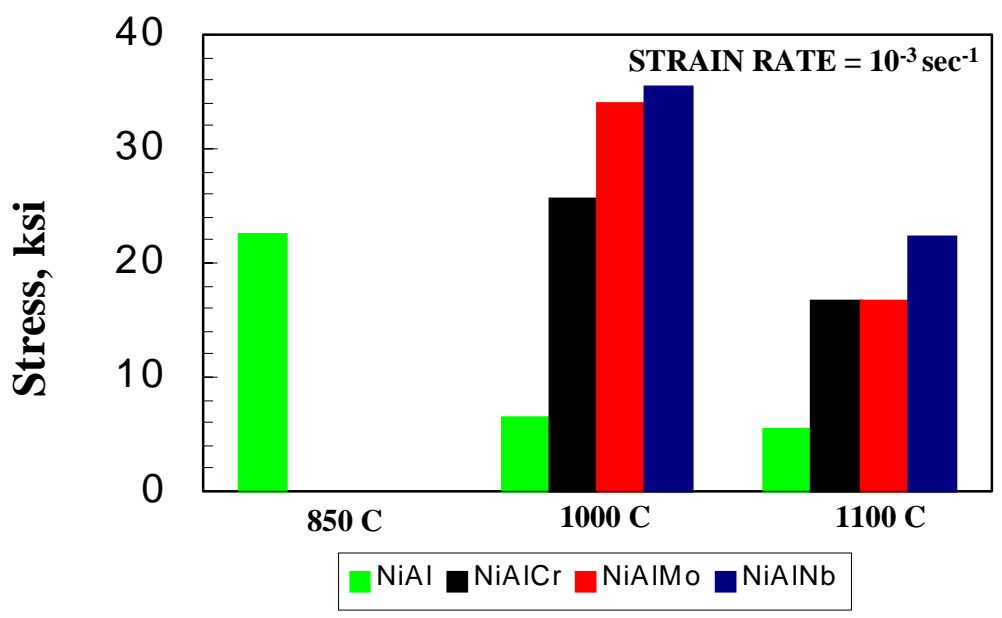

Figure 5.1: Flow Stress Comparison from Constant Strain Rate

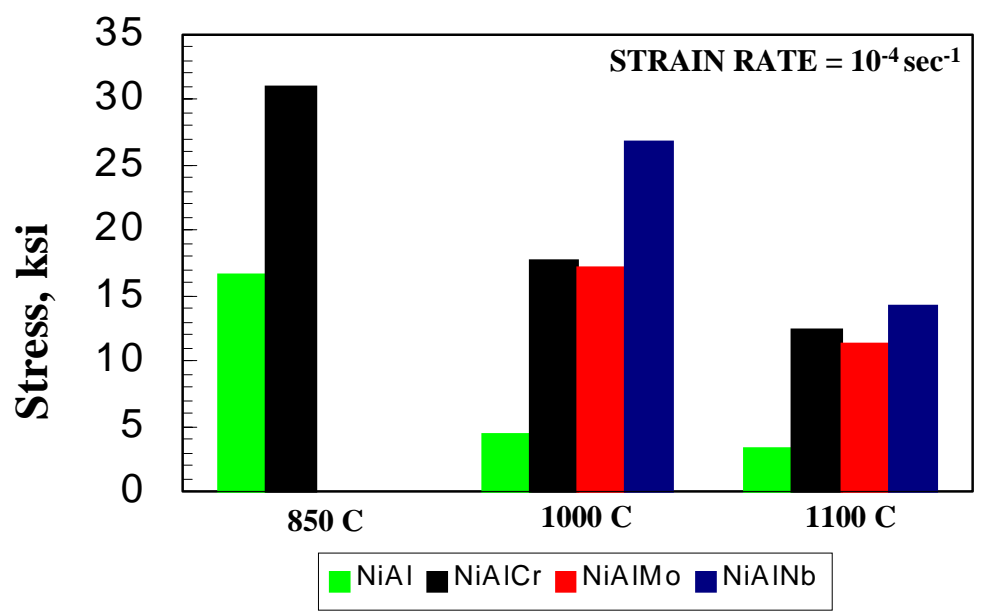

Figure 5.2: Flow Stress Comparison from Constant Strain Rate

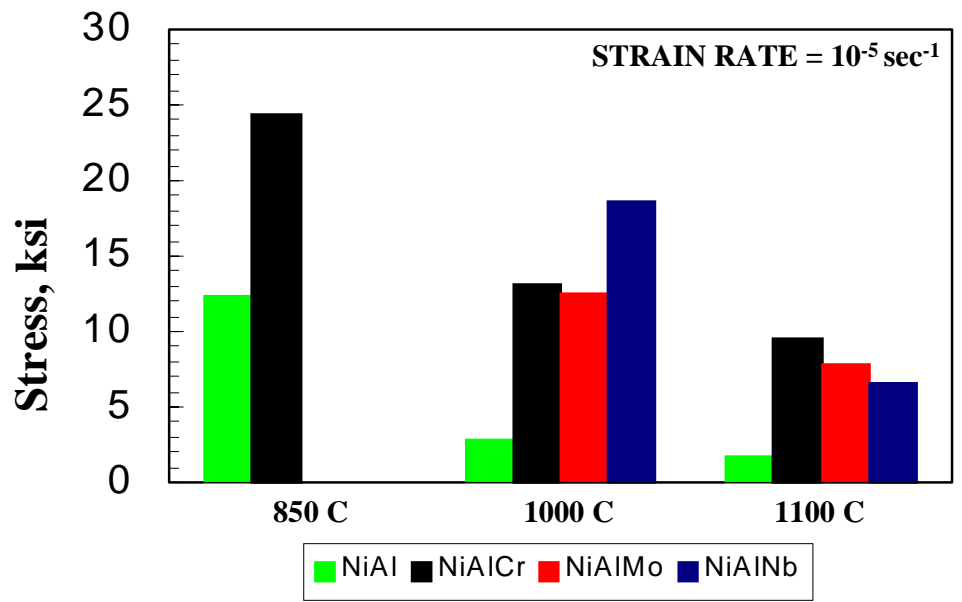

Figure 5.3: Flow Stress Comparison from Constant Strain Rate 


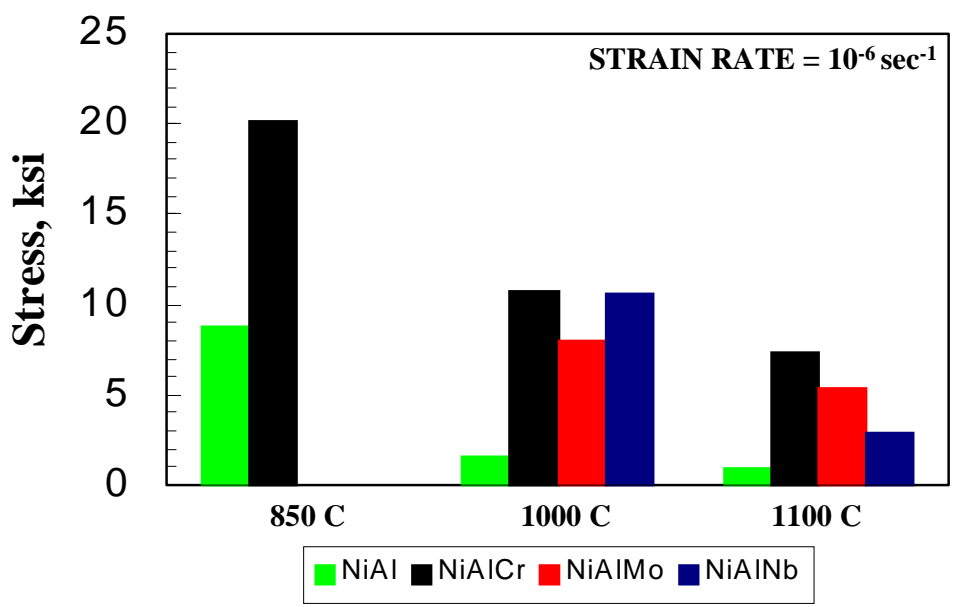

Figure 5.4: Flow Stress Comparison from Constant Strain Rate

\section{Temperature and Alloy Effect on Stress Dependency}

The stress exponent values obtained from the regression analysis, determines the stress dependency of the material. With a higher stress dependency the creep rate is more sensitive to changes in applied stress. From chapter 4, the results section, the stress dependency experienced changes resulting from changes in testing temperature. As temperature increases the stress exponent will decrease. Shown in figure 5.5, the change in the stress dependency values from different testing temperatures. From the stress dependency data, the materials exhibited the same range in stress dependency values for testing temperatures. The decrease in stress dependency with temperature is the result of different mechanisms controlling deformation. 


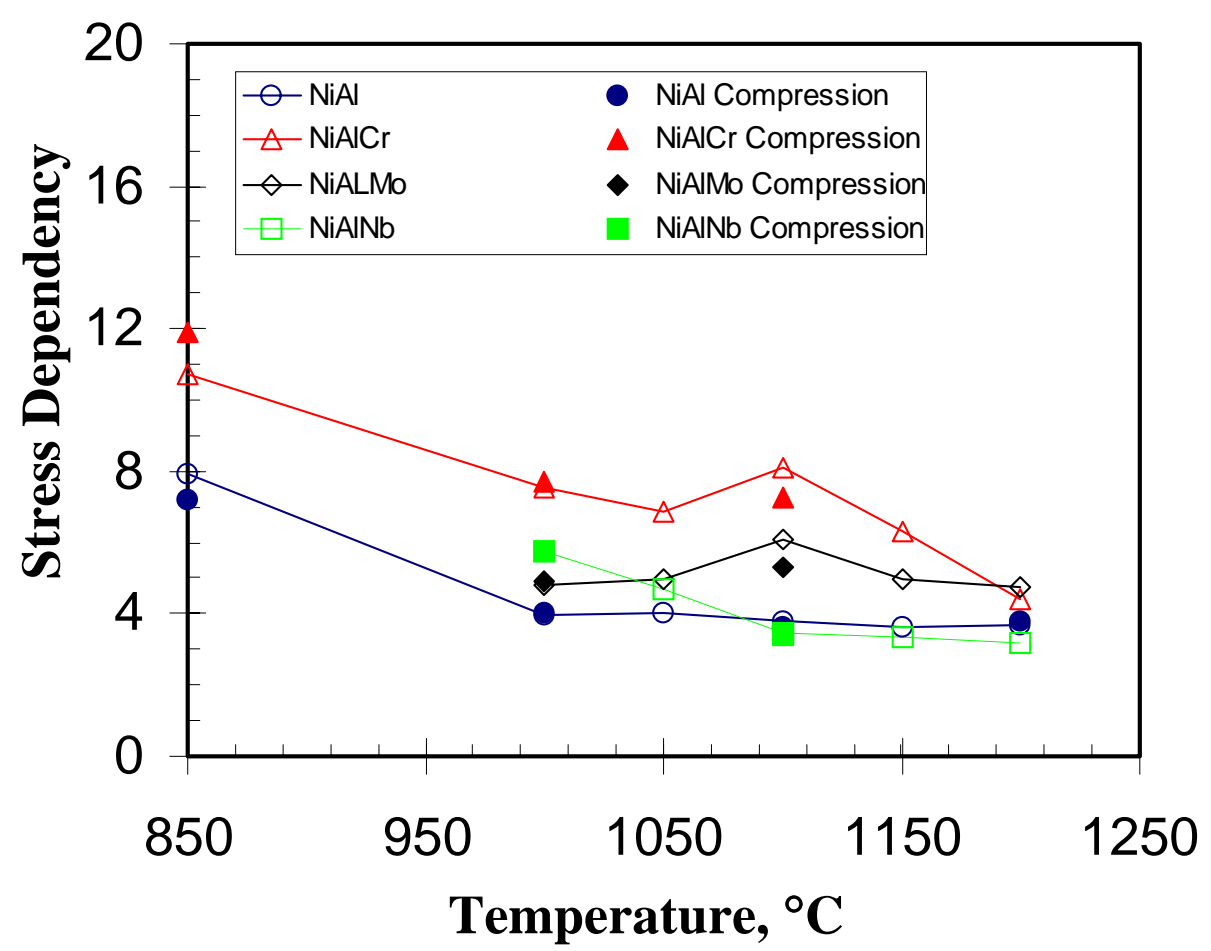

Figure 5.5: Stress Exponent Comparison

\subsubsection{Atomic Size Factor Effect}

Figure 2.3 was used to approximate the atomic diameter of the solute and solvent atoms. The number located in the top left-hand corner represents the percent difference in atomic diameter from the nickel atoms. The equation used to compare the atomic size factor was:

$$
\Delta \Omega=\frac{\Omega n e w-\Omega \text { old }}{\Omega \text { old }}[1
$$

where $\Delta \Omega$ is the percent change in volume from the replaced solvent atom and the solute atom. Before the size factor could be calculated, the lattice site the solute would occupy, had to be assumed. It was assumed the chromium atoms would replace the nickel atoms, the niobium atoms would replace the aluminum atoms, and the molybdenum atoms 
would be equally dispersed over the nickel and aluminum sites. Using this information, the material compositions were designed to prevent site defects.

From figure 2.3 the approximate atomic diameters of the three alloy elements were found in terms of nickel. Nickel was found to be $a_{n}$, chromium $1.03 a_{n}$, molybdenum $1.12 \mathrm{a}_{\mathrm{n}}$, Niobium $1.18 \mathrm{a}_{\mathrm{n}}$, and aluminum $1.06 \mathrm{a}_{\mathrm{n}}$. From this the approximate volume change could be calculated. Tabulated below are the results from the percent volume change. Since molybdenum was substituted for both nickel and aluminum, the effects from the volume change could be approximated by averaging the calculated values for nickel and aluminum substitution.

Table 5.1: \% Volume Change from Solute Addition

\begin{tabular}{ccc}
\hline Material & Lattice Site & \% Volume Change \\
\hline Chromium & Nickel & 9.27 \\
Chromium & Aluminum & -8.25 \\
Molybdenum & Nickel & 40.49 \\
Molybdenum & Aluminum & 17.96 \\
Niobium & Nickel & 64.30 \\
Niobium & Aluminum & 37.95 \\
\hline
\end{tabular}

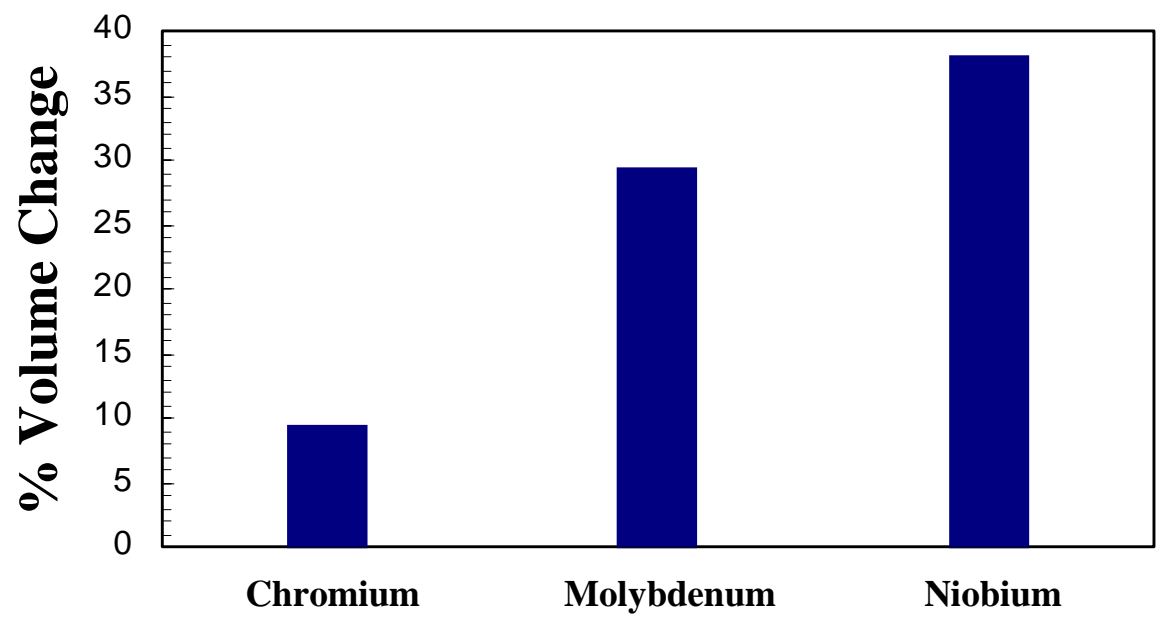

Figure 5.6: \% Volume Change from Solute Addition 
From the table based on the atomic size factor alone the specimen containing niobium would provide the largest increase in strength and the specimen containing chromium would provide very little increase in strength.

The effect on dislocation mobility by a volume change in a material lattice can be expressed by the equation:

$$
\mathrm{K}^{\mathrm{p}}=-\mathrm{Gb} \Delta \mathrm{V} 2(\mathrm{x} / \mathrm{z}) / \pi \mathrm{z}^{2}\left(1+(\mathrm{x} / \mathrm{z})^{2}\right)^{2}[5]
$$

where $\mathrm{K}^{\mathrm{p}}$ is the interaction force on the dislocation in the slip direction $\mathrm{x}, \mathrm{z}$ the distance from the slip plane, and $\Delta \mathrm{V}$ is the volume change of the lattice. Another factor related to the atomic size difference is the modulus interaction. The distortion field of the dislocation induces an elastic moment in the neighborhood of the solute atom if this possesses different elastic properties from those of the matrix. The energy density of the distortion field of the dislocation is proportional to the shear modulus $G$, the interaction energy can be represented in the form[5]:

$$
\Delta \mathrm{E}^{\mathrm{d}}=\mathrm{Gb}^{2} \Omega \eta / 8 \pi^{2} \mathrm{r}^{2}[5]
$$

where $\Omega$ is a function of volume change in the lattice. These equations represent the interaction with a solute and dislocation in a material. From the equations the amount of interaction is proportional to the volume change in the lattice structure as a result of the solute addition. The reduced strength in the materials is a result of increased dislocation mobility, therefore reducing dislocation mobility with solute atoms that interact with dislocations, will provide improvements in the material behavior.

To compare the effectiveness of the atomic size factor a comparison can be done from the estimated volume change calculated above. Molybdenum provided the larger change in volume than chromium, however they had the same electron valence. Based on 
this relationship considering the atomic size factor, molybdenum would produce the most significant increase in strength over binary $\mathrm{NiAl}$.

Molybdenum and niobium provided the largest difference in atomic size when compared to chromium. At temperatures below $1100{ }^{\circ} \mathrm{C}$ molybdenum and niobium additions provided more creep resistance than chromium additions. Above $1100{ }^{\circ} \mathrm{C}$ chromium and molybdenum provided comparable creep resistance properties, while niobium additions provided less creep resistance. From these observations the strengthening that occurs due to atomic misfit providing elastic and modulus interaction lose effectiveness with increasing temperature.

\subsubsection{Electron Number Effect}

The electron number effect is the result in the different electron valence in the solute atoms. Elements are placed on the periodic table based on electron configuration, which effects the properties the element possesses. The three solid solution strengtheners selected for this research are located next to one another on the periodic table. They are all located in the group B transition elements section of the periodic table. Chromium and molybdenum are located in group VIB and niobium in group VB.[19]

\begin{tabular}{|c|c|c|c|c|c|c|c|c|c|}
\hline \multirow[b]{2}{*}{ IIIB } & \multirow[b]{2}{*}{ IVB } & \multirow[b]{2}{*}{ VB } & \multirow[b]{2}{*}{ VIB } & \multirow[b]{2}{*}{ VIIB } & \multicolumn{3}{|c|}{ VIII } & \multirow[b]{2}{*}{ IB } & \multirow[b]{2}{*}{ IIB } \\
\hline & & & & & & & & & \\
\hline \begin{tabular}{|c|}
21 \\
Sc \\
44.95591
\end{tabular} & $\underset{47.88}{22}$ & $\begin{array}{c}23 \\
\mathbf{V} \\
50.9415\end{array}$ & $\begin{array}{c}24 \\
\mathbf{C r} \\
51.9961\end{array}$ & $\begin{array}{c}25 \\
\mathbf{M n} \\
54.9380\end{array}$ & $\begin{array}{c}26 \\
\text { Fe } \\
55.847\end{array}$ & $\begin{array}{c}27 \\
\text { Co } \\
58.93320\end{array}$ & $\begin{array}{c}28 \\
\mathbf{N i} \\
58.6934\end{array}$ & $\begin{array}{c}29 \\
\text { Cu } \\
63.546\end{array}$ & $\begin{array}{c}30 \\
\mathbf{Z n} \\
65.39\end{array}$ \\
\hline $\begin{array}{c}39 \\
\mathbf{Y} \\
88.90585\end{array}$ & $\begin{array}{c}40 \\
\mathbf{Z r} \\
91.224\end{array}$ & $\begin{array}{c}41 \\
\mathbf{N b} \\
92.90638\end{array}$ & $\begin{array}{c}42 \\
\text { Mo } \\
95.94\end{array}$ & $\begin{array}{c}43 \\
\text { TC } \\
98.9072\end{array}$ & $\begin{array}{c}44 \\
\mathbf{R u} \\
101.07\end{array}$ & $\begin{array}{c}45 \\
\text { Rh } \\
102.90550\end{array}$ & $\begin{array}{c}46 \\
\text { Pd } \\
106.42\end{array}$ & \begin{tabular}{|c|}
47 \\
$\mathbf{A g}$ \\
107.8682
\end{tabular} & $\begin{array}{c}48 \\
\text { Cd } \\
112.411\end{array}$ \\
\hline $\begin{array}{c}57 \\
{ }^{*} \mathbf{L a} \\
138.9055\end{array}$ & $\begin{array}{c}72 \\
\text { Hf } \\
178.49\end{array}$ & $\begin{array}{c}73 \\
\mathrm{Ta} \\
180.9479\end{array}$ & $\begin{array}{c}74 \\
\mathbf{W} \\
183.85\end{array}$ & $\begin{array}{c}75 \\
\mathbf{R e} \\
186.207\end{array}$ & $\begin{array}{c}76 \\
\text { OS } \\
190.2\end{array}$ & $\begin{array}{c}77 \\
\text { Ir } \\
192.22\end{array}$ & $\begin{array}{c}78 \\
\mathbf{P t} \\
195.08\end{array}$ & $\begin{array}{c}79 \\
\mathbf{A u} \\
196.96654\end{array}$ & $\begin{array}{c}80 \\
\mathrm{Hg} \\
200.59\end{array}$ \\
\hline $\begin{array}{c}89 \\
+\mathbf{A C} \\
227.0278\end{array}$ & $\begin{array}{c}104 \\
\text { Unq } \\
261.11\end{array}$ & $\begin{array}{c}105 \\
\text { Unp } \\
262.114\end{array}$ & $\begin{array}{c}106 \\
\text { Unh } \\
263.118\end{array}$ & $\begin{array}{c}107 \\
\text { Uns } \\
262.12\end{array}$ & $\begin{array}{c}108 \\
\text { Uno } \\
(265)\end{array}$ & $\begin{array}{l}109 \\
\text { Une }^{b} \\
(266)\end{array}$ & & & \\
\hline
\end{tabular}

Figure 5.7: Periodic Table 
The group location on the periodic table determines the amount of electrons in the outermost shell, the valence electrons. Listed in table 5.2 are the electron configurations on the solute atoms. Since chromium and molybdenum are in the same group the have the same electron valence. Niobium is in a different group, giving niobium a different electron valence. This difference in electron valence can be used to help explain the difference in creep behavior and secondary phase behavior in the NiAl alloys.

Table 5.2: Electron Configuration of Solute Atom [19]

\begin{tabular}{cc}
\hline Material & Electron Configuration \\
\hline Chromium & {$[\mathrm{Ar}] 4 \mathrm{~s}^{1} 3 \mathrm{~d}^{5}$} \\
Molybdenum & {$[\mathrm{Kr}] 5 \mathrm{~s}^{1} 4 \mathrm{~d}^{5}$} \\
Niobium & {$[\mathrm{Kr}] 5 \mathrm{~s}^{1} 4 \mathrm{~d}^{4}$} \\
\hline
\end{tabular}

From figure 2.1 the expected phase behavior can be determined when alloying NiAl. From the diagram chromium and molybdenum are predicted to have similar phase behavior when added to NiAl. They will both form metallic precipitates when added beyond their solubility limit. The additon of niobium would produce intermetallic precipitates when solubility limit was exceeded. This expected behavior would agree with the findings from this research. Chromium was found to have a higher solubility in $\mathrm{NiAl}$ than molybdenum, however they were found to produce metallic precipitates. The precipitates formed were $\alpha$ precipitates in the form of chromium and molybdenum. Niobium, when added beyond solubility limits, produced intermetallic precipitates in the form of $\beta^{\prime} \mathrm{Ni}_{2} \mathrm{AlNb}$, Heusler phase.

The resulting phases behavior difference between the alloying additions can be attributed to the difference in electron valence. From table 5.2 molybdenum and chromium have the same electron valence, however niobium differed by one electron in the d subshell. 
The difference in creep behavior can also be a result of different eletron configurations. To provide a comparison strengthening effect from different solute additions, the effect of different electron valences on dislocation mobility and atomic diffusion must be determined. For strengthening to occur there must be some kind of interaction with dislocation mobility or atomic diffusion.

For this reason niobium and molybdenum were selected as a comparision to the effect different electron configurations would have on solute addition to NiAl. From the atomic size factor comparison molybdenum and niobium would produce similar results based on the atomic size factor alone. At lower testing temperatures where atomic misfit produces more effective strengthening niobium and molybdenum additions outperformed strengthening with chromium. However as temperature increased above $1100{ }^{\circ} \mathrm{C}$, where the atomic size factor lost effectiveness, chromium and molybdenum produce comparable derformation properties. The difference in atomic size had little effect on the deformation propeties above $1100^{\circ} \mathrm{C}$. The similarities above $1100{ }^{\circ} \mathrm{C}$ can be attributed to the same electron valence of molybdenum and chromium.

\subsection{Compression and Stress Relaxation Comparison}

The constant strain rate compression testing and stress relaxation testing were used to evaluate high temperature deformation behavior of the specimens. To correlate the properties found from compression testing and stress relaxation testing, the results from testing at the same temperature were plotted together. Shown in figure 5.8 the results from the compression testing, shown in red, and the stress relaxation testing produced the same behavior. The figure reveal the stress relaxation and compression testing can be correlated to compare the high temperature deformation behavior. 


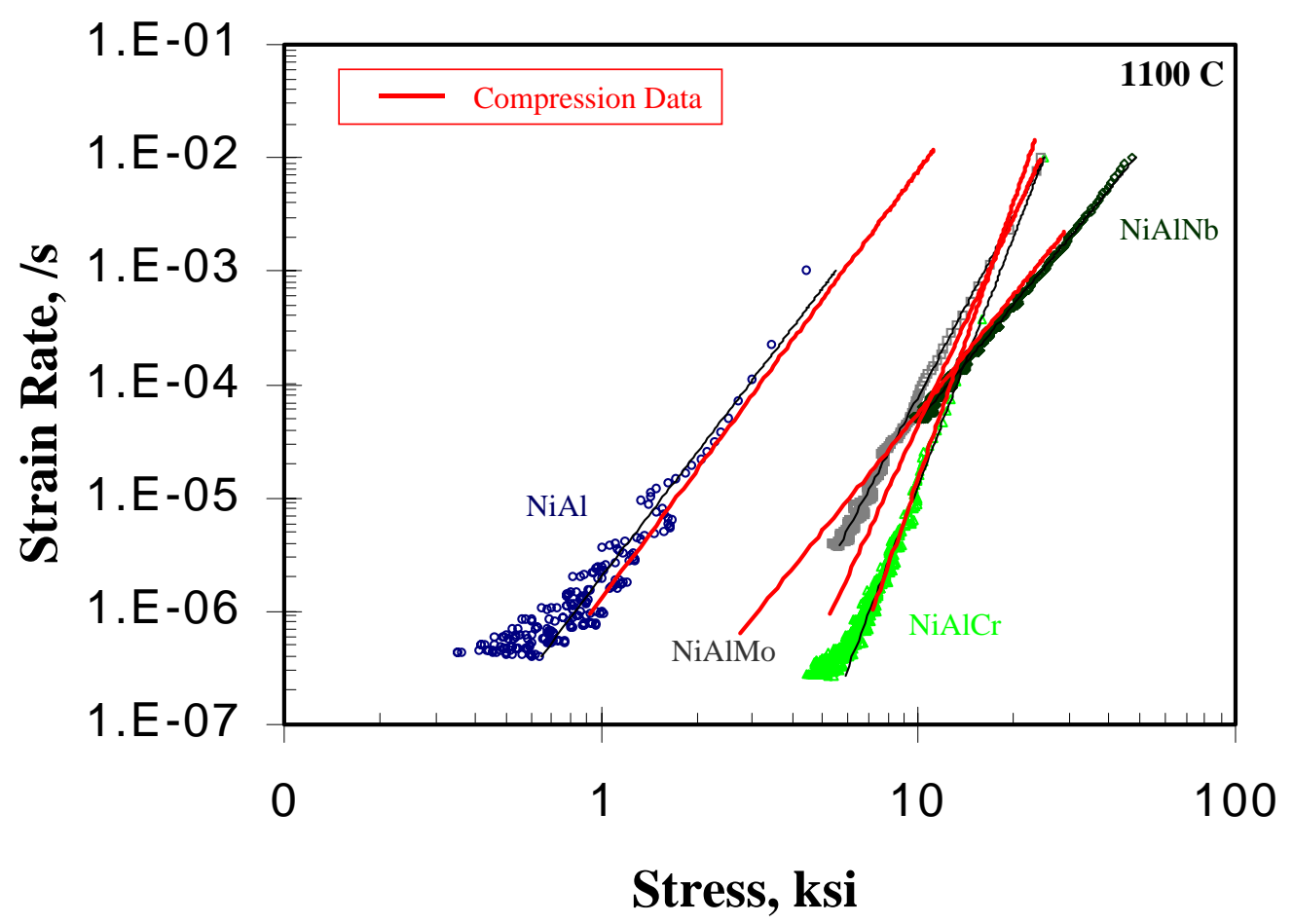

Figure 5.8: Stress relaxation and Compression Comparison

\subsection{Single Crystal Comparison}

Included in the figures below are single crystal data from literature. The single crystal data will be used as a comparison to the DS specimens. Comparing the data from single crystal specimens may help explain the possible creep mechanisms occurring at the testing temperatures.

The "soft" <111> and <223> single crystal data provided comparable results above $1000{ }^{\circ} \mathrm{C}$ to the DS NiAl material. The "hard" <001> material proved to be more creep resistant than the "soft" or DS materials. This was also the case for the alloyed specimens. The alloyed $\langle 001\rangle$ single crystal material NiAl-1Hf revealed more creep resistance than the DS alloyed specimens. However the alloyed specimens were more creep resistant than the <001> single crystal material in binary form. 
At $1000^{\circ}$ the $<001>\mathrm{NiAl}-1 \mathrm{Hf}$ material, from published data, provide the most creep resistance, followed by $\mathrm{NiAl}-2 \mathrm{Nb}$. NiAl-2Cr and NiAl-2Mo provided slightly less strengthening at $1000{ }^{\circ} \mathrm{C}$. At $1100{ }^{\circ} \mathrm{C}$ it appears $\mathrm{NiAl}-2 \mathrm{Nb}$ has lost effectiveness when compared to NiAl-2Cr and NiAl-2Mo. NiAl-2Nb

The alloyed and "hard" single crystal material provide large improvements in creep resistance, however the values for their stress dependency were very similar to DS $\mathrm{NiAl}$ and "soft" crystal orientations of $\mathrm{NiAl}$. NiAl-2Cr experienced a stronger stress dependency than the other specimens until $1200{ }^{\circ} \mathrm{C}$, at which all of the specimens had a stress exponent value of approximately 4.

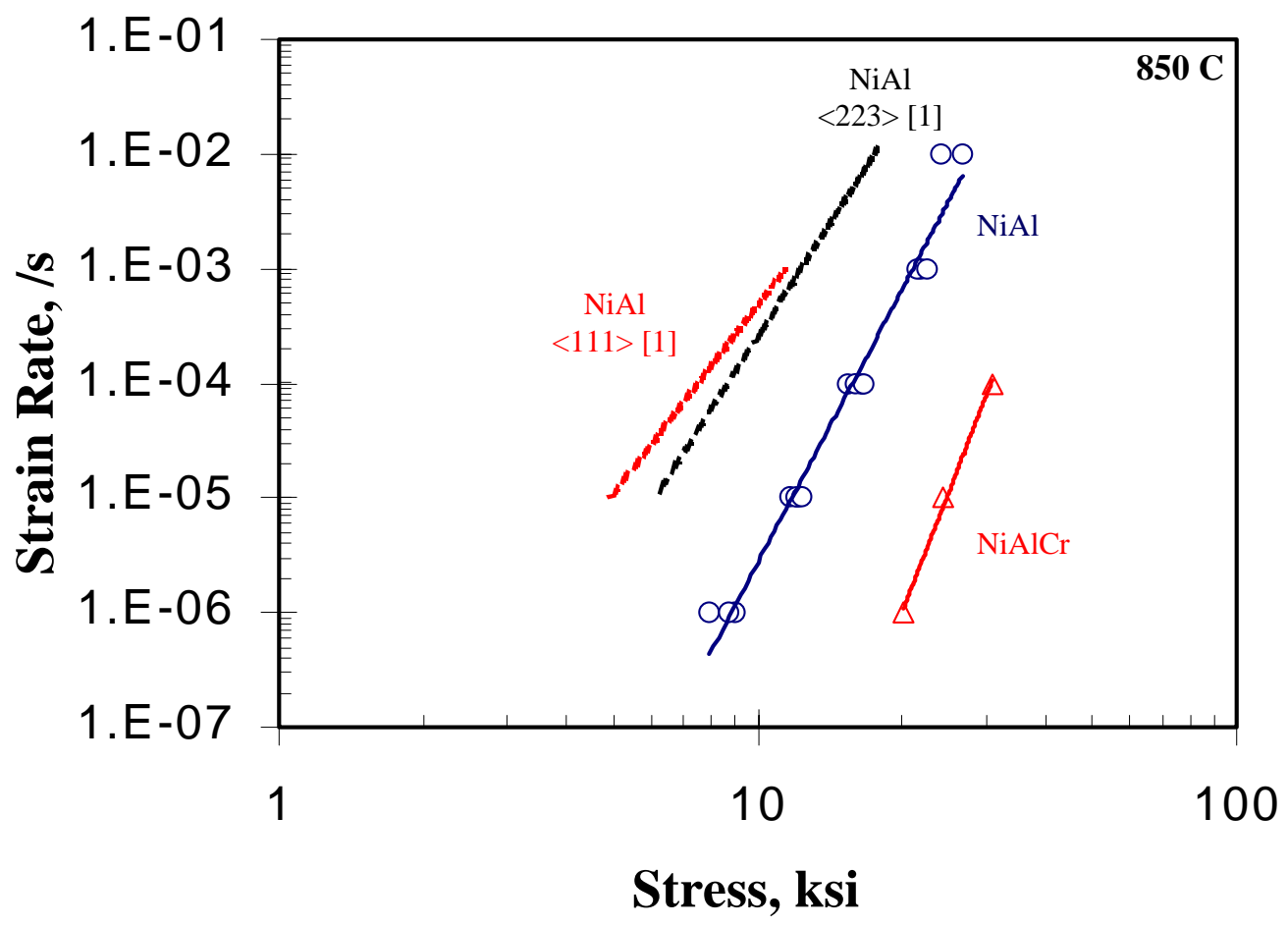

Figure 5.9: Single Crystal Comparison at $850 \mathrm{C}$ 


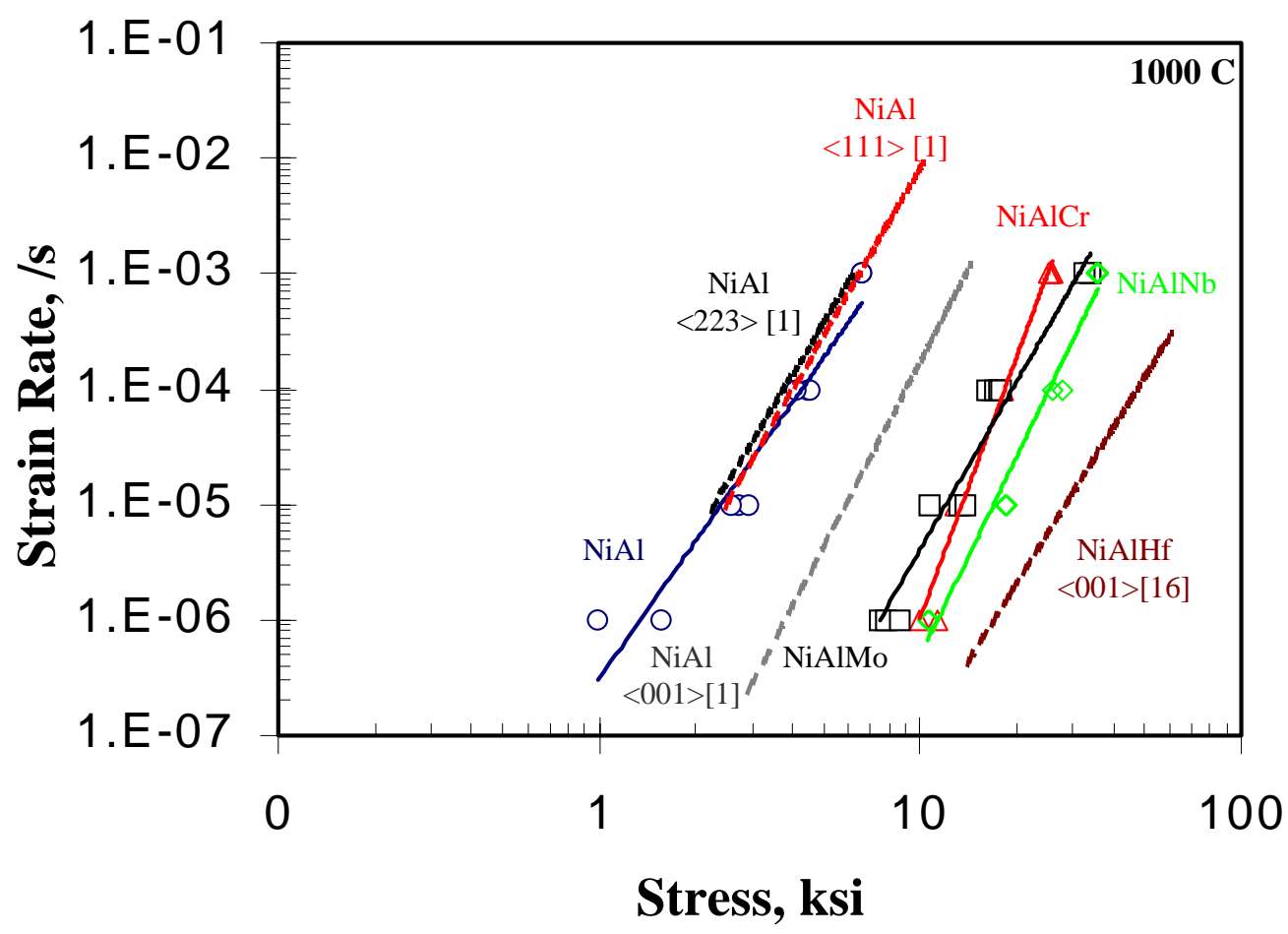

Figure 5.10: Single Crystal Comparison at $1000 \mathrm{C}$

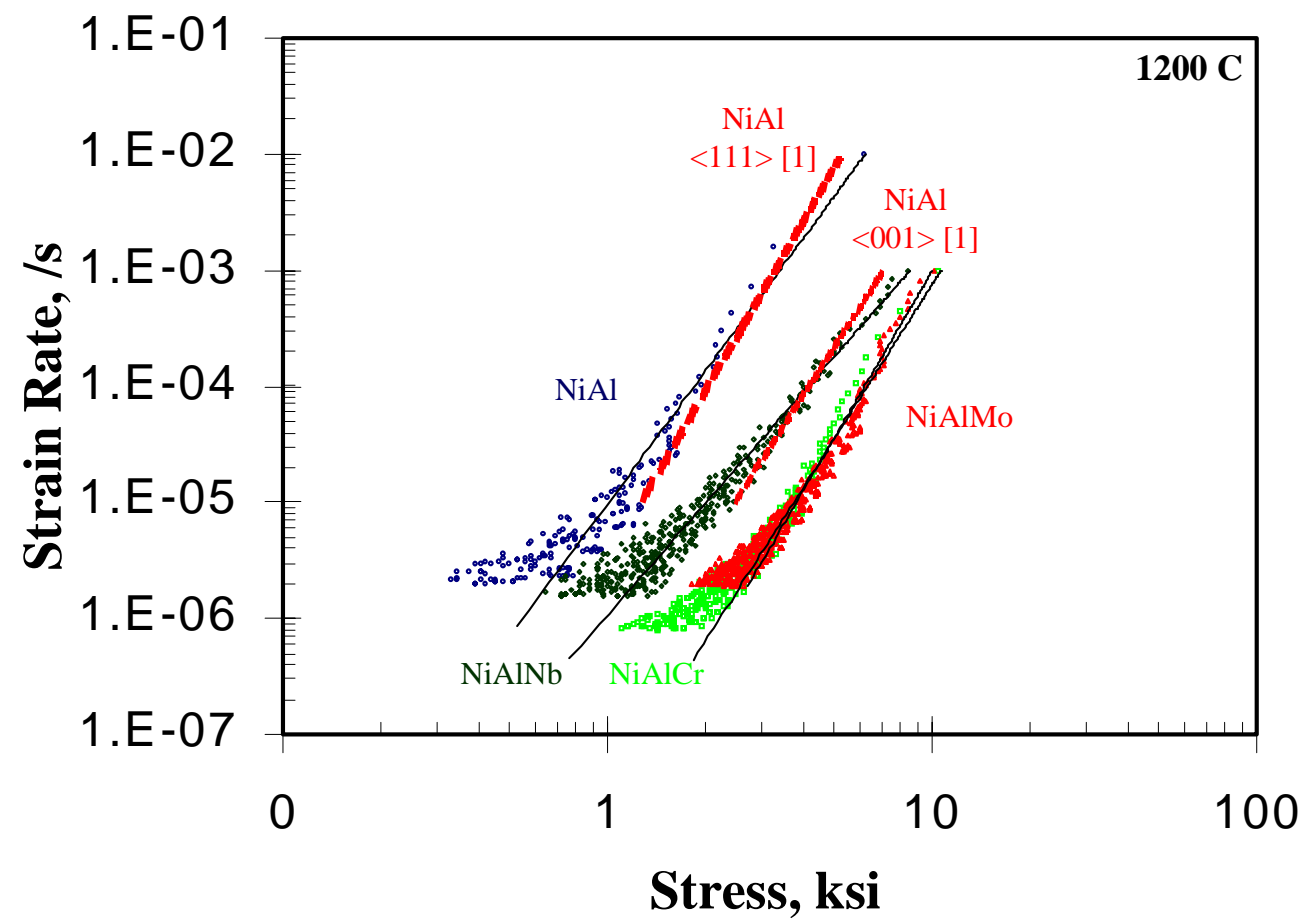

Figure 5.11: Single Crystal Comparison at $1200 \mathrm{C}$ 
Illustrated in figures 5.12 and 5.13 a comparison of sigle crystal and DS stress dependency. From figure 5.12 the microstructure effect on stress dependency can be compared. At temperatures below $1000{ }^{\circ} \mathrm{C}$ microstructural differences had a significant effect on the stress dependency of the materials. Above $1000{ }^{\circ} \mathrm{C}$ the stress dependency became less dependent on microstructure. This same pattern was also observed in figure 5.13 comparing alloyed single crystal data with alloyed DS data. The reason for the change in stress dependency is from changing deformation properties. The creep mechanism controlling deformation changes with increasing testing temperature. At higher temperatures the creep mechanism become less dependent on microstructure.

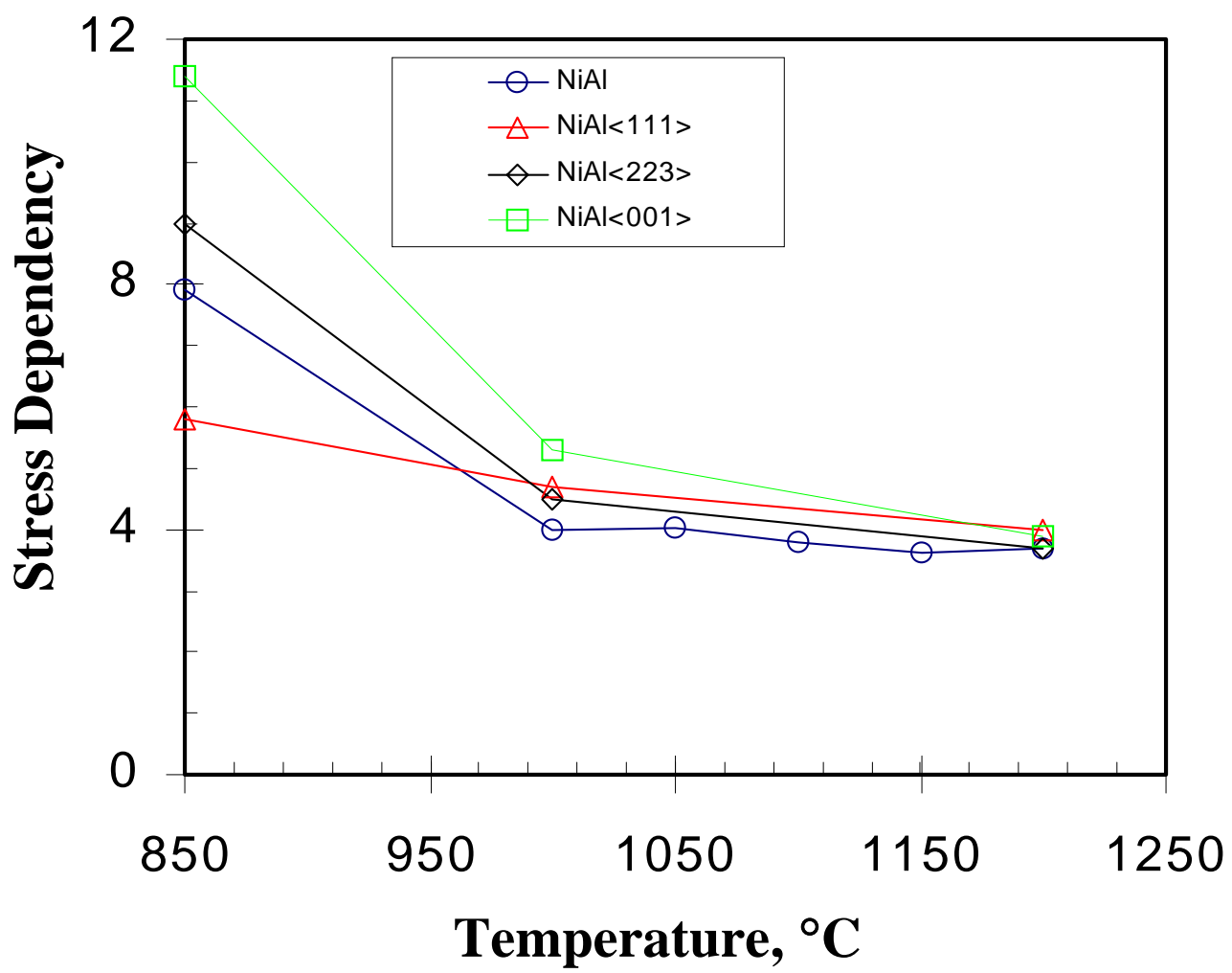

Figure 5.12: Stress Dependency Comparison Between Single Crystal NiAl and DS NiAl 


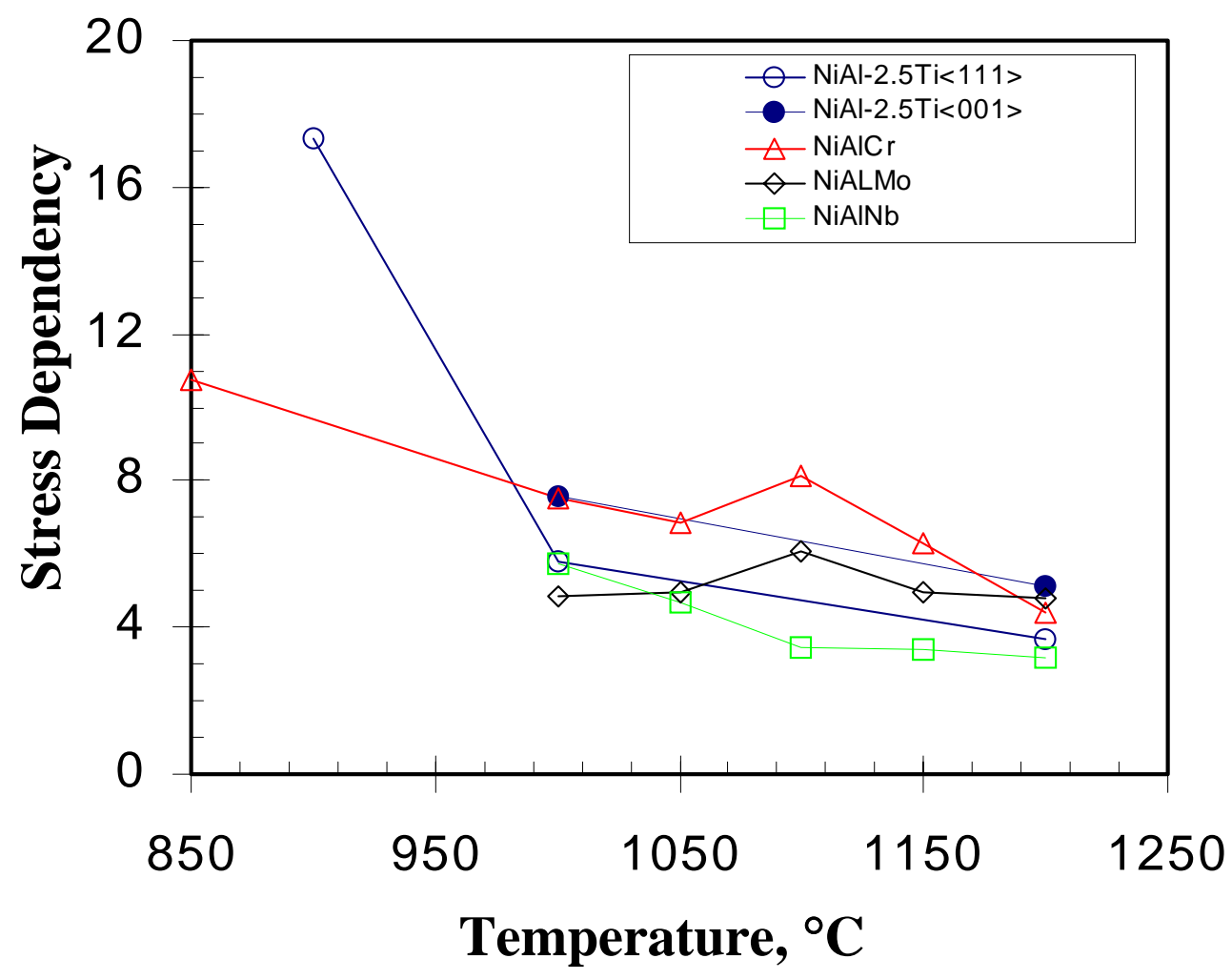

Figure 5.13: Stress Dependency Comparison Between Single Crystal Alloyed NiAl and DS Alloyed NiAl

\subsection{High Temperature Deformation Properties}

There several observations that can be made from the high temperature testing on NiAl. One observation that can be made is at elevated temperatures, the steady state creep rate dependency increases. Also the flow stress dependency decreases as testing temperature increased. The flow stress becomes more sensitive to changes in strain rate at elevated temperatures and the creep rate becomes less sensitive to changes in stress. With increasing temperature the flow stress becomes more dependent on applied strain rate. This can be seen from the pattern in the stress exponents. As the values of the stress exponents decrease the flow stress becomes more sensitive to changes in strain rate. This can be viewed by rearranging the equation for plastic strain rate to the form: 


$$
\sigma=(1 / \mathrm{k}) \dot{\epsilon}^{(1 / \mathrm{n})}
$$

From this equation it can be observed that with decreasing values of $n$ the strain rate exponent would increase. This would make the flow stress more sensitive to changes in strain rate.

From the testing data of the four specimens all of the materials experienced the same pattern in stress sensitivity and strain rate sensitivity with increasing temperature. However the extent at which each of the materials seemed to be more sensitive in temperature changes will be used to compare the high temperature deformation properties between the alloyed and unalloyed specimens.

Based on the data received from the high temperature testing, all of the alloyed specimens outperformed binary NiAl. From this it can be concluded solid solution strengthening provides significant improvements over unalloyed binary NiAl. Tabulated in appendix $\mathrm{A}$ are the results from the compression testing on the $\mathrm{NiAl}, \mathrm{NiAl}-2 \mathrm{Cr}, \mathrm{NiAl}-$ 2Mo, and $\mathrm{NiAl}-2 \mathrm{Nb}$ specimens. There was a wide range of temperature and strain rate testing done to evaluate the materials. In determining which alloying element displayed the most significant result over binary $\mathrm{NiAl}$ the temperature and strain rate would have to be considered. At $1000{ }^{\circ} \mathrm{C}$ the $\mathrm{NiAl}-2 \mathrm{Nb}$ specimen outperformed $\mathrm{NiAl}-2 \mathrm{Cr}$ and $\mathrm{NiAl}-$ 2Mo. However at $1200{ }^{\circ} \mathrm{C}$ the NiAl-2Cr specimen outperformed NiAl-2Mo and NiAl$2 \mathrm{Nb}$. From this it can be concluded that different solid solution strengthening mechanism may be temperature dependent.

Upon examination of the results of the data at temperatures between 1000 and $1200{ }^{\circ} \mathrm{C}$, the superior-performing specimen was also dependent on the region of strain rate the specimen may be subjected to. For example at $1100{ }^{\circ} \mathrm{C}$ NiAl-2Nb and $\mathrm{NiAl}-2 \mathrm{Mo}$ 
provided the most significant strengthening at higher strain rates while NiAl-2Cr proved superior as strain rate decreased. Based on this the effectiveness of the solid solution strengthening mechanism may also be dependent on the applied strain rate.

Based on the results from the data the atomic size factor may be more effective at lower temperatures and lose effectiveness with increasing temperature. With increasing temperature the effectiveness of the atomic size factor may become more dependent on the applied strain rate. In comparison the electron number effect seems less temperature and strain rate dependent at the testing temperatures used for this research.

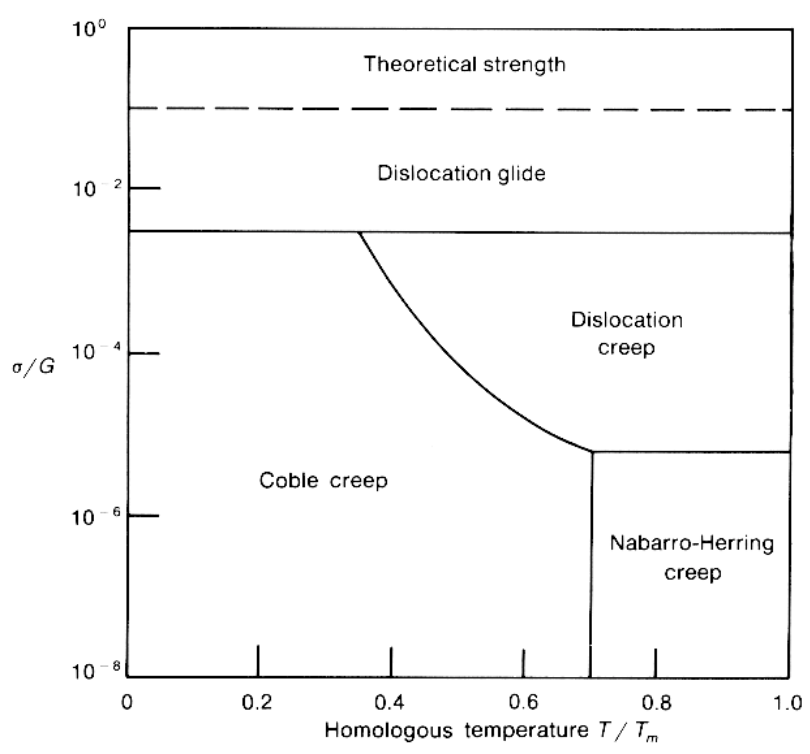

Figure 5.14: Creep Mechanisms[3]

The difference in strengthening effect provided at different temperatures can be attribute to different deformation mechanisms. Illustrated in figure 5.14, a typical deformation mechanism map. The controlling creep mechanism is temperature and stress dependent. The controlling mechanisms for this research would fall in the dislocation creep region and the Nabarro-Herring creep or diffusion creep region. Observed in the testing data, microstructural differences provided significant differences in stress 
dependency at lower testing temperatures. Also observed the atomic size factor provided more strengthening at lower temperatures. These observations would indicate at testing temperatures $850{ }^{\circ} \mathrm{C}$ to approximately $1100{ }^{\circ} \mathrm{C}$, the main controlling deformation mechanism would be dislocation creep. At temperatures above $1100{ }^{\circ} \mathrm{C}$ stress dependency became less dependent on microstructure. The atomic size factor was observed to be less effective in this range also. This would indicate the primary deformation mechanism in this ranged would be controlled by diffusion creep.

To help confirm these observations it is useful to plot testing data using a semi$\log$ scale. Illustrated in figures 5.15-5.18 are constant strain rate lines on a semi-log plot to help determine the different creep mechanisms. The graphs illustrated below represent a small region on a typical creep mechanism map. The testing temperatures ranged from 0.61Tm to $0.73 \mathrm{Tm}$. Due to the limited testing data only the dislocation and diffusion creep regions would be covered. By viewing the constant strain rate lines changes in creep mechanisms can be determined.

In figure 5.15, the $\mathrm{NiAl}$ specimen, there were no apparent transitions in the constant strain rate lines. From this information the primary mechanism controlling deformation in the $\mathrm{NiAl}$ material in the testing range completed was dislocation creep. Observed in figure 5.16, the $\mathrm{NiAl}-2 \mathrm{Cr}$ specimen, a transition in the constant strain rate lines. It was determined that this would indicate a transition in mechanisms controlling deformation. The areas were separated with a dotted line to illustrate the different mechanisms. Most of the data fell into the dislocation creep region, however as testing temperature increased and stress decreased, diffusion creep became the primary mechanism controlling deformation. 
In figure 5.17, the NiAl-2Mo specimen, the constant strain rate lines did not produce any transitions within the testing range conducted. From this it was determined that the data obtained from testing the NiAl-2Mo specimen was within the dislocation creep region. Illustrated in figure 5.18, there was an apparent transition in the constant strain rate lines. Using this transition the data could be separated into region of different creep mechanisms. Most of the testing data was found to be in the dislocation creep region. As temperature increased and the stress level decreased the transition in the constant strain rate lines were observed. This was determined to be a result in a transformation of dislocation creep to diffusion creep becoming the primary mechanism controlling deformation.

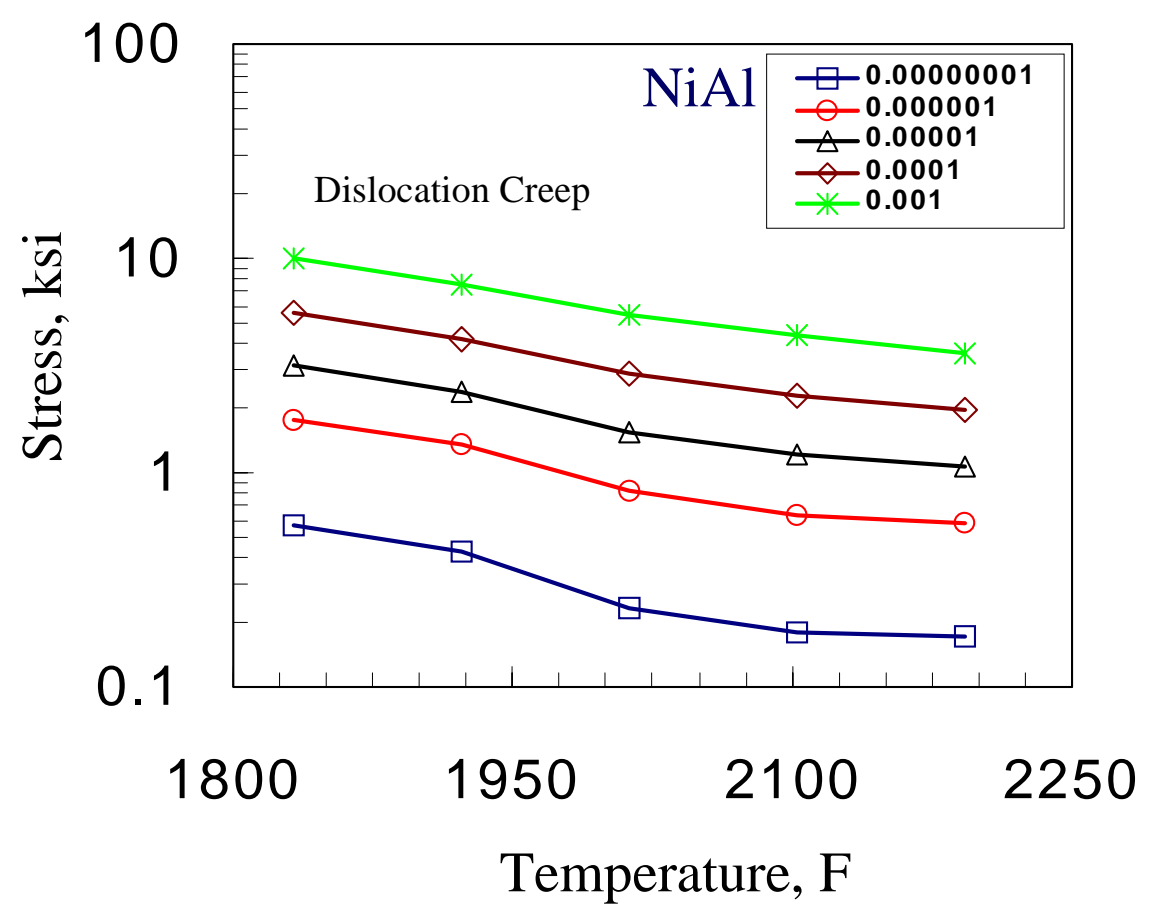

Figure 5.15: Creep Mechanisms NiAl 


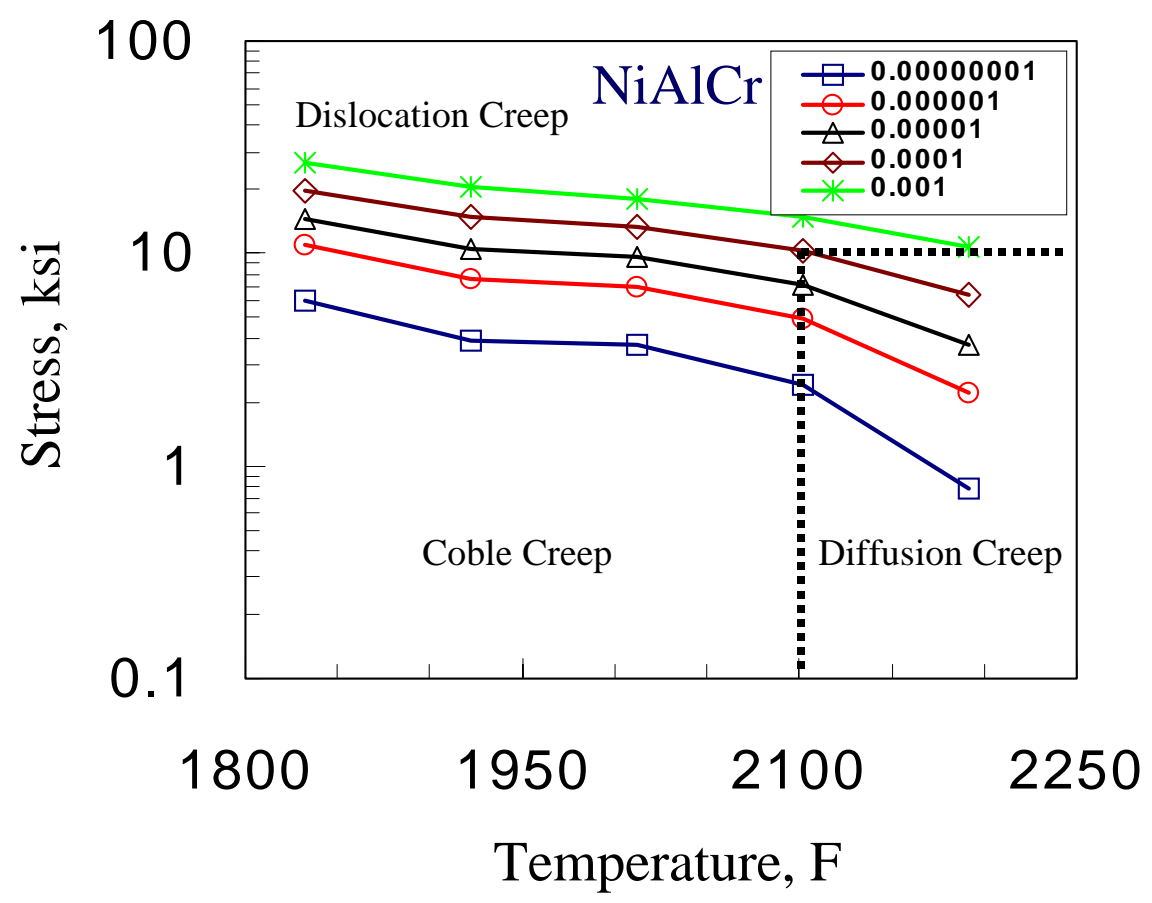

Figure 5.16: Creep Mechanisms NiAlCr

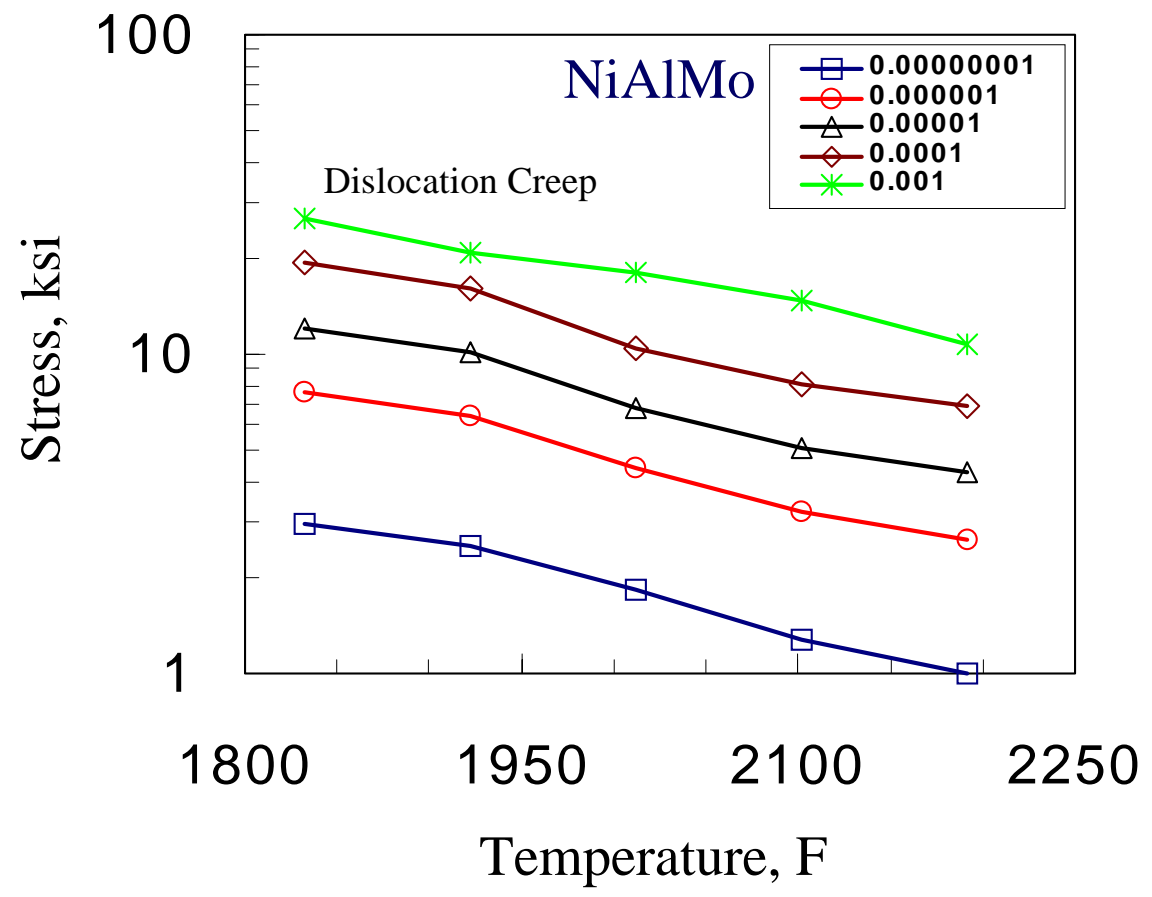

Figure 5.17: Creep Mechanisms NiAIMo 


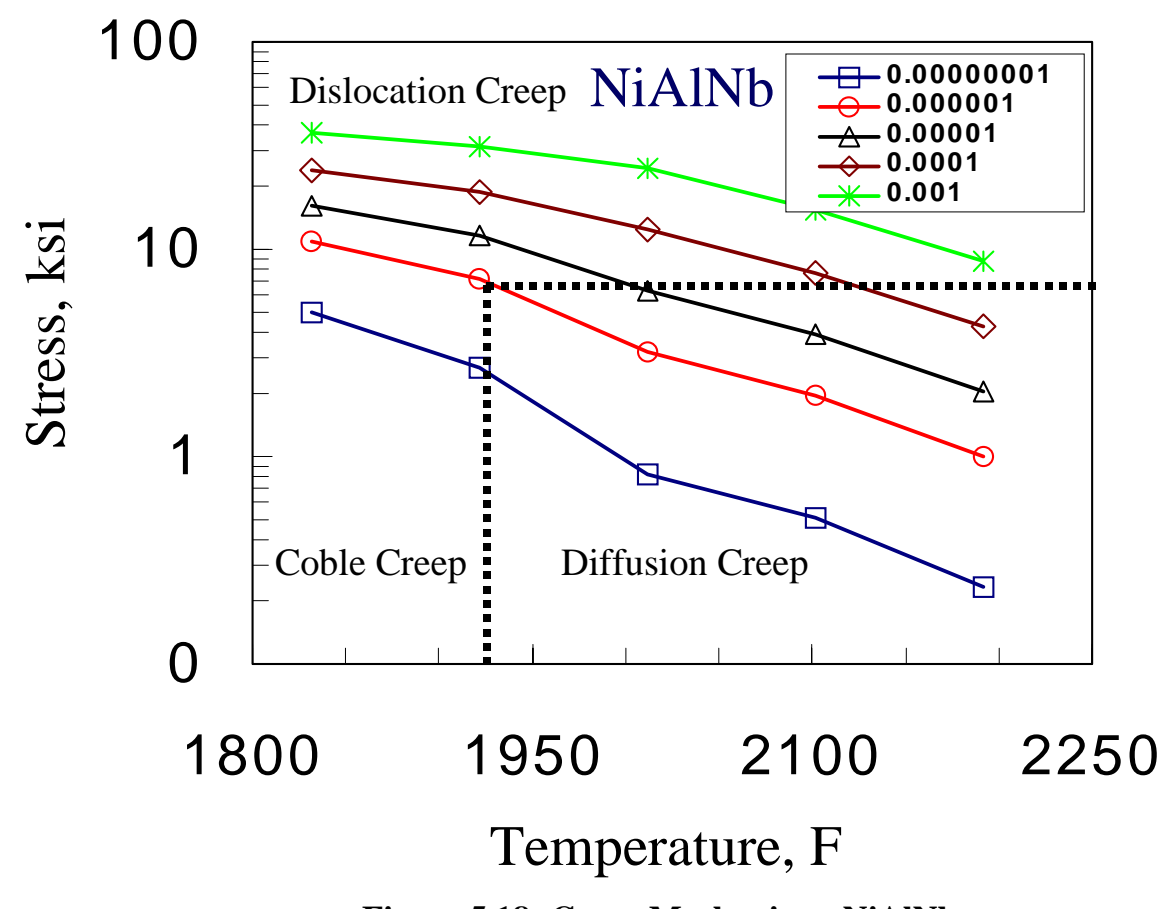

Figure 5.18: Creep Mechanisms NiAlNb

\subsection{Metallurgical Consideration}

Observed in the microstructural section were eutectic precipitates within NiAl$2 \mathrm{Mo}$ and $\mathrm{NiAl}-2 \mathrm{Nb}$. For this research it was assumed that most or all of the secondary phases present would be dissolved at testing temperature. However if some precipitates did remain at testing temperature the effect they would have on strength can be neglected. The size, shape, and distribution of the precipitates formed in the testing specimens would provide very little strengthening. 


\section{Chapter 6 - Conclusions and Recommendations}

\subsection{Conclusions}

1. Solid solution strengthening had a large effect on the flow stress of nickel aluminide. The flow stresses of the alloyed specimens significantly increases at temperatures $850{ }^{\circ} \mathrm{C}$ to $1200{ }^{\circ} \mathrm{C}$ with strain rates from $10^{-6} \mathrm{sec}^{-1}$ to $10^{-2} \mathrm{sec}^{-1}$. Chromium, molybdenum, and niobium all provided significant strength improvements in nickel aluminide.

2. The atomic size factor, when comparing chromium and molybdenum alloys, did not produce a significant difference in the properties when added to nickel aluminide at elevated testing temperatures. The NiAl-2Cr specimen produced significant improvements over binary $\mathrm{NiAl}$ even with a very small misfit percent. The atomic size factor seemed less effective with increasing temperature. Also at higher temperatures the atomic size factor seemed less effective at lower strain rates.

3. The electron number effect, when comparing molybdenum and niobium alloys, seemed to produce the most significant difference in the properties when added to nickel aluminide at elevated testing temperatures. The strengthening mechanism seemed to provide significant strengthening at lower testing temperatures also. However with increasing testing temperature the effective did not reduce as much as the atomic size factor strengthening.

4. From the strain rate-flow stress graphs it can be determined that the flow stress is dependent on both temperature and strain rate. With increasing temperature the flow stress becomes more sensitive to changes in strain rate. At elevated temperatures the creep rate becomes less sensitive to changes in stress. 
5. Molybdenum and Niobium have limited solubility in nickel aluminide. Chromium has high solubility at in nickel aluminide. Niobium and molybdenum are larger atoms making them less soluble than chromium. Molybdenum forms eutectic $\alpha$ precipitates when added to nickel aluminide beyond solubility limits. Niobium forms $\beta$, precipitates, in the form $\mathrm{Ni}_{2} \mathrm{AlNb}$ Heusler phase, when added to nickel aluminide.

6. Constant strain rate and stress relaxation testing provide very similar results for comparison.

\subsection{Recommendations}

1. Prepare more specimens with 2 at $\%$ added in different combinations to compare with the results obtained from this testing. For example substitute chromium in place of aluminum in stead of nickel. Using 1 at\% additions may also be helpful to ensure all of the addition contributes to solid solution strengthening.

2. Use x-ray to measure change in lattice perimeter to confirm estimates from volume change from solute addition.

3. Attempt to view dislocation structure with TEM to find partial dislocations. This may help confirm strengthening occurred by reducing stacking fault energy between extended partial dislocations.

4. Perform DTA to determine solvus temperature of secondary phases present in NiAl2Mo and NiAl-2Nb. 


\section{References}

1. K.R. Forbes, U. Glatzel, R. Darolia, and W.D. Nix, "High Temperature Deformation Properties of NiAl Single Crystals," Metallurgical and Materials Transactions, pp 1229-1240, Volume 27A, May 1996.

2. Ram Darolia, "NiAl Alloys for High Temperature Structural Applications," $\underline{\text { JOM}}$, pp 44-48, March 1991.

3. George E. Dieter, "Mechanical Metallurgy," pp 103-470 McGraw-Hill Series in Material Science and Engineering, 1986.

4. Robert E. Reed-Hill, "Physical Metallurgy Principles,” pp 327-335 Read-Hill 1973.

5. Peter Haasen, "Physical Metallurgy," pp 333-336, Cambridge University Press 1978.

6. Thaddeus B. Massalski, American Metals Society, Binary Alloy Phase Diagrams", pp 142, Volume 1, October 1986.

7. Vinod K. Sikka, "Intermetallics for Structural Applications," Metals and Ceramics Division, Oak Ridge National Laboratory.

8. M.P. Brady, B.A. Pint, P.F. Tortorelli, I.G. Wright, R.J. Hanrahan, "High Temperature Oxidation and Corrosion of Intermetallics," Corrosion and Environmental Degradation of Materials, Volume 19, Oak Ridge National Laboratory.

9. WS Walston, RD Field, JR Dobbs, DF Lahrman, R Darolia, "Microstructure and High Temperature Strength of NiAl Alloys" Structural Intermetallics The Minerals, Metals \& Materials Society 1993. 
10. R Darolia, "NiAl For Turbine Airfoil Applications" Structural Intermetallics The Minerals, Metals \& Materials Society 1993.

11. JA Oti, KO Yu, "Production Processing of Investment Cast Complex Shaped NiAl Single Crystal Airfoils" Structural Intermetallics The Minerals, Metals \& Materials Society 1993.

12. JD Cotton, RD Noebe, MJ Kaufman, “Ternary Alloying Effects in Polycrystalline $\beta$-NiAl” Structural Intermetallics The Minerals, Metals \& Materials Society 1993.

13. PH Kitabjian, A Garg, RD Noebe, WD Nix, "High Temperature Creep Behavior of Single Crystals of the Solid Solution Alloy NiAl-2.5Ti”

14. "Energy Dispersive Spectroscopy", Handbook of Analytical Methods Materials Evaluations and Engineering, Inc., http://www.mee-inc.com/eds.html

15. RF Decker, "Strengthening Mechanisms in Nickel-Base Superalloys", Steel Strengthening Mechanisms Symposium, Zurich, Switzerland, May 5 and 6, 1969.

16. J Daniel Whittenberger, IE Locci, Ram Darolia, R Bowman, “1300 K creep behavior of [001] oriented Ni-49Al-1Hf (at\%) single crystals", Material Science \& Engineering, pp 165-183, October 23,1998.

17. Chester T. Sims, William C. Hagel, “The Superalloys” pp 491-493, John Wiley \& Sons, Inc., 1972.

18. William D. Callister, Jr., "Materials and Science Engineering” pp 30-86, John Wiley \& Sons, Inc., 1994.

19. Brady and Holum, "Chemistry The Study of Matter and Its Changes" pp 50-58, John Wiley \& Sons, Inc., 1993. 
Appendix A - Compression Data 
Table A.1: NiAl Compression Data

\begin{tabular}{ccc}
\hline $\begin{array}{c}\text { Temperature } \\
\left({ }^{\circ} \mathbf{C}\right)\end{array}$ & $\begin{array}{c}\text { Stress } \\
(\mathbf{k s i})\end{array}$ & $\begin{array}{c}\text { Strain Rate } \\
\left(\mathbf{s}^{\mathbf{1}}\right)\end{array}$ \\
850 & 7.95 & $1.00 \mathrm{E}-06$ \\
850 & 11.70 & $1.00 \mathrm{E}-05$ \\
850 & 15.46 & $1.00 \mathrm{E}-04$ \\
850 & 21.89 & $1.00 \mathrm{E}-03$ \\
850 & 24.06 & $1.00 \mathrm{E}-02$ \\
850 & 8.95 & $1.00 \mathrm{E}-06$ \\
850 & 12.12 & $1.00 \mathrm{E}-05$ \\
850 & 16.47 & $1.00 \mathrm{E}-04$ \\
850 & 21.64 & $1.00 \mathrm{E}-03$ \\
850 & 12.06 & $1.00 \mathrm{E}-05$ \\
850 & 16.11 & $1.00 \mathrm{E}-04$ \\
850 & 8.72 & $1.00 \mathrm{E}-06$ \\
850 & 12.38 & $1.00 \mathrm{E}-05$ \\
850 & 16.60 & $1.00 \mathrm{E}-04$ \\
850 & 22.59 & $1.00 \mathrm{E}-03$ \\
850 & 26.71 & $1.00 \mathrm{E}-02$ \\
1000 & 1.55 & $1.00 \mathrm{E}-06$ \\
1000 & 2.72 & $1.00 \mathrm{E}-05$ \\
1000 & 4.48 & $1.00 \mathrm{E}-04$ \\
1000 & 6.54 & $1.00 \mathrm{E}-03$ \\
1000 & 0.99 & $1.00 \mathrm{E}-06$ \\
1000 & 2.92 & $1.00 \mathrm{E}-05$ \\
1000 & 4.52 & $1.00 \mathrm{E}-04$ \\
1000 & 6.56 & $1.00 \mathrm{E}-03$ \\
1000 & 2.57 & $1.00 \mathrm{E}-05$ \\
1000 & 4.09 & $1.00 \mathrm{E}-04$ \\
1100 & 0.92 & $1.00 \mathrm{E}-06$ \\
1100 & 1.63 & $1.00 \mathrm{E}-05$ \\
1100 & 2.98 & $1.00 \mathrm{E}-04$ \\
1100 & 5.07 & $1.00 \mathrm{E}-03$ \\
1100 & 11.18 & $1.00 \mathrm{E}-02$ \\
1100 & 0.92 & $1.00 \mathrm{E}-06$ \\
1100 & 1.67 & $1.00 \mathrm{E}-05$ \\
1100 & 3.19 & $1.00 \mathrm{E}-04$ \\
1100 & 5.62 & $1.00 \mathrm{E}-03$ \\
1100 & 2.05 & $1.00 \mathrm{E}-05$ \\
1100 & 3.60 & $1.00 \mathrm{E}-04$ \\
1100 & 5.71 & $1.00 \mathrm{E}-03$ \\
1200 & 3.31 & $1.00 \mathrm{E}-03$ \\
1200 & 6.18 & $1.00 \mathrm{E}-02$ \\
\hline & & \\
\hline & & \\
\hline & &
\end{tabular}


Table A.2: NiAl-2Cr Compression Data

\begin{tabular}{ccc}
\hline $\begin{array}{c}\text { Temperature } \\
\left({ }^{\mathbf{C}} \mathbf{C}\right)\end{array}$ & $\begin{array}{c}\text { Stress } \\
(\mathbf{k s i})\end{array}$ & $\begin{array}{c}\text { Strain Rate } \\
\left(\mathbf{s}^{-\mathbf{1}}\right)\end{array}$ \\
\hline 850 & 20.17 & $1.00 \mathrm{E}-06$ \\
850 & 24.40 & $1.00 \mathrm{E}-05$ \\
850 & 30.92 & $1.00 \mathrm{E}-04$ \\
1000 & 9.99 & $1.00 \mathrm{E}-06$ \\
1000 & 12.99 & $1.00 \mathrm{E}-05$ \\
1000 & 16.56 & $1.00 \mathrm{E}-04$ \\
1000 & 25.42 & $1.00 \mathrm{E}-03$ \\
1000 & 11.39 & $1.00 \mathrm{E}-06$ \\
1000 & 13.45 & $1.00 \mathrm{E}-05$ \\
1000 & 17.82 & $1.00 \mathrm{E}-04$ \\
1000 & 25.74 & $1.00 \mathrm{E}-03$ \\
1000 & 12.94 & $1.00 \mathrm{E}-05$ \\
1000 & 18.20 & $1.00 \mathrm{E}-04$ \\
1000 & 25.35 & $1.00 \mathrm{E}-03$ \\
1000 & 18.18 & $1.00 \mathrm{E}-04$ \\
1000 & 25.27 & $1.00 \mathrm{E}-03$ \\
1100 & 7.19 & $1.00 \mathrm{E}-06$ \\
1100 & 9.84 & $1.00 \mathrm{E}-05$ \\
1100 & 12.93 & $1.00 \mathrm{E}-04$ \\
1100 & 16.76 & $1.00 \mathrm{E}-03$ \\
1100 & 23.32 & $1.00 \mathrm{E}-02$ \\
1100 & 7.54 & $1.00 \mathrm{E}-06$ \\
1100 & 9.56 & $1.00 \mathrm{E}-05$ \\
1100 & 12.23 & $1.00 \mathrm{E}-04$ \\
1100 & 16.43 & $1.00 \mathrm{E}-03$ \\
1100 & 9.17 & $1.00 \mathrm{E}-05$ \\
1100 & 11.88 & $1.00 \mathrm{E}-04$ \\
\hline
\end{tabular}


Table A.3: NiAl-2Mo Compression Data

\begin{tabular}{ccc}
\hline $\begin{array}{c}\text { Temperature } \\
\left({ }^{\circ} \mathbf{C}\right)\end{array}$ & $\begin{array}{c}\text { Stress } \\
(\mathbf{k s i})\end{array}$ & $\begin{array}{c}\text { Strain Rate } \\
\left(\mathbf{s}^{-\mathbf{1}}\right)\end{array}$ \\
\hline 1000 & 7.45 & $1.00 \mathrm{E}-06$ \\
1000 & 10.69 & $1.00 \mathrm{E}-05$ \\
1000 & 16.21 & $1.00 \mathrm{E}-04$ \\
1000 & 33.93 & $1.00 \mathrm{E}-03$ \\
1000 & 7.83 & $1.00 \mathrm{E}-06$ \\
1000 & 13.18 & $1.00 \mathrm{E}-05$ \\
1000 & 17.09 & $1.00 \mathrm{E}-04$ \\
1000 & 33.68 & $1.00 \mathrm{E}-03$ \\
1000 & 8.59 & $1.00 \mathrm{E}-06$ \\
1000 & 13.78 & $1.00 \mathrm{E}-05$ \\
1000 & 17.47 & $1.00 \mathrm{E}-04$ \\
1000 & 32.28 & $1.00 \mathrm{E}-03$ \\
1000 & 17.76 & $1.00 \mathrm{E}-04$ \\
1100 & 5.50 & $1.00 \mathrm{E}-06$ \\
1100 & 8.51 & $1.00 \mathrm{E}-05$ \\
1100 & 12.07 & $1.00 \mathrm{E}-04$ \\
1100 & 17.12 & $1.00 \mathrm{E}-03$ \\
1100 & 24.32 & $1.00 \mathrm{E}-02$ \\
1100 & 5.29 & $1.00 \mathrm{E}-06$ \\
1100 & 7.68 & $1.00 \mathrm{E}-05$ \\
1100 & 11.33 & $1.00 \mathrm{E}-04$ \\
1100 & 16.10 & $1.00 \mathrm{E}-03$ \\
1100 & 7.30 & $1.00 \mathrm{E}-05$ \\
1100 & 10.75 & $1.00 \mathrm{E}-04$ \\
\hline
\end{tabular}

Table A.4: NiAl-2Nb Compression Data

\begin{tabular}{ccc}
\hline $\begin{array}{c}\text { Temperature } \\
\left({ }^{\mathbf{O}} \mathbf{C}\right)\end{array}$ & $\begin{array}{c}\text { Stress } \\
(\mathbf{k s i})\end{array}$ & $\begin{array}{c}\text { Strain Rate } \\
\left(\mathbf{s}^{-1}\right)\end{array}$ \\
\hline 1000 & 10.70 & $1.00 \mathrm{E}-06$ \\
1000 & 18.70 & $1.00 \mathrm{E}-05$ \\
1000 & 27.56 & $1.00 \mathrm{E}-04$ \\
1000 & 35.68 & $1.00 \mathrm{E}-03$ \\
1000 & 10.56 & $1.00 \mathrm{E}-06$ \\
1000 & 18.42 & $1.00 \mathrm{E}-05$ \\
1000 & 25.91 & $1.00 \mathrm{E}-04$ \\
1000 & 35.14 & $1.00 \mathrm{E}-03$ \\
1000 & 35.71 & $1.00 \mathrm{E}-03$ \\
1100 & 2.96 & $1.00 \mathrm{E}-06$ \\
1100 & 6.59 & $1.00 \mathrm{E}-05$ \\
1100 & 14.52 & $1.00 \mathrm{E}-04$ \\
1100 & 21.76 & $1.00 \mathrm{E}-03$ \\
1100 & 28.90 & $1.00 \mathrm{E}-02$ \\
1100 & 2.74 & $1.00 \mathrm{E}-06$ \\
1100 & 4.74 & $1.00 \mathrm{E}-05$ \\
1100 & 13.69 & $1.00 \mathrm{E}-04$ \\
1100 & 22.82 & $1.00 \mathrm{E}-03$ \\
1100 & 8.19 & $1.00 \mathrm{E}-05$ \\
1100 & 14.35 & $1.00 \mathrm{E}-04$ \\
\hline
\end{tabular}




\section{Vita}

Name: $\quad$ Robert A. Coulter II

Date of Birth: $\quad$ August 11, 1972

Place of Birth: $\quad$ Morgantown, West Virginia

Education: $\quad$ Master of Science in Mechanical Engineering

West Virginia University, Morgantown WV

Graduated: May 2000

Bachelor of Science in Mechanical Engineering

West Virginia University, Morgantown WV

Graduated: August 1998

University High School, Morgantown WV

Graduated: June 1990 